Forecast of Criticality Experiments and Experimental Programs Neded to Support Nuclear Operations in the United States of America:

1994-1999

Debra Rutherford* 
Conients

Forward

Abstract

Executive Summary

The Experiment Veeds Identification Workgroup

and the Faluation of Proposed Evperiments. 5

i) eartment veeds for Criticality Research of Various Programs.....................15

Department of Energy Criticality Safety Program-Qualified Analytical Methods and Vuclear Data

Acronyms.

Participants in the Experimental Veeds Identification Workgroup ...................5

Acknowledgments.

Criticality Fxperiments Yeeded to Support

Highly Enriched Uranium Operations.

Contents. HEL -2

Experimen 101

('193) Metal Retilectrod by Anneuling Salts HEL -3

Experiment 10? Large Array of Small Lnits HEU-4

Expenment 103 Experimen 104 Slighaly Moderaled L,93; Oxide Powder HEL $\mathrm{H}-\mathrm{O}$

- Advanced Veutron Sourci HEL -7

Experinent lis High-Energy Burst Reactor HEL -8

Experment 106

TOPAZ.1I Reacior. HEL -10

Expermental

Program 1117

Crilcally Evaluanums of Space Power \& Propulsion

Arsemblies. HEL -11

Criticality Experiments Veeded to Support Iow-Enriched Uranium Operations . LEL-1

Contents LEU-2

Experiment 201

Experiment 20?

Experiment 203

Experimental Program 204

Experiment 205

Experiment 206 Experiment ?07 Experiment Zns
SP-100 Surety Program

Atomic Vapor Laser lsotope Separation (AVLIS) LEL-3

Uranium Fuel Feed Operations LEL -4 LEL-5

Monitored Retrievable Storage (MRS) Facility LEL -7

Effect of Interspersed Moderation on an Uninoderated

Storage Array LEL -8

Sheba Reactivity Parameterization. LELI-9

Sheba Reactivity Void Coefficient. LEL'-10 Benchmark Measurements 
Criticality Experiments Needed to Support Plutonium Operations ................Pu-1

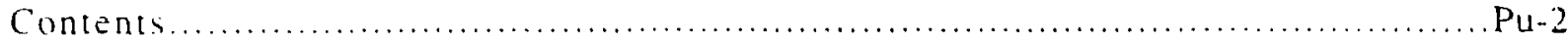

Experiment $301 \quad$ Plutonium Solution in the Concentration Range

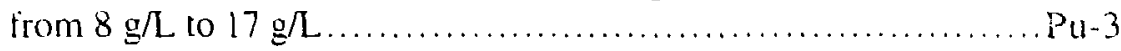

Experment $302 \quad$ Transuranic Extraction (TRUEX) Process ........................ Pu-4

Experiment $303 \quad$ Effectiveness of Iron in Plutonium Storage and Transport Arrays......Pu-5

Experiment 304 Plutonium with Extremely Thick Beryllium Reflection...............Pu-6

Experimental

Program 305

Arrays of $3-\mathrm{kg}$ Pu-Metal Cylinders Immersed in Water

$\mathrm{Pu}-7$

Criticality Experiments Veeded to Support

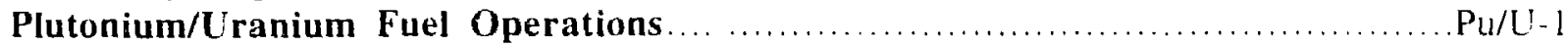

Contents................................

Experiment $401 \quad$ Advanced Reactor Design for Metal Fuel (Pu-U-Zr) ..................Pu/U-3

Experiment $402 \quad$ Mixed Oxides of $\mathrm{Pu}$ and $\mathrm{U}$ at Low Moderation..................... . Pu/U-4

Experiment $403 \quad$ Minimum Critical Pu Fraction in Pu/Natural-U Mixture................Pu/U-5

\section{Criticality Experiments Needed to Support}

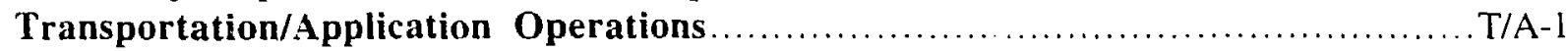

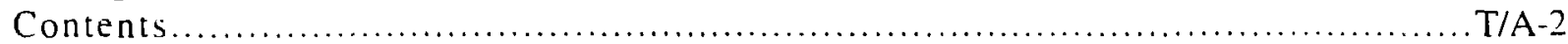

Experiment 501

Experimental

Program 502

Experiment 502a

Experiment 502b

Experiment 502c

Experiment 502d

Experiment 502e

Experiment $502 \mathrm{f}$

Experiment 502g

Experiment $502 \mathrm{~h}$

Experiment 502i

Experimentid

Program 503

Experimental

Program 504

Experimeri al

Program 505

Experiment 506
Assessment for Materials Used to Transport and Store

Discrete Items and Weapons Components T/A-3

Waste Processing, Transportation, and Storage .................. T/A-5

Absorption Properties of Waste Matrices............................. T/A-6

In Situ Drum Stacking .......................................... T/A-7

Validation of WIPP Hydrogen Generation Calculations............... T/A-8

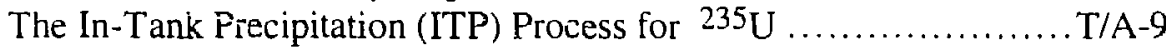

The In-Tank Precipitation Process for ${ }^{235} \mathrm{U}+{ }^{239} \mathrm{Pu} \ldots \ldots \ldots \ldots \ldots . \mathrm{T} / \mathrm{A}-10$

The In-Tank Precipitation (ITP) Process for ${ }^{239} \mathrm{Pu} \ldots \ldots \ldots \ldots \ldots \ldots . \mathrm{T} / \mathrm{A}-12$

Determination of Fissionable Material

Concentrations in Waste Materials .......................... T/A-13

Minimum Critical Mass of Fissile-Polyethylene Mixture ............ T/A-14

Criticality Studies that Emphasize Intermediate Energies............ T/A-15

Validation of Criticality Alarms and Accident Dosimetry ............. T/A-16

Accident Simulation and Validation of Accident Calculations.......... T/A-17

Evaluation of Measurements for Subcritical Systems...............T/A-18

Safe Fissile Mass Thresholds for an Array

of Waste Storage Drums

T/A-19 


\section{Criticality Experiments Needed to Support Transportation/Application Operations} (continued)

Experimental

Program 507

Simulator Development

T/A-20

Experimental

Program 508

Development of a Demonstration Experiment. T/A-21

Criticality Experiments Needed to Resolve Baseline Theoretical Problems........... BT-1

Contents.

Experiment 601

Experiment 602

Experiment 603

Experiment 604

Experimental

Program 605

Experiment $605 \mathrm{a}$

Experiment 605b

Experiment 606

Experiment 607

Experiment 608

Experiment 609
Critical Mass Experiments tor Actinides................................... BT -3

Neutron Absorber Property of PVC ............................... BT -4

Effect of Poorly Absorbing, Neutron-Scattering Elements

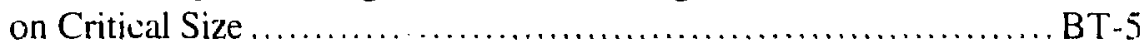

Unusual Fissile Shapes..................................... BT-6

Measurement of Delayed-Neutron Parameters and Time-Dependent, Delayed-Neutron Spectra for ${ }^{235} \mathrm{U},{ }^{238 \mathrm{U}},{ }^{237} \mathrm{~Np},{ }^{239} \mathrm{Pu}$, and ${ }^{241} \mathrm{Am} \ldots \ldots \ldots \ldots \ldots \ldots \ldots . . . \ldots$. $\mathrm{T}-7$

Delayed Neutron Fraction Measurement from ${ }^{237} \mathrm{~Np} . . . \ldots \ldots \ldots \ldots \ldots$. BT -8

Measurement of Time-Dependent Delayed-Neutron Spectra ............ B? $:-9$

Establishing the Validity of Neutron-Scattering Kernels ............... PT-10

Extending Standard ANSUANS 8.7 to Moderated Arrays ............... BT-11

Fission Rate Spectral Index Measurements in Three Assemblies......... BT-12

Validation of Calculational Methodology in the Intermediate Energy Range ............................................

Criticality Experiments Needed to Support Criticality Physics Operations ........... CP-1

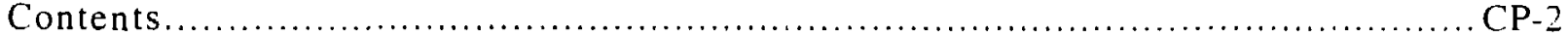

Experimental Program 701

Experiment 702

Experimental Program 703

Experimental Program 704

Experiment 705

Experiment 706

Experiment 707

Investigation and Development of Subcritical Measurements.......... CP-3

Spent Fuel Safety Experiments (SFSX) ........................ CP-5

Differential Parameter Measurements ............................ CP-7

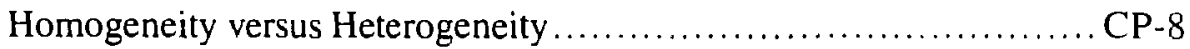

How to Measure Hydrogen .................................... CP-9

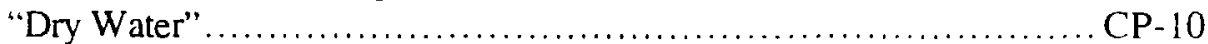

Anomalous Critical Experimental Results ........................ CP-11 
Archived Experiments. $A X-1$

Consents $A x-2$

Experiment 8011

Experiment 8()$_{2}$

Lyerentent sil?

Experment $80+4$

Experment kos

Experiment she

Experiment $x(67$

Experiment sos

Experiment $8(x)$

Experiment : 111

Experincme
Fuel-Processing Reworttion Project $A x \cdot 3$

Fluminel and Storage (FAST) Fachlity

$\therefore \mathrm{x}-\mathrm{t}$

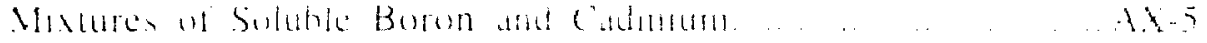

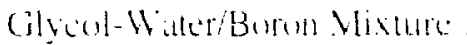

$A x \cdot h$

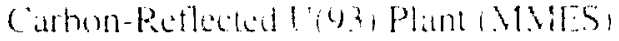

A. 7

liv3, Metal Reflected by Retatery Materials

IX 8

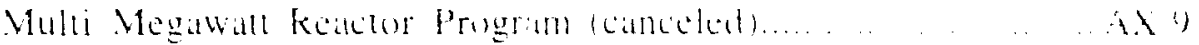

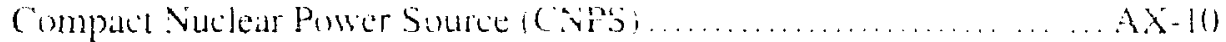

Relurbishmen or Replatement for the D-Reator................... AX-11

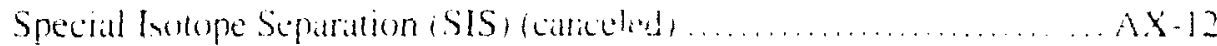

veurron Aburber Propery of Pyrex cylinder Wall

Appendix A Glossary of Nuclear Criticaits Terms

App A-1

Criticality Symbols.

Referen : s.

App $A-8$

App A-10

App B-1

App C-1

App D-1

App E-1

App F-1 


\section{Forenord}

This report identrifes cratical experiments forecast for 1994-1999, which are bassed on the concensus of the Expermant Veeds Identification Workgroup (ENIWG). Generatled by the shair of the workgroup. this Forecast is considered a living document and will be updated periodically. It includes a listing of the ENIWG members and their addresses; an overview that has ypecific information pertaining to priority-l critical aperments, facilites, and programmatic resources, and physics eriteria for benchmark experiments.

The forerast has been divided into sections, each with a separate table of contents. Refer wo the lable of Contents at the beginning of the document for information on the section you wish to itcest. Appendix A concains a glossary of nuclear -riticality terms to help you with the nomenclature. 


\title{
FORECAST OF CRITICALITY EXPERIMENTS AND EXPERIMENTAL PROGRAMS NEEDED TO SUPPORT NUCLEAR OPERATIONS IN TIEE UNITED STATES OF AMERICA: \\ 1994-1999
}

by

Debra Rutherford

\begin{abstract}
This Forecast is generated by the Chair of the Experiment Needs Identification Workgroup (ENIWG), with input from Department of Energy and the nuclear community. One of the current concerns addressed by ENIWG was the Defense Nuclear Facilities Safety Board's Recommendation 93-2. This Recommendation delineated the need for a critical experimental capability, which includes (1) a program of general-purpose experiments, (2) improving the information base, and (3) ongoing departmental programs. The nuclear community also recognizes the importance of criticality theory, which, as a stepping stone to computational analysis and safety code development, needs to be benchmarked against well-characterized critical experiments. A summary projection of the Department's needs with respect to criticality information includes (1) hands-on training, (2) criticality and nuclear data, (3) detector systems, (4) uranium- and plutonium-based reactors, and (5) accident analysis. The Workgroup has evaluated, prioritized, and categorized each proposed experiment and program. Transportation/Applications is a new category intended to cove the areas of storage, training, emergency response, and standards. This category has the highest number of priority-1 experiments (nine). Facilities capable ci performing experiments include the Los Alamos Critical Experiment I acility (I.ACEF) along with Area $V$ at Sandia National Laboratory. The LACEF continues to house the most significant collection of critical assemblies in the Western Hemisphere. The staff of this facility and Area $\mathrm{V}$ are trained and certified, and documentation is current. ENIWG will continue to work with the nuclear community to identify and prioritize experiments because there is an overwhelming need for critical experiments to be performed for basic research and code validation.
\end{abstract}

\section{Executive Surnmary}

This report identifies critical experiments forecast for 1941-1999, based on the consensus of the Experiment Needs Identification Workgroup, which is sponsored by the Department of Energy's (DOE) Nuclear Criticality Technology and Safety Project. This Forecast is generated by the Chair of the Workgroup, with input from DOE contractors, DOE program offices, special groups working in the area of criticality safety, DOE critical mass laboratories, and the Nuclear Regulatory Commission. 


\section{Forecast of Criticality Experiments: Executive Summary}

\section{The Need for Critical Experiments and Experimental Programs}

One of the current concerns uddressed is the Defense Nuclear Facility Safety Board (DNFSB) Recommendation 93-2, which delineated the need for a critical experimental cilpability. Specifically, the Buard recommends that:

1. The Department of Energy should retain its program of generial-purpose critical experiments.

2. This program should normally be directed along lines that satisty the objectives of improving the information batse

3. The results and resoures of the criticility program should be used in ongoing departmental progratins where nuclear criticality would be an important concern.

Craticality phosics and catculational methods being used for criticality analysis are extremety important as the DOE complex changes its misson, an it faces numerous returns from the suckple.

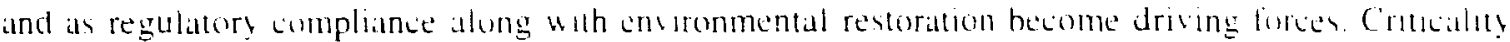

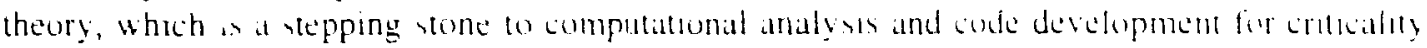
safety, therefore needs to be benchmarked against well-characterized eritical experiments. Sipecilic experimental and programmatic responses to the DNFSB Recommendation are lasied in Table 1

Table I: Experiments and experimental programs identified by ENWIG that address specific DNFSB Recommendations.

\begin{tabular}{|c|c|}
\hline DNFSB Recommendation & $\begin{array}{l}\text { Experiments or Experimental Programs that } \\
\text { Address the Recommendation }\end{array}$ \\
\hline $\begin{array}{l}\text { ". . maintain a good base of information for } \\
\text { criticality control, covering the physical } \\
\text { situations that will be encountered in handling } \\
\text { and storing fissionable material. .." }\end{array}$ & $\begin{array}{l}104,106,202,203,302,303,305,306,402 \\
502 \mathrm{~g}, 502 \mathrm{~h}, 504,406, \text { and } 701\end{array}$ \\
\hline $\begin{array}{l}\text { ". . theoretical understanding of neutron } \\
\text { multiplication processes in critical and } \\
\text { subcritical systems ..." }\end{array}$ & $\begin{array}{l}103,105,204,205,207,208,301,501,502 \\
502 \mathrm{a} .502 \mathrm{~d}, 502 \mathrm{e}, 502 \mathrm{f}, 502 \mathrm{i}, 503,505,6(1) 1 \\
605,605 \mathrm{a}, 609,702,703 \text {, and } 704\end{array}$ \\
\hline $\begin{array}{l}\text { ". . to ensure retaining a community of } \\
\text { individuals competent in practicing the } \\
\text { [criticality] control." }\end{array}$ & $\begin{array}{l}\text { All experiments and experimental programs, } \\
\text { specifically } 507 \text { and } 508 \text { - training }\end{array}$ \\
\hline $\begin{array}{l}\text {.. . experiments targeted at the major sources } \\
\text { of discrepancy between the theory and the } \\
\text { experiments..." }\end{array}$ & $101,102,304,606$, and $7 !) 7$ \\
\hline
\end{tabular}

\section{The Need for a Critical Facility}

The DOE and DNFSB's requirements show the overwhelming need for a critical facility. A critical facility typically operates with core configurations at zero power, versatile fuel configurations, little or no heat removal, and minimal fission product controls. These systems lend themselves to the ease of physics data acquisition and system change. Only DOE's Defense Programs have this breadth of facility technology and criticality knowledge. The following list is a summary projection of the Department's needs with respect to nuclear data and criticality informatıon: 


\section{Forecast of Criticality Experiments: Executive Summary}

\section{The Need for a Critical Facility continued)}

1. Hands-on training;

2. Crucalicy and nuclear data on

is aper prompt criticals and fitst configurations,

h. new fuels for space propulsion and wide temperalure ranges.

- new fisste material configuratuons,

d hargete arrays.

$\therefore$ Iransuramtivand atclindes (for upent-fuel processing), and

1. atublary-powere reactors:

; Deketur wems with neutron and gamma burst and steady hate test systems;

4. Lramum and plubonimm-hased reactors: and

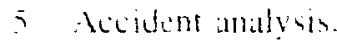

\section{Criticality Experiments and Experimental Programs}

All proposed experiments and experimental programs needed to support our nuclear operations have heen assigned $(0$ one of seven categories listed in the table below. Each of these categories has il eparate section in this report (the parenthetical abbreviations in the table). Experimental programs deluneate general representations of a broad experimental need (i.e., dosimetry). Experiments are mort specitic in nature. At the beginning of each experiment and experimental program listing, the limlowmg general information is given: (1) the contractor requiring the experir sntal data, (2) the cyperunent ur experimental program category: and (3) the application of the experiment or :ypermential program.

Fiah experiment litted in this document has a priority listing that is one of the following: (1) Maxum:n pratical attention; (2) Required for new or ongoing DOE operation; or (3) Less argent than priority 123. The status ranking of each experiment is designated as one of the following: (1) Justification Completed, (2) Justification Being Prepared, (3) Experiment Identified, 14) Anticipated Need, (5) Experiment in Progress, or (6) Experiment Complete. Note that status and minrity are different and can differ for any single experiment and experimental program. However, every effiort shoulu be made to bring them to an equivalent level so that, for instance, the highest priurly experiments should also be the ones closest to completion. Table Il lists the 59 experiments that have been identified and prioritized.

Table II: ldentified and Prioritized Experiments.

\begin{tabular}{|c|c|c|c|}
\hline & \multicolumn{3}{|c|}{ Number of Priority } \\
\hline laltegurles & Priority 1 & Priority 2 & Priority 3 \\
\hline Highly Fnriched Urunium (HEU) & 2 & 5 & 0 \\
\hline Law-Enriched Lranium & 2 & 5 & 1 \\
\hline Plutomium & 4 & 1 & 0 \\
\hline Plutumum/L s:anum Fuel & 1) & $!$ & 2 \\
\hline Transportallion/Applicallons (T/A) & 9 & 8 & 0 \\
\hline Buscline Theoretwal & 6 & 2 & 4 \\
\hline Crumiality Phystis & 1 & 5 & 1 \\
\hline Trual (59) & 24 & 27 & 8 \\
\hline
\end{tabular}




\section{Criticality Experiments and Experimental Programs (continued)}

Transportaton/Applicatoms is a new subset of criticality experiments that is intended to cover the areas of storage, transportation, waste, dosinetry alarm systems, training, emergency response, processing. and regulations and standards. Trainirg is included as part of continuing capability.

\section{Resources and Status of Facilities}

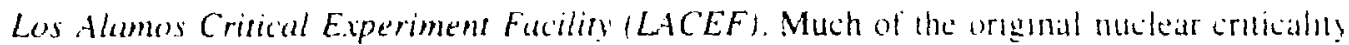
research was performed at this ste, and the facility continues to house the most rynificant collectum of eritkal atsiemblies in the Western Hemisphere. The combunatun of the asismblies, a latge inventory of fissile material, and structural materials makes the LACEF one of the mum diverulfied facilities for the simulation of nuclear reactors, weapons, and process applications; it is also at resource for performing research for the nuclear community. The LACEF staff is trained and certified and documentation is current.

Area V. Sandia National Laboratories (SNL). Area V at Sandia National Laboratonies (Albuquerque, New Mexico) comprises numerous research and test laboratories whose main activities center upon research work conducted at versatile reactors and gamma-ray source fatilities. The SNL staff is trained and certified and documentation is current.

Other Facilities. Argonne National Laboratories (West), the location of the Zero Power Physics Reactor (ZPPR), Hanford Laboratories and the Hanford Critical Mass Laboratory, Oak Ridge National Laboratory (ORNL), and Rocky Flats are either on stand-by or have been shut down.

\section{Conclusions}

An evaluation of experimental status and priority indicates the following:

- The majority of Priority-1 experiments and experimental programs (9) are in the Transportation/Applications category, with the Baseline Theoretical and Plutonium categories having 6 and 4 Priority-1 experiments and experimental programs, respectively.

- Criticality safety training is recognized as one of the most important aspects of maintaining our technical capability.

- The new priorities for needed experiments reflect the change in the mission of the DOE and the current thinking in the nuclear community.

Future Directions. There is an overwhelming need for critical experiments to be performed for basic research and code validation. The Workgroup will continue to work with the changing direction of the DOE and the nuclear community to identify experiments and prioritize them. 


\title{
The Experiment Needs Identification Workgroup and the Evaluation of Proposed Criticality Experiments
}

\author{
D. Rutherford, Los Alamos National Laboratory
}

\section{Introduction}

From July 27 through 28, 1993, the Experimental Needs Identification Workgroup (ENIN: $)$ held a meeting to discuss the curent and projected needs for criticality experiments and facilitics. Spunsored by the Department of Energy's (DOE) Nuciear Critucality Feciunology and Safety Project (.VCT\&SP), the ENIWG comprises representatives from the following communities: DOE contractors, DOE pro eram offices, special groups working in the area of criticalicy safety, DOE criticai mass laboratories, and the Nuclear Regulatory Commission (the map on the following page shows the location of the DOE nuclear facilities involved in the Workgroup). At this meeting, the Workgroup identified those nuclear criticality experiments that are necessary to support the DOE's changing programs and diverse production operations. This Forecast is generated by the Chair of the Workgroup, with input from the aforementioned groups.

This document is considered a "living" document and will be updated periodically. A glossary of nuclear criticality terms and a list of symbols used in this report can be found in Appendix A. A list of criticality acronyms can be found at the end of this section, along with a list of ENIWG participants.

Current Concerns. The Defense Nuclear Facilities Safety Board unanimously approved Recommendation 93-2 (Appendix B) which deals with "the need for critical experiment capability." The Board delineated in its Recommendation that a continuing program of general-purpose critical experiments is necessary to insure safety in the handling and storing of fissionable material. Specifically, the Board recommends that:

1. The Department of Energy should retain its program of general-purpose critical experiments.

2. This program should normally be directed along lines that satisfy the objectives of improving the information base, which underlies the prediction of criticality and serves in the education of the criticality engineer community.

3. The results and resources of the criticality program should be used in ongoing departmental programs where nuclear criticality would be an important concern.

Specific experimental ard programmatic responses to the DNFSB Recommendation are listed in Table I.

Also, based on the previous version of this forecast, several questions were raised concerning criticality physics and the calculational methods being used for criticality analysis. These evaluations and questions become extremely important as the DOE complex changes its mission, faces numerous weapons returns from the stockpile, and places an ever increasing importance on regulatory compliance. Because the experimental facility chosen must conduct their operations based on their financial and personnel resources, the ENIWG provides the guidance and information that are needed for the allocation of resources in the early planning of criticality experiments. 


\section{USA Department of Energy Nuclear Facilities}

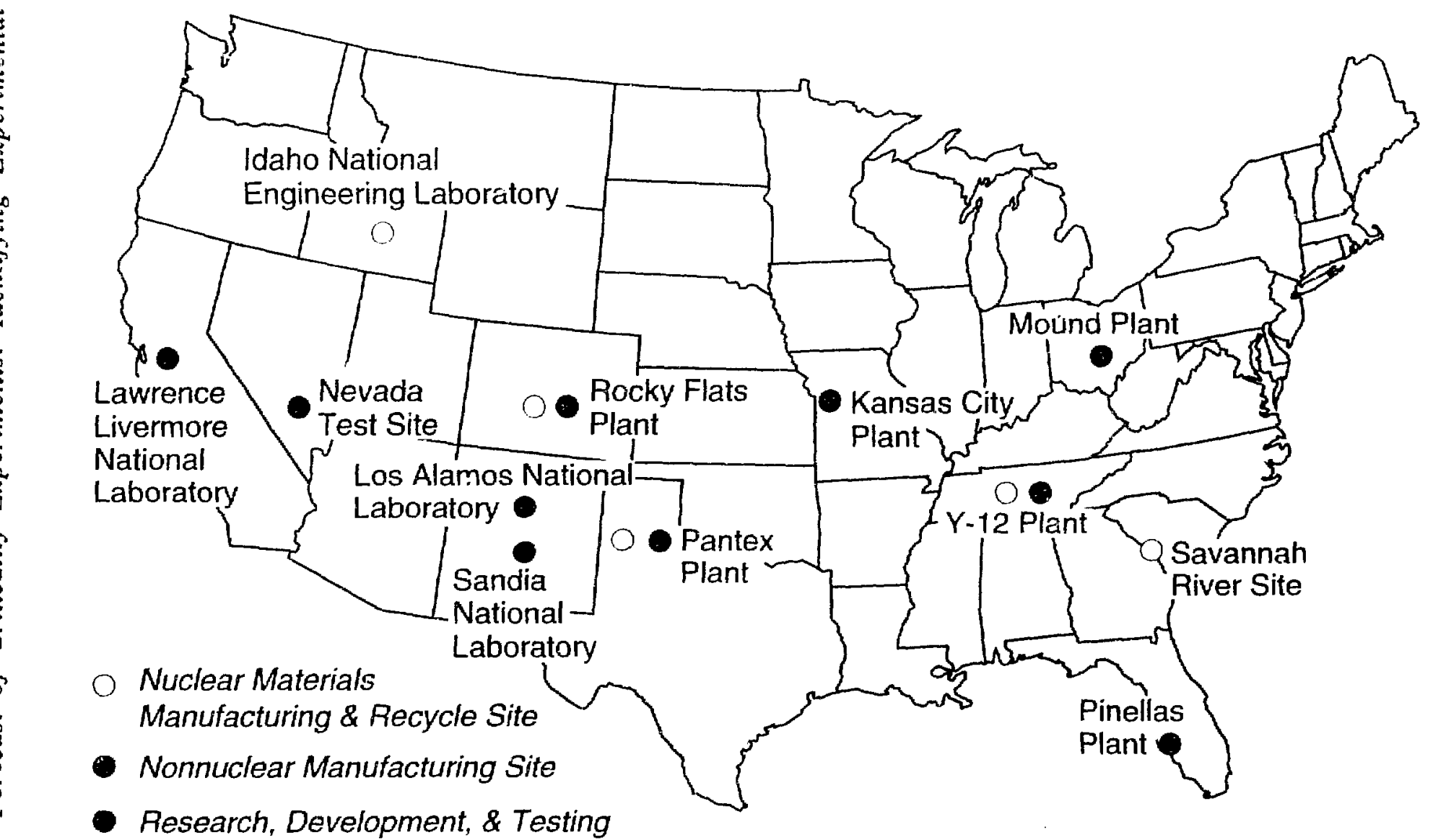


Table I: Experiments and experimental programs identified by ENWIG that address specific DNFSB Recommendations.

\begin{tabular}{|c|c|}
\hline DNFSB Recommendation & $\begin{array}{l}\text { Experiments or Experimental Programs that } \\
\text { Address the Recommendation }\end{array}$ \\
\hline $\begin{array}{l}\text {. . maintain a good base of information for } \\
\text { criticality control, coverng the physical } \\
\text { situations that will be encountered in handling } \\
\text { and storing fissionable malterial . .." }\end{array}$ & $\begin{array}{l}104,106,202,203,302,303,305,306,402 \\
5(1) 2 \mathrm{~g}, 502 \mathrm{~h}, 5() 4,406, \text { and } 701\end{array}$ \\
\hline $\begin{array}{l}. . \text { theoretical understinding of neutron } \\
\text { multiplicattion processes in critical and } \\
\text { subcriticial systems..." }\end{array}$ & 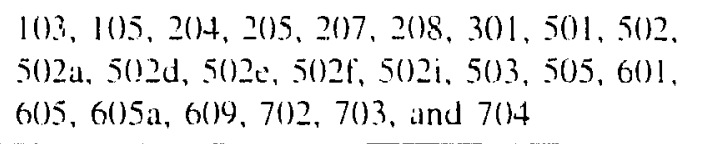 \\
\hline $\begin{array}{l}\text { ". . to ensure retaining a community of } \\
\text { individuals competent in practicing the } \\
\text { |critucality| control." }\end{array}$ & $\begin{array}{l}\text { All experiments and experimental programs, } \\
\text { specifically } 507 \text { and } 5(08 \text { - training }\end{array}$ \\
\hline $\begin{array}{l}\text { oxperiments targeted at the major sources } \\
\text { of discrepancy between the theory and the } \\
\text { experiments. . }\end{array}$ & $101,102,3(04,606$, and 7017 \\
\hline
\end{tabular}

\section{ENIVG Operations}

The function of the Workgroup is to provide the criticality community with a hierarchy of experiments needed to support U.S. DOE contractor operations. At the beginning of a new DOE program or modification to an existing program that involves fissile material, the ENIWG makes an evaluation to determine if current criticality benchmarks are adequate. If these benchmarks are found to be inaldequate, a new criticality experiment may be necessary for safety and/or economic reasons If such an experiment is indeed required, then a listing will appear in this document.

Identifing Experiments and Experime'ntal Programs. Experimental Programs delineate general representations of a broad experimental need (i.e., dosimetry). Experiments are more specific in nature.

For each experiment and experimental program identified by the Workgroup, the requester or sponsor provides a justification statement (see form in App. C). This justification information is used to evaluate the need for the experiment and should (1) discuss existing criticality data (if any) and why it is deficient; (?) provide a description of the needed experiments; and (3) list potential benefits.

At the beginning of each experiment and experimental program listing the following general inf:amation is given: (1) the DOE contractor who needs the experimental data; (2) the experiment or experimental program category; and (3) the application of the experiment or experimental program.

Rating Experiments and Experimental Programs. Experiments and experimental programs are rated by representatives from the ENIWG who have determined the priority listing for each entry. These representatives also consider the identification of a sponsor and the extent to which such experiments will support programma:ic needs or provide basic physics data.

In addition. a subcommittee has been formed of the Weapons Criticality Committee to identify the need: nd priorities of nuclear safety experiments that are nuclear-tveapons specific. This effort will be coordinated with the Workgroup. 


\section{Forecast of Criticality Experiments: Identifying Experimental Needs}

\section{ENIWG Operations}

Rating Experiments and Experamental Programs (continued).

Each experiment and experimental program listed in the document has a priority listing that is one of the following: (1) Maximum practical attention; (2) Required for new or ongoing DOE operation; or (3) Less urgent than priority (2).

The status ranking of each experiment and experimental program is designated as one of the following: (1) Initial Request, (2) Justification Completed, (3) Justilication Being Prepared, (4) Experiment Idencified, (5) Anticipated Need, (6) Experiment in Frogress, or (7) Experiment Complete.

Note that status and priority are different and can differ for any single experiment and experimental program. However, every effort siviuld he made to bring them to an equivalent level sol that, for instance, the highest priority experi!nents should also be the ones closest to completion.

Summary Listing of Experiments and Experimental Programs and Their Priorities. Table II lists the 59 experiments and experimental programs ihat have been identified and prioritized. The 21 experiments considered highest priority (maximum practical attention) are listed in Table III.

Table II: Identified and Prioritized Experiments and Experimental Programs.

\begin{tabular}{|c|c|c|c|}
\hline & \multicolumn{3}{|c|}{ Number of Priority } \\
\hline Categories & Priority 1 & Priority 2 & Priority 3 \\
\hline Highly Enriched Uranium (HEU) & 2 & 5 & 0 \\
\hline Low-Enriched Uranium & 2 & 5 & $\mathrm{I}$ \\
\hline Plutonium & 4 & i & 0 \\
\hline Plutonium/Uranium Fuel (PUF) & 0 & 1 & 2 \\
\hline Transportation/Applications (T/A) & 9 & 8 & 0 \\
\hline Baseline Theoretical & 6 & 2 & 4 \\
\hline Criticality Physics & I & 5 & 1 \\
\hline Total (59) & 24 & 27 & 8 \\
\hline
\end{tabular}

New Transportation/Applications Category. This new subse: of criticality experiments is intended to cover the areas of storage, transportation, waste, dosimciry alarm systems, training, emergency response, processing, and regulations and standards. The material is divided into two parts-Programs and Specific Experiments. The program areas are further subdivided into specific experiments where appropriate.

It is assumed that the physical facilities of the critical mass Iaboratories are "User Facilities." These facilities would be maintained to support experimental capability, and are made available to experimenters. Of course, the permanent facility staff would maintain the capability to conduct experiments, or to supervise the temporary staff for particular experiments. 
Table III: Highest Priority Experiments and Experimerial Programs.

\begin{tabular}{|c|c|c|}
\hline Category & Experiment & Experimental Program or Experiment Title \\
\hline \multirow[t]{2}{*}{ HEU } & 104 & Advanced Neutron Source \\
\hline & 106 & TOPAZ-II Reactor \\
\hline \multirow[t]{2}{*}{ LEU } & 206 & Sheba Reactivity Parameterization \\
\hline & 207 & Sheba Reactivity Void Coefficient \\
\hline \multirow[t]{4}{*}{ P } & 301 & Plutonium Solution in the Concentration Range from $8 \mathrm{~g} / \mathrm{L}$ to $17 \mathrm{~g} / \mathrm{L}$ \\
\hline & 303 & Effectiveness of Iron in Plutonium Storage and Transport Ar:ays \\
\hline & $3(1) 4$ & Plutonium with Extremely Thick Beryllium Reflection \\
\hline & 306 & Arrays of $3-\mathrm{kg}$ Pu-Metal Cylinders Immersed in Water \\
\hline \multirow[t]{9}{*}{$\mathrm{T} / \mathrm{A}$} & 501 & $\begin{array}{l}\text { Assessment for Materials Used to Transport and Store Discrete Items } \\
\text { and Weapons Components }\end{array}$ \\
\hline & Program 502 & Waste Processing, Transportation, and Storage \\
\hline & 5020 & Validation of WIPP Hydrogen Generation Calculations \\
\hline & $502 \mathrm{~h}$ & Minimum Critical Mass of Fissile-Polyethylene Mixture \\
\hline & $502 \mathrm{i}$ & Criticality Studies that Emphasize Intermediate Energies \\
\hline & Program 503 & Validation of Criticality Alarms and Accident Dosimetry \\
\hline & Program 504 & Accident Simulation and Validation of Accident Calculations \\
\hline & Program 505 & Evaluation of Measurements for Subcritical Systems \\
\hline & 508 & Development of a Demonstration Experiment \\
\hline \multirow[t]{6}{*}{ BT } & 601 & Critical Mass Experiments for Actinides \\
\hline & 606 & Plutonium with Extremely Thick Beryllium Reflection \\
\hline & 607 & Establishing the Validity of Neutron-Scattering KerneIs \\
\hline & 608 & Extending the Standard ANSI/ANS 8.7 to Moderated Arrays \\
\hline & 609 & Fission Rate Spectral Index Measurements in Three Assemblies \\
\hline & 610 & $\begin{array}{l}\text { Validation of Calculational Methodology in the Intermediate Energy } \\
\text { Range }\end{array}$ \\
\hline $\mathbf{C P}$ & 702 & Spent Fuel Safety Experiments (SFSX) \\
\hline
\end{tabular}

\section{ENIWG Operations}

New Trunsportation/Applications Category (continued).

Training would be included as part of continuing capability. The training is divided into three parts. Training is provided to those who operate the critical experiments, which is the first part. The secund part is a continuation and expansion of the nuclear-criticality-safety hands-on, 2-, 3-, and 5 -day training courses that have been provided for several years. The third type of training is an "intern-in-residence" program to allow personnel an opportunity to gain experience in the day-today operation of a critical experiment facility. An important adjunct of the training program is developing a simulator to demonstrate the characteristics of critical systems. We proposed that this development becomes a "catalog" item under the auspices of the DOE and that this simulator is made available to contractors and others at cost. 


\section{Forecast of Criticality Experiments: Identifying Experimental Needs}

Programs and experiments included in this category are identified in Table IV.

Table IV. New Transportation/Applications Experiments and Experimental Programs.

\begin{tabular}{|c|c|c|}
\hline Experiment 501: & $\begin{array}{l}\text { Assessment for Material Used to Transport and Store } \\
\text { Discrete Items and Weapon Components. }\end{array}$ & Priority 1 \\
\hline Experimental Program 502: & Waste Processing, Transportation, and Storage. & Priority 1 \\
\hline Experiment $5(1) 2 \mathrm{a}$ & Absorption Properties of Waste Matrices & Priority 2 \\
\hline Experiment $502 \mathrm{~b}$ & In Situ Drum Stacking & Priority 2 \\
\hline Experiment $502 \mathrm{c}$ & Validation of WIPP Hydrogen Generation Calculations & Priority 1 \\
\hline Experiment $502 \mathrm{~d}$ & The In-Tank Precipitation (ITP) Process for ${ }^{235} \mathrm{U}$ & Priority 2 \\
\hline nt $502 \mathrm{e}$ & 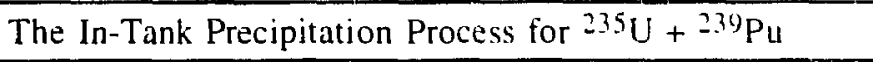 & 42 \\
\hline ent $502 \mathrm{f}$ & The In-Tank Precipitation Process for ${ }^{239} \mathrm{Pu}$ & Priority 2 \\
\hline Experiment $502 \mathrm{~g}$ & $\begin{array}{l}\text { Determination of Fissionable Material Coicentrations in } \\
\text { Waste Materials }\end{array}$ & ity 2 \\
\hline Experiment $502 \mathrm{~h}$ & Minimum Critical Mass of Fissile-Polyethylene Mixture & Prioriry i \\
\hline Experiment $502 \mathrm{i}$ & Criticality Studies That Emphasize Intermediate Energies & Priority 1 \\
\hline Experimental Program 503: & Validation of Criticality Alarms and Accident Dosimetry. & Priority 1 \\
\hline Experimental Program 504: & $\begin{array}{l}\text { Accident Simulation and Validation of Accident } \\
\text { Calculations. }\end{array}$ & Priority ! \\
\hline Experimental Program 505: & Evaluation of Measurements for Subcritical Systems. & Priority 1 \\
\hline Experiment 506: & $\begin{array}{l}\text { Safe Fissile Mass Thresholds for an Array of Waste } \\
\text { Storage Drums. }\end{array}$ & Priority 2 \\
\hline Experimental Program 507: & Simulator Development & Priorily 2 \\
\hline Experiment 508: & Development of a Demonstration Experiment & Priority 1 \\
\hline
\end{tabular}

\section{Resources and Status of Facilities}

The current (1994) status of available critical facilities and their resources are listed below. Although several facilities have been closed, they are listed here for historical reasons. Included in the description of each facility are the:

- core technical capabilities (that is, what assemblies, or test cells, and what materials are available for experiments);

- current documentation (for example, SARs, TSRs, and operating procedures); and

- personnel resources.

\section{A. LACEF}

1. Core Technical Capabilities. The mission of the Los Alamos National Laboratory (LANL) is:

"The Los Alamos National Laboratory is dedicated to applying world-class science and technology to the nation's security and well being. The Laboratory will continue its special role in defense, particularly in nuclear weapons technology, and will increasingly use its multidisciplinary capabilities to solve problems in the civilian sector." 
Operating at Pajarito Site since 1946, the Los Alamos Critical Experiments Facility (LACEF) has been actively involved in this mission. Much of the original nuclear criticality research was performed at this site, and the facility continues to house the most significant collection of critical assemblies in the Western Hemisphere. The LACEF consists of three remotely controlled laboratories, known as kivas, which are located approximately one-quarter mile from the main building that houses the individual control rooms for each kiva. The assemblies in the kivas are described below. The combination of the assemblies, a large invintory of fissile material, and structural materials makes the LACEF one of the most diversified facilities for the simulation of nuclear reactors, weapons, and process applications; it is also a resource for performing research for the nuclear community.

Assemblies. The assemblies that may be operated at LACEF (see Table V for those currently availiable) can be subdivided into four categories:

1. Benchmark assemblies are stable, definable configurations containing precisely known components. They can have interchangeable or adjustable fissile cores and reflectors.

2. Assembly machines are general-purpose platforms into which fissile, moderating, refleting, and control components can be loaded for short-range study of the neutronic properties of the materials.

3. Solution assemblies are specifically designed to allow critical operations with configurations containing fissile solutions.

4. Experimental reactors are either cooled naturally or by self-contained heat rejection systems and may be operated for a significant time at low-power levels.

2. Current Documentation and Personnel Resources. The LACEF staff is trained and certified and documentation is current.

Table V. Critical Assemblies at the LACEF.

\begin{tabular}{|l|l|l|}
\hline Assembly & Type & Applications \\
\hline Big Ten & Large, fast-spectrum, steady-state benchmark assembly & $1,2,3,4$ \\
\hline Comet & General-purpose, vertical assembly machine (portable) & $2,5,6$ \\
\hline Flattop & Fast-spectrum, steady-state benchmark assembly & $1,5,6$ \\
\hline Godiva IV & Fast-burst assembly (portable) & $1,2,4,6,7,8$ \\
\hline Honeycomb & Large, general-purpose, horizontal assembly machine & $5,9,10$ \\
\hline Mars & Large, general-purpose, vertical assembly machine & $3,5,6$ \\
\hline Planet & General-purpose vertical assembly machine & $2,5,6$ \\
\hline Sheba & Liquid, steady-state and burst assembly & $1,2,4,7,8$ \\
\hline Skua & Annular-core fast-burst assembly & $1,2,7,8$ \\
\hline Venus & Large, general-purpose machine (used for solutions) & $1,4,5,6,8$ \\
\hline
\end{tabular}

Applications Legend

1. Irradiation studies

2. Neutron/gamma transport effects

3. Nuclear fuel development

4. Detector development studies

5. Critical mass and separation studies
6. Criticality safety training

7. Vulnerability, lethality, and countermeasures (VL\&C)

8. Criticality alarm development

9. NEST \& START technique development

10. Weapons safety study 


\section{Resources and Status of Facilities (continued).}

\section{B. Area $V$, Sandia National Laboratories (SNL)}

1. Core Technical Capabilities. Area V at Sandia National Laboratories (Albuquerque) comprises numerous research and test laboratories whose main activities center upon research work conducted at versatile reactors and gamma-ray source facilities. The main components of Area $V$ are the Annular Core Research Reactor, the Sandia Pulse Reactor It, the Sandia Pulse Reactor III, the Ganma Irraldation Facility, the Hot Cell Laboratory IGlove Box Laboratory and Analytical Laboritory 1, and the Radiation Metrology Laboratory.

Assemblies.

1. The Annular Core Research Reactor (ACRR) is a pool-type research reactor capable of steady-state, pulse, and tailored-transient operation. The reactor was designed to accommodate a $21,000-\mathrm{cm}^{3}$ experimental package in a high-flux, near-uniform radiation fie!d. In addition, it has two interchangeable, fici-ringed external cavities, an unfueled external cavity. and two neutron radiography facilities.

2. The Sandia Pulse Reactor II (SPR-II) is a bare, fast-burst, unreflected and unmoderatedcore reactor capable of pulse and limited steady-state operation. It has a small central cavity and is used primarily for narrow-pulse, high-dose-rate testing.

3. The Sandia Pulse Reactor III (SPR-III) is a bare, fast-burst, unreflected and unmoderated-core reactor capable of pulse and limited steidy-state operation. The primary experiment chamber is a large central cavity that extends through the core. SPRIII is used for high-neutron-fluence or pulsed, high-dose testing.

4. The kiva that houses the SPR reactor has also been used for the CX experiment recently. This critical assembly was used to pertorm experiments in support of the Space Thermal Propulsion program.

2. Current Documentation and Personnel Resources. The SNL staff is trained and certified and documentation is current.

\section{Argonne National Laboratories (West)}

1. Core Technical Capabilities. The Zero Power Physics Reactor (ZPPR) is a modern, world-class critical facility canable oi thí-scale siniu!ation of fast-spectrum reactors. ZPPR has the flexibility necessary to accor:anodate critical assemblies for a wide range of reactor types, from very small space reactors to the largest, fast reactors. The facility design makes it possible not only to perform measurements, bu: also to switch rapidly from one reactor to another. ZPPR's inventory of critical experimental materials is irreplaceable and immense. This is due to the cost of specialized materials for the facility and nonexistent manufacturing capability.

The ZPPR facility, located at the Idaho site of Argonne National Laboratory (ANL), consists of a reactor cell, a fuel-element loading room, a control room, a materials storage building, and workshops. The reactor cell and loading room are situated under a large earthen mound that provides a stable experimental environment and effective safeguards.

2. Current Documentation and Personnel Resources. Last active in March of 1992, the ZPPR facility is presently in nonoperational standby. The documentation is not current. The staff is no longer certified and has been reduced to three personnel. 


\section{Resources and Status of Facilities (continued).}

\section{Hanford Laboratories}

The Hanford Critical Mass Laboratory was shut down at the end of December 1988; it is no longer functional as a critical facility.

The majority of the world's safety data on criticality of plutonium-bearing solutions was from this facility.

\section{E. Oak Ridge National Laboratory (ORNL)}

1. Core Technical Capabilities. Located on the South Boundary of Y-12, Building 9213 housed the critical facility at ORNL. The facility, which was operational between 1950-1975, contained three cells: one was equipped to pertorm solution critical experiments, and the other two were equipped to perform solid critical experiments on split tables.

2. Current Documentation and Personnel Resources. The facility has been shut down. There is no trained and certified staff and no current documentation.

\section{F. Rocky Flats}

1. Core Technical Capabilities. The Rocky Flats Critical Mass Laboratory (CML) is currently in a standby mode. The facility is gradually being defueled, decontaminated, and decommissioned. This process is not completed.

The CML has one test cell that is large and well equipped with versatile handling equipment. It is thick walled and has a history of a very low leak rate from intentional over pressurization. The interior atmosphere can be completely isolated during an experiment. These properties make the test cell ideal for the safe performance of critical experiments.

Assemblies. This test cell contains four assembly machines, two of which are a vertical split table and the "liquid-reflector apparatus." The former has never been used and cannot be operated without major repairs; the latter was dismantled in the 1980s, pending rebuilding using a more efficient design, but this has not yet occurred. The other two assemblies are still present and fully operational:

- The "horizontal split table" is a large assembly capable of being loaded to many tons. It 3 separation parameters can also be precisely controlled and accurately measured.

- The "Solution Base" is an assembly that is still connected to a uranium solution tank farm that contains $560 \mathrm{~kg}$ of high-enriched uranyl nitrate solution in $2700 \mathrm{~L}$ of solution. The solution is quite free of impurities and exists at an ideal acid normality. Two concentrations are housed: one is approximately the minimum-critical-volume concentration; the other is $-120 \mathrm{~g} / \mathrm{L}$ of uranium. The uranium is enriched to about $93 \%{ }^{235} \mathrm{U}$.

2. Current Documentation and Personnel Resources. Documentation for this facility is not current; it hus neither an SAR nor any procedures. The staff has been reduced to one person who has been a part of this facility since its construction in 1964; however, he is no longer certified. He is approaching retirement age but plans to continue living in the area and will be available if needed.

\section{Conclusions}

At the July 1993 meeting, there was broad representation from DOE contractors, DOE program offices, research reactor facilities, and critical mass laboratories. 
This group successfully prioritized the set of experiments, ongoing and new, that wt.re submilted by the U.S. nuclear communities and established the status of each proposed experiment.

Experimental Categories. Evidence presented at this meeting shows the overwhelming need for a wide variety of critical experiments (refer to Table I). Some conclusions that can be drawn from the intormarion presented here include the following:

1. The majority of Priority-1 experiments and experimental programs (9) are in the Transportation/Applications calegory, with the Baseline Theoretical and Plutonium categories having 6 and 4 Priority-1 experiments and experimental programs, respectively.

Note: Currendly, there are no funded experiments in these three categories. Nor is there a facility that is currently open which is capable of performing plutonium solution experiments.

2. Criticality safery training is recognized as one of the most important aspects of maintaining our technical capability.

3. The new priorities for needed experiments reflect the change in the mission of the DOE. and the current thinking in the nuclear commuinty, as well as continued experinicinis inalt are recognized as supporting U.S. processing facilities.

4. A concerted effort has been made to integrate Physics Criteria for the Benchmark Critical Experiments document (see App. D) into this forecast.

5. An important activity that arose from the meeting was to create an initial draft of criteria for establishing areas of applicability (see App. E).

Resources and Status of Facilities. Currently, there is only one general-purpose critical facility that remains open: the Los Alamos Critical Experiments Facility. Sandia National Laboratories (Albuquerque) has research reactors and the capability to perform small critical experimenis in their kiva; however, there is no capability to perform solution critical experiments.

Rocky Flats CML is currently on standby status.

Future Directions. There is an overwhelming need for critical experiments to be performed for basic research and code validation. The Workgroup will continue to work with the changing direction of the DOE and the nuclear community to identiry experiments and prioritize them. 


\section{Forecast of Criticality Experiments}

\section{Department Needs for Criticality Research in Support of Various F'rograms}

R. Walston, DOE/AL/SPD

\section{Introduction}

The department is facing downsizing. The weapons program is being downsized. The budget is being downsized. Fut'lre technologies are in their infai. The question of support for a nuclear criticality facility comes at a time when nucle wergy, nuclear education, and nuclear technology is un the downswing in the U.S.; proliferation, nuclear energy, and technological competition are on the upswing in other cuuntries. Nuciear material inventories will increase significantly. Of recessity, one is forced to speculate on the need, merit, and nature of future critical experiments and the need of a dedicated sinity in support of the nations' weapons development and nuclear technology role.

\section{i. DOE Critical Facilities}

The DOE critical facilities have historically been a source of critica! mass data, cross sectional data, new core criticals, prompt reactor data, and vital criticality training for the nation. A DOE critical facility provided the interaction with the British, Canadian, French, Japanese, Mexican, Russian, and various university scientists over the years. DOE critical facilities have historically been the most significant creators of safety information and sources of nuclear technology transfer. It will be a DOE facility that maintains the technological core competency for the nation's nuclear criticality analysis.

DOE nuclear criticality facilities have the unique ability to perform classified and unclassified research by drawing on the support of other DOE facilities such as Sandia National Laboratories simulation facilities, Nevada Test Site, Phermix at LANL, and other sites. Only DOE facilities are ailowed to have plutoniums, actinides, highly enriched uraniums, and other such materials.

The loss of a nuclear criticality facility (the remaining one) would of necessity imply the relocation of material and personnel. Should the need arise for a nuclear critical experiment, it could be particularly difficult to reassemble the equipment and personnel, especially if it were a classified experiment. It could take several years to resume operation, depending on how long the facility had been secured. It may become necessary to purchase our criticality data from the Japanese, for example.

\section{DOE Needs for Nuclear Data and Criticality Information}

The following list is a projection of the Department's needs with respect to nuclear data and criticality information as it relates to nuclear safety and the need for a criticality research facility:

\section{A. Safety, Training, and Code Validation}

1. Hands-on training for the department's fissile material workers and oversight personne! will continue to be needed to assure safe operations at many of the department's facilities. This training creates considerable nuclear safety inguiry within nuclear facilities.

2. Nuclear data on super prompt criticals for thermal and fast configurations is important to the department's safety database. Considerable amount of new research is needed in this area to assure safe operations.

3. Neutron and gamma burst and steady state machines are needed to test and validate various criticality detector systems within the department. 


\section{Forecast of Criticality Experiments: Department Needs}

\section{DOE Needs for Nuclear Data and Criticality Information}

\section{A. Safety, Training, and Code Validation (continued)}

4. The nuclear criticality community has many desired experiments to replace extrapolated or sketchy data with validated experimental data.

5. A total weapons test ban may require alternate methods to verify relevant nuclear data for safety and reliability.

6. A critical facility would suppoit emergency analyses for accident scenarios within the department (for example weapons, reactor accidents, or NEST-type events). Analysis of East Block material storage and handling is anticipated. Support for nuclear nonproliferation activities must be available.

\section{B. New Fuels and Reactor Core Designs}

1. New fuels (for example particle bed-lype fuels) are being considered for space propulsion systems. Datti leading to nuclear safety must come from modeling and experiments with fuel configurations in a core, and particle distributions representing accident-caused dispersions of particles.

2. New fuels and coolants will operate over temperature ranges from crycgenic temperatures to possibly several thousand degrees Kelvin in the nuclear propulsion reactor. Basic cross-sectional data for cryogenic hydrogen, for example is not thoroughly developed but is important in the nuclear safety and design of the core. Very little physics data exist on materials at very low temperatures.

3. Exploration of fissile material configurations, other than configurations "at critical," is needed to achieve nuclear data for safe design. The dynamics of solution criticals and excursions are not well understood and should be explored.

4. New reactor-core nuclear data will be needed. New reactivity exploration will be needed. The Oak Ridge "Advanced Neutron Source" is such an example. The most recent example is the CX at Sandia National Laboratories.

5. Alternate uses of plutonium (plutonium-based reactors) driven by stockpile reductions and control may require plutonium criticality analyses in support of safety and design of processing equipment and fuel development.

6. Nuclear safety data may be needed for compact auxiliary-power reactors used in space exploration, such as the SNAP type cores, and the accident environments they could be subjected to as potential plutonium burners.

\section{Waste Processing and Storage}

1. The weapon downsizing programs in the U.S. (and the East Block) will produce unknowns in storage arrays, including the spacing of various units in potentially hostile environments (for example, flooding, fire, etc.).

2. Critical mass data for many of the transuranics and actinides is limited. Some of these elements have large fission cross sections, some have threshold fission energies, and others have combinations of both characteristics. Many of these elements will become abundant and of concern if spent-fuel processing resumes. 


\section{Forecast of Criticality Experiments: Department Needs}

\section{DOE Needs for Nuclear Data and Criticality Information}

\section{Waste Processing and Storage (continued)}

3. Pressure will exist for compacting wastes that contain fissile material, while at the same time preserving nuclear safety. The threshold value for economic recovery will go up, thus increasing fissile materials in nuclear wastes. Nuclear criticality for large arrays is not well understood.

It is anticipated that other criticality related information will be desired as the country moves forward into space missions, new reactor concepts, and new methods for dealing with safety. In addition, the department must consider that the "critical facility concept" provides an avenue for a collection of materials and experts who will provide inquiry and expertise for safety issues as they arise, and wili be the center of focus for any nationally and internationally related data creation and exchange.

\section{The Need for a Critical Facility}

In the past, severai critical facility laboratories existed within the department to explore fissile material configurations in support of specific activities, for example plutonium parts fabrication, fissile material recovery processes, etc. For most of these facilities, the original mission has been canceled or moved and the critical facility laboratery has been decommissioned.

A critical facility typically operates with core configurations at zero power, versatile fuei contigurations, little or no heat removal, and minimal fission prodict controls. These systems lend themselves to the ease of physics data acquisition and system change to accommodate experimental needs. The technical safety requirements and safety analysis report typically reflect generic issues and limitations, as opposed to specific reactors. Independent review, oversight, training, and configuration control is unique for these types of facilities. Only DOE's Defense Programs have this breadth of facility technology and criticality knowledge in the United States.

\section{Conclusion}

A report was produced in May 1987 "FORECAST OF CRITICALITY EXPERIMENTS NEEDED TO SUPPORT U.S. DOE CONTRACTOR OPERATIONS 1987-1992" (DOE/NCT-03) by members of the criticality research community. It suggests a :ariety of critical experiments that would support enhanced safety or efficiency in operations, transportation, storage, and analysis. However, they could not have anticipated the massive changes that would occur in the national and international situation with regard to weapons, nuclear power, or space exploration. A few of the experiments have been carried out, but most of the facilities have been decommissioned. 


\title{
Department of Energy Criticality Safety Program: Qualified Analytical Methods and Nuclear Data
}

\author{
R. Westfall, Oak Ridge National Laboratory
}

\section{Recommendation 93-2}

In its Recommendation 93-2 to the Secretary of Energy (Appendix B), the Defense Nuclear Facilities Safety Board recognizes as a principal ingredient of nuclear criticality control the "theo etical understanding of neutron multiplication processes in critical and subcritical systems, leadirig to predictability of the critical state of a system by methods that use theory benchmarked against good and well characterized critical experiments." In this regard, DOE Order 5480.24, NUCLEAR CPITICALITY SAFETY, incorporates as basis elements and control parameters for its contractor criticality safety programs the requirements of six ANSVANS nuclear criticality safety standards. The principal standard dealing with the use and qualification of analytical methods is ANSU/ANS 8.1, "Nuclear Criticality Safety in Operations with Fissionable Materials Outside Reactors."

\section{Paragraph 4.3}

Paragraph 4.3 of this standard admits a wide variety of methods for predicting effective multiplication factors or for deriving subcritical limits. However, a common procedure for establishing the validity of these methods is specified in paragraphs 4.3 .1 through 4.3.6. To implement this standard, the nuclear criticality safety community, primarily through the DOE Nuclear Criticality Technology and Safety Project, has initiated several efforts. Under this project, the Nuclear Criticality Methods Resource Center has developed and enhanced criticality methods, as well as provided training in the use of the computational software. The concept of criticality methods development being performed on a DOE-wide basis has been very useful and cost effective. However, it should be expanded to include the full range of software required for systems analyses, nuclear data preparation, and sensitivity analyses. Also, the objective of providing redundant capabilities developed with independent approaches should be pursued. This objective is consistent with the Double Contingency Principle employed widely in criticality safety practice.

\section{Paragraphs 4.3.1 through 4.3.6}

Paragraph 4.3.1 of ANSI/ANS 8.1 deals with establishing analytical biases in the calculation of effective multiplication factors ( $k_{e f f}$ ). The primary tools for calculating $k_{e f f}$ and supported by the Resource Center are the KENO codes, developed at ORNL, and the MCNP codes, developed at LANL. They both employ the Monte Carlo method to exploit its flexibility in treating complex material-geometry systems. However, the two codes have substantially different geometry treatment. schemes and neutron kinematics, KENO being an energy multigroup code and MCNP being an energy pointwise code. Thus the pair of codes provide the independent, corroborative capability required for a successful program. Deterministic neutron transport methods are very useful for establishing the analytical bias. Free of the statistical uncertainty associated with Monte Carlo analyses, these techniques yield closed-form solutions for the neutron flux throughout fissile material systems. The Resource Center has supported the use of deterministic transport methods at ORNL (XSDRN, DORT/TORT) and LANL (TWODANT/THREEDANT) in the processing of multigroup cross sections and in studying reaction rates. In the case of second-order accuracies, deterministic methods must be applied to determine the contributions to analytical bias. In addition to keff, several 


\section{Forecast of Criticality Experiments: Analytical Methods and Vuclear Data}

\section{Paragraphs 4.3.1 through 4.3.6}

Paragraph 4.3 .1 of ANSI/ANS 8.1 (continued).

reactor physics parameters are useful for this purpose. They are listed in the Physics Criteria for Benchmark Critical Experiments, Appendix D. In addition to providing validation for specific applications, critical experiments should be performed to provide this basic physics information. The proposed Experiments 206 and 208 are of this nature. Finally, the analytical biases are dependent on both the neutron transport methodologies and the cross-section data. Support of neutron processing software such a.s the AMPX system at ORNL and the NJOY system at LANL should be put on all ongoing basis.

Paragraph 4.3.2 of ANSI/ANS 8.1 addresses the issue of the application range for qualifying critical experiments designed to validate the analyses of specific systems. Heretofore, this issue has been treated primarily by professional judgment. A rudimentary effort to define criteria for matching experiments with fissile systems is included here as Appendix E. The DOE Criticality Safety Program should support the testing and refinement of these criteria. An effective set of criteria for establishing the range of applicability would be of great value to the criticality safety community.

Paragraph 4.3 .3 addresses the concept of the safety margin, including the analytical bias and various areas of uncertainty. The criticality safety community has generally adopted this concept ather than always adhering to a single criterion for subcriticality ( $k_{\text {eff }} \leq 0.95$ ). The safety margin concept justifies economies and, in some instances, provides more effective margins of safety. The DOE should support the development of uncertainty-sensitivity methods for enhancing this process.

Paragraph 4.3 .4 addresses the issues of software verification, which is the responsibility of the developing organization, and software configuration control, which is the responsibility of the user. Software verification is an important furction performed by the Resource Center. It would greatly benefii from more varied and accurate measurements of physics parameters, as discussed above.

Paragraph 4.3 .5 of ANSI/ANS 8.1 states that "Nuclear properties such as cross sections should be consistent with experimental measurements of these properties." Towards this end, the DOE Criticality Safety Program should make more effective use of the Evaluated Nuclear Data Files developed by the nuclear data community and formally tested by elements of the Cross Section Evaluation Working Group (CSEWG). Heretofore, CSEWG data testing has been primarily in the areas of fast reactors, thermal reactors, and radiation shielding. This data testing should be extended to the broad range of nuclides and material compositions of interest to nuclear criticality safety. Substantial benefit would accrue to the DOE Criticality Safety Program from its involvement with CSEWG data testing procedures, including the use of uncertainty-sensitivity techniques. Results from this activity would include the justification for lower uncertainties in measured data and, ultimately, more accurate criticality analyses and reduced analytical biases.

Paragraph 4.3.6 addresses the elements of validation studies that should be documented. Documentation of software verification and the performance of cross-section libraries should continue as important functions of the Resource Center.

\section{SUMMARY}

In summary, the DOE Criticality Safety Program, under the Nuclear Criticality Technology and Safety Project, has made substantial progress in providing both analytical software and measured data. However, this effort should be expanded to include the full range of software required for systems analyses, nuclear data preparation, and sensitivity analyses. An overall objective should be the provision of redundant capabilities developed with independent technical approaches. 


\section{Acronyms}

ACRR Annular Core Research Reactor

AEC Atomic Energy Commission

AMPX neutron processing software at ORNL

ANL Argonne National Laboratory, University of Chicago

ANSI/ANS 8.1 American National Standards Institure/American Nuclear Society Standard 8.1, "Nuclear Criticality Safety in Operations with Fissionable Materials Outside Reactors"

ANSI/ANS 8.7 ANSI/ANS Standard 8.7, "Guide for Nuclear Criticality Safety in the Storage of Fissile Materials"

APRFR Air Force Pulse Reactor

AVLIS Advanced Laser Isotope Separation Program

B \& W Babcock and Wilcox Company

BNFL British Nuclear Fuels, Ltd.

BNL Brookhaven National Laboratory

BWR boiling water reactor

CAIDOE-RFO M. S. Chew and Associates, Inc./Rocky Flats Operations Office

CML critical mass laboratory

CMPO octylphenyl-N,N-disobutylcarbamethylphosphine oxide

CNPS Compact Nuclear Power Source

CNR Center for Neutron Research

CSEWG Cross Section Evaluation Working Group

CX Critical experiment at Sandia National Laboratories

DC delayed critical

DNFSB Defense Nuclear Facility Safety Board

DOE Department of Energy

DOE-HQ Department of Energy Headquarters

DOE-TIC Department of Energy Technical Information Center

DOE/AL/SPD Department of Energy, Albuquerque Operations Office, Special Projects Division

DORT/TORT ORNL deterministic transport code for neutron cross sections

EBR-II Experimental Breeder Reactor II

EG\&G Edgerton, Germeshausen, and Grier, Inc.

EM-30 WIPP site

ENCOG Experimental Needs Coordinating Group

ENIWG Experimental Needs Identification Workgroup

ERDA Energy Research and Development Agency 
Forecast of Criticality Experiments: Acronyms

FAST Fluorinal and Storage

FERMCO Fernald Environmental Management Co.

FFR Fast Fission Ratio

FFTF Fast Flux Test Reactor

FWHM full width at half maximum

GDP gaseous diffusion plant

HE high explosive

HEU highly enriched uranium

HPRR Health Physics Research Reactor

ICPP Idaho Chemical Processing Plant

INEL Idaho National Engineering Laboratory, EG\&G Inc.

ITP in-tank precipitation

KAPL Knolls Atomic Power Laboratory

KENO Computer code for keff at ORNL

LACEF Los Alamos Critical Experiments Facility

LACEF/SHEBA Los Alamos Critical Experiments Facility/Solution High-Energy Burst Assembly

LACEF/SNL Los Alamos Critical Experiments Facility/Sandia National Laboratories - Area V

LANL Los Alamos National Laboratory, University of California

LET linear energy transfer

LEU low-enriched uranium

LLNL Lawrence Livermore National Laboratory, University of California

LWR Light Water Reactor

LYNER Low Yield Nuclear Explosive Ręsearch

MCM minimum critical mass

MCNP Monte Carlo n-particle (code)

MIT Massachusetts Institute of Technology

MMES Martin Marietta Energy Systems at ORNL

MRS monitored retrieval storage

NCIS Nuclear Criticality Information System

NCT\&SP Nuclear Criticality Technology and Safety Project

NE213 Nuclear Enterprize-213 (detector)

NEST Nuclear Emergency Search Team

NEST \& ARG Nuclear Emergency Search Team \& Accident Response Group

NIST National Institute of Standards Technology

NPR New Production Reactor 
Forecast of Criticality Experiments: Acronyms

NRC Nuclear Regulatory Commission

ORNL Oak Ridge National Laboratory, MMES

OSTT Office of Scientific and Technical Information

PHERMEX Pulse High-Energy Machine Emitting X-Rays, LANL

PNC Power F actor and Nuclear Fuel Development Corporation

PNL Battelle-Pacific Northwest Laboratory

PVC. polyvinylchloride

PWR pressurized water reactor

QA quality assurance

$R$ roentgen, unit of exposure

RBE relative biological effectiveness

RCR Relative Conversion Ratio

RF CML Rocky Flats, Critical Mass Laboratory

RFP Rocky Flats Plant

SAR Safety Analysis Report

SFSX Spent Fuel Safety Experiments

SIS special isotope separation

SNAP Systems for Nuclear Auxiliary Power

SNL Sandia National Laboratory

SNM Special Nuclear Material

SPD Safety Programs Division

SPR-II Sandia Pulse Reactor-II

SPP-III Sandia Pulse Reacior-III

SRL Savannah River Laboratory

SRP Savannah River Plant, Westinghouse Company

SRS Savannah River Site

START I \& II Strategic Arms Rediction Treaiy İ and II

TRU transuranic waste

TRUEX transuranic extraction

TSR Technical Specification Requirements

TWODANT/ LANL deterministic transport code for neutron cross sections and reaction THREEDANT rates

UKAFA United Kingdom Atomic Energy Authority

$\checkmark$ L\&C vulnerability, lethality, and countermeasures

WHC Westinghouse Hanford Company

WINCO Westinghouse Idaho Nuclear Company

WTPP Waste Isolation Pilot Plant 
Forecast of Criticality Experiments: Acronyms

\author{
WMCO Westinghouse Material Company of Ohio \\ WPPS Washington Public Power System \\ WSMR White Sands Missile Range \\ WSRC Westinghouse Savannah River Company \\ XSDRN ORNL deterministic transport code for neutron cross sections \\ $Y-12$ Plant Oak Ridge Y-12 Plant \\ ZPPR Zero Power Physics Reactor
}




\section{Experiment Needs Identification Workgroup}

John Anderson

Courtney Apperson

J. Blair Briggs

Blake Brown

C. Les Brown

James Bryson

Ken Butterfield

Roger Carter
U. S. Department of Energy

Savannah River Operations Office

Safety Division

P.O. Box A

Aiken, SC 29802

(803) $725-9716$

Westinghouse Savannah River Company

Building 773-42A, Rm. 124

P.O. Box 616

Aiken, SC 29892

(803) 725-8215

FAX: (803) 725-4704

INEL

P.O. Box 1625

Idaho Falls, ID 83415-0528

(208) 526-7628

FAX: (208) 526-0528

Private Consultant

20661 Highland Hall Drive

Gaithersburg, MD 20879

(301) $831-1388$

CAIDOE-RFO

1050 Tantra Park Circle

Boulder, CO 80303

(303) 966-6185

FAX: (303) 966-4703

Sandia Nationa' Laboratories

P.O. Box 580']

Dept. 6521

Albuquerque, NN. $37111-5800$

(505) 845-3210

FAX: (505) 845-9868

Los Alamos National Laboratory

P.O. Box 1663

N-2, MS J562

Los Alamos, NM 87545

(505) 567-8944

FAX: (505) 665-3657

Mohr \& Associates

1440 Agnes

Richland, WA 99352

(509) 946-0941

FAX: (509) 946-4395 
Dile Chung

Charlie Crune Jr.

Paul Felsher

Ivon E. Fergus

Dunald Finch

Denelle Friar

Adolf Garcia

David Heinrich
Office of Engineering and Operations Support United States Department of Energy DP-62, A-127

Germantown, MD 20585

(301) 903-3968

FAX: (301) 903-8754

Oak Ridge National Laboratory

P.O. Box 2008

Oak Ridge, TN 37831-6244

(615) 574-45.58

FAX: (615) 576-0610

EG\&G/Rocky Flats, Inc.

P.O. Box 464

Bldg. 886

Golden, $\mathrm{CO} 80402$

(303) $966-8395$

FAX: (303) 966i-7326

U.S. DOE

Performance Assessment Division 19901 Germantown Rd., NS-10, E-438

Germantown, MD 20874

(301) 903-6364

FAX: (301) 903-7358

Westinghouse Savannah River

P.O. Box 616

Aiken, SC 29802-0616

(803) 725-5291

FAX: (803) 725-3272

Westinghouse Hanford Company

P.O. Box 1970

MISN R3-01

Richland, WA 99352

(509) 372-2891

FAX: (509) 372-3522

Argonne National Laboratory

P.O. Box 2528

ANL-W, Bldg. 765-A

Idaho Falls, ID 83403-2528

(208) 533-7252

FAX: (208) 533-7403

Lawrence Livermore National Laboratory

P.O. Box 808

L-390

Livermore, CA 94551-9900

(510) $424-5679$

FAX: (510) 423-2854 
Calvin Hopper

Martin Huebner

Jerry Koelling

Richard Malenfant

Jerry McKamy

James Mecca

James Mincey

Naomi Moon
Oak Ridge National Laboratory

113 Cumberland Drive

Oak Ridge, TN 37830-7145

(615) 576-8617

FAX: (615) $576-3513$

Argonne National Laboratory

P.O. Box 2528

Idaho Falls, ID 83403-2528

(208) 533-7587

FAX: (208) 533-7172

Los Alamos National Laboratory

P.O. Box 1663

N-DO, MS E561

Los Alamos, NM 87545

(505) 667-5590

FAX: (505) 665-.5340

Los A iamos National Laboratory

P.O. Box 1663

$\mathrm{N}-2$, MS J562

Los Alamos, NM 87545

(505) 665-5645

FAX: (505) 665-3657

EG\&G/Rocky Flats

P.O. Box 464

Bldg. 886

Golden, CO 80402

(303) 966-4017

FAX: (303) 966-7326

U.S. Department of Energy

Operations and Transition

Richland Operations Office

Richland, WA 99352

(509) 376-9471

FAX: (50) 396-0695

Westinghouse Savannah River

Bldg. 773-22A

P.O. Box 616

Aiken, SC 29802

(803) $725-2718$

FAX: (803) 725-8829

U.S. DOE/Rocky Flats

P.O. Box 928

Golden, CO 80402-0928

(303) $966-3498$

FAX: (303) 966-4763 
R. Douglas O'Dell

Cecil Parks

Jeffrey Philbin

Raymond Reed

Mark Robinson

Robert Rothe

Burton Rothleder

Debra Rutherford Chair
Los Alamos National Laboratory P.O. Box 1663 H:S-6, MS F691

Los Alamos, NM 87545

(50) $667-4614$

FAX: (505) 665-4970

Oak Ridge National Laboratory

P.O. Box 2008

Bldg. 6011 , MS 6370

Oak Ridge, TN 37831-5280

(615) 574-5280

Sandia National Laboratory

P.O. Box 5800

Dept. 6523

Albuquerque, NM 87185-5800

(505) 845-9036

FAX: (505) 845-9868

Westinghouse Savannah River P.O. Box 616 Building 773-42A, Rm. 182

Aiken, SC 29802

(803) 725-3468

FAX: (505) 725-4074

U.S. DOE/Rocky Flats

P.O. Box 928

Golden, CO 80402-0928

(303) $966-5414$

FAX: (303) 966-2256

EG\&G/Rocky Flats, Inc.

P.O. Box 464

Building 886

Golden, CO 80402

(303) 966-2989

FAX: (303) 966-7326

U.S. DOE

NE-74

19901 Germantown Road

Germantown, MD 20874

(301) 903-3726

FAX: (301) 903-8693

Los Alamos National Laboratory

P.O. Box 1663

$\mathrm{N}-2$, MS J562

Los Alamos, NM 87545

(505) 665-5038

FAX: (505) 665-3657 
Bret Simpkins

John Smartt

John Tanner

Richard Taylor

Vice Chair

Hans Toffer

Richard Vornehm

Paul Webb

Robert (Mike) Westfall
Battelle Pantex

P.O. Box 30020

Amarillo, TX 79177

(806) $577-5621$

FAX: (806) 477-5613

U.S. DOE/Savannah River Site

Safety Division, 703-A

P.O. Box A

Aiken, SC 29802

(803) 725-1658

FAX: (803) 725-3376

Westinghouse Idaho Nuclear

P.O. Box 4000

MS 5222

Idaho Falls, ID 83403

(208) 526-9643

FAX: (208) 526-9805

Martin Marietta Energy Systems

Oak Ridge Y-12 Plant

P.O. Box 2009

Oak Ridge, TN 37831-8193

(615) 574-3529

FAX: (615) 241-2772

Westinghouse Hanford Company

P.O. Box 1970

HO-38

Richland, WA 99352

(509) 376-2894

FAX: (509) 376-1293

Martin Marietta

P.O. Box 2007

Y-12, MS A238

Oak Ridge, TN 37831

(615) 576-2289

FAX: (615) 241-2772

M.H. Chew \& Associates, Inc. 1424 Concannon Blvd.

Bldg. G

Livermore, CA 94550

(510) 455-3511

FAX: (510) 373-0624

Oak Ridge National Laboratory

P.O. Box 2008

Oak Ridge, TN 37831-6151

(615) 574-5267

FAX: (615) 574-3527 


\section{Acknowledgments}

I would like to thank the ENIWG for their invaluable contribution in identifying the fi. ure needs of the criticality siftety community. I would also like to acknowledge the contributions madt' by C. L. Brown (CAI/DOE-RFO), J. J. Koelling, R. E. Malenfant, and R. D. O'Dell (LANL), B. M. Rothleder (DOE-HQ), and R. M. Westfall (ORNL). Thanks also to the Publici uuns Team at NIS-6 (Randi Bagley, Marty Riehm, AnnMarie Dyson, and Gerry Edwards), and to Celine Apodaca Charla Höhner, and Jeanette Martinez for their support. 


\section{Criticality Experiments Needed to Support Highly Enriched Uranium Operations}

HEU - 1 


\section{Table of Contents}

\section{Criticality Experiments Needed to Support Highly Enriched Uranium Operations}

Experiment 101 U(93) Metal Reflected by Annealing Salts

Experiment 102 Large Array of Small Units.

Experiment 103 Slightly Moderated U(93) Oxide Powder.....

Experiment 104 Advanced Neutron Source

Experiment 105 High-Energy Burst Reactor......

Experiment 106 TOPAZ-II Reactor.

Experimental

Program 107 Criticality Evaluations of Space Power \& Propulsion Assemblies Program
HEU - 3

HEU - 4

HEU - 6

HEU - 7

HEU - 8

HEU -10

HEU - 11 


\section{Experiment 101 \\ U(93) Metal Keflected by Annealing Salts}

\begin{tabular}{|c|c|c|}
\hline Contractor $\mathbf{R}$ & quiring Data & Y-12 Plant (Martin Marietta Energy Systems) \\
\hline & Category & Highly enriched uranium \\
\hline & Application & $\begin{array}{l}\text { Provide basic safety information to enhance the process of nuclear criticality } \\
\text { safety analysis }\end{array}$ \\
\hline Rating & Status & Justification completed \\
\hline & Priority & Required for new or ongoing DOE operation \\
\hline
\end{tabular}

Description of For highly enriched uranium metal working operations at the Oak Ridge Y-12 Plant, it is operation and necessary to immerse individual units in a mixture of salts (sodium carbonate, potassium experimental carbonate, and lithium carbonate) at elevated temperature. These salts are also occasionally data needed present in the process area as solids. There is an indication from computational studies thut solid sodium carbonate may be a better reflector than water, hence, the frequent assumption of a water reflector may not be conservative. Experiments need to be performed to determine the effectiveness of the individual salts and salt mixtures used as reflectors about highly enriched uranium metal. These experiments could be readily combined with other proposed experiments.

Proposed
experimental
facility

Contact R. Vornehm

Martin Marietta Energy Systems- $Y-12$

P. O. Box 2007

Knoxville, TN 32830

615) 574-3529; FAX (615) 241-2772 


\section{Experiment 102 \\ Large Array of Small Units}

Contractor Requiring Data Y-12 Plant (Martin Marietta Energy Systems)

Category Highly enriched uranium

Application Enhance current DOE operation

Rating Status Justitication completed

Priority Required for new or ongoing DOE operation

Description of Available experimental data for highiy enriched uranium (and plutonium) have:

operation and ( 1 ) individual units which are relatively massive compared to the actual units that are experimental typically stored; (2) much closer spacing between individual units than the spacing data needed ordinarily encountered in storage; and (3) considerably fewer units in the experimental array compared to the number in typical storage arrays. Monte Carlo nuclear criticality safety codes are validated by comparing the codes with experimental data. Then these codes are used to calculate storage arrays that are characteristically different from the experimental arrays, as described above. There is some concern that the neutron coupling in actual large arrays of relatively small units may be different, hence, less conservative, than the coupling found in the experimental small arrays of relatively large units. This concern applies to uranium and plutonium, both of which will likely require more storage in the future.

These experiments could also be easii. zombined with other propused arr.iy experiments, such as studies of interunit moderations.

\footnotetext{
Proposed experimental

LACEF, or Rocky Flats (arrays of uranium solutions)

facility
} 
Contact J. Tanner

Westinghouse Idaho Nuclear Co.

P.O. Box 400; MS5222

Idaho Falls, ID 83404

(208) 526-9643; FAX (208) 526-9805

C. Hopper

Martin Marietta Energy Systems

Oak Ridge National Laboratory

P.O. Box 2008

Oak Ridge, TN 37831

(615) 576-8617; FAX (615) 576-3513
E. Elliott

Martin Marietta Energy Systems

Oak Ridge Y-12 Plant

P.O. Box 2007

Oak Ridge, TN 37831-8238

(615) 241-2771; FAX (615) 241-2772 


\section{Experiment 103 \\ Slightly Moderated U(93) Oxide Powder}

Contractor Requiring Data Y-12 Plant (Martin Marietta Energy Systems)

Category Highly enriched uranium

Application Enhance current DOE operation

Rating Status Justification completed

Priority Required for new or ongoing DOE operation

Description of Past critical benchmarks have included experiments with dry uranium oxide and

operation and experiments with uranium in solution. However, critical benchmark experiments with experimental uranium oxide at low moderation (for example, $\mathrm{H} / \mathrm{X}=1$ ) are not adequate. Potential

data needed processing conditions at the Y-12 Plant and Rocky Flats could involve moist uranium oxide. The criticality safety data for such processes must be provided. Critical experiments that involve moist uranium oxide are needed as the basis for critical mass data and as the basis for validating criticality codes for situations involving moist uranium oxide. Such experiments can also be applied to undermoderated systems involving uranium oxide.

\section{Proposed LACEF experimental facility}

Contact R. Vornehm

Martin Marietta Energy Systems-Y-12

P. O. Box 2007

Knoxville, TN 32830

(615) 574-3529; FAX (615) 241-2772 


\section{Experiment 104 Advanced Neutron Source}

\section{Contractor Requiring Data Oak Ridge National Laboratory \\ Category Highly enriched uranium \\ Application Support new DOE program \\ Rating Status Justification completed \\ Priority Maximum practical attention}

Description of The Advanced Neutron Source reactor program has been authorized by DOE. This will operation and become the largest such farility in the world. The ANS program will develop an ultra-highexperimental flux compact reactor concept to provide a high-intensity, steady-state source of neutrons for data needed research on condensed matter. The preliminary core design consists of a $\mathrm{D}_{2} \mathrm{O}$-cooled and moderated, highly enriched uranium/silicon/aluminum ( $\mathrm{U}_{3} \mathrm{Si}_{2} / \mathrm{Al}$ ) fuel in an offset split core. The $\mathrm{D}_{2} \mathrm{O}$ reflector tank will have several beam tubes, cold and hot neutron sources.

A critical experiment program will be needed to support fabrication and subsequent handling and storage of the fuel. Measurements of critical configuration, control rod calibration, fission power density, neutron flux per fission, gamma flux density, temperature coefficient, and reactivity worth measurements in beam tubes are needed to calibrate design computer calculations.

\section{Proposed LACEF/SNL experimental facility}

\section{Contact D. Selby} ORNL

104 Union Valley Road

P.O. Box 209, MS 8218

Oak Ridge, TN 37830

(615) 574-6161; FAX (none) 


\title{
Experiment 105 \\ High-Energy Burst Reactor
}

\author{
Contractor Requiring Data Los Alamos National Laboratory \\ Category Highly enriched uranium \\ Application Upgrade basis for high-energy burst reactor \\ Rating Status Justification completed \\ Priority Required for new or ongoing DOE operation
}

Description of In the area of neutron fast-burst reactors, the state-of-the-art ailows the production of fewoperation and tens of microsecond pulses with energy yields approaching $10^{17}$ to $10^{18}$ fissions. Much experimental beyond this, uranium metal and currently used alloys melt or fracture. Current weapon data needed technology allows reliable production of low yields in the range of a few tons of yield. Presently, there is little or no experimental measurements of burst reactor behavior in the range up to $50 \mathrm{lbs}$ of yield. The only available data on these systems at such yields come from accident situations, which were not precisely instrumented. Indeed, there are no calibrated computer codes which can calculate the behavior of burst assemblies in this range.

This information is important because the design basis accidents for burst reactor facilities (Godiva-IV, Skua, HPRR, SPR-II, SPR-III, WSMR-Molly-G, and APRFR) is calculated without adequate verification data in the range of interest $\left(10^{18}-10^{19}\right.$ fissions). Such information would serve as a basis for defining the safety envelopes of the high-energy burst reactor SARs.

Furthermore, the state-of-the-art in burst reactors has reached the limit of current fuel technology. Production of bursts beyond $2 \times 10^{17}$ will require new fuel materials and technology currently not in use.

Specifically, we propose a program of high-energy burst reactor experiments (up to $50 \mathrm{lbs}$ equivalent $\mathrm{HE}$ yield) to be performed within a containment sphere. Here, we define highexplosive (HE) equivalent yield as:

Fission yield $x$ (Kinetic Energy/ Total Energy) $=$ HE equivalent yield

$10^{17}$ fissions: $\quad 1.4 \mathrm{lb} \mathrm{HE} \times 1 \%=0.014 \mathrm{lb}$ HE equivalent

$10^{18}$ fissions: $\quad 14 \mathrm{lb} \mathrm{HE} \times 5 \%=0.7 \mathrm{lb} \mathrm{HE}$ equivalent

$10^{19}$ fissions: $\quad 140 \mathrm{lb} \mathrm{HE} \times 10 \%=14 \mathrm{lb} \mathrm{HE}$ equivalent 
Experiment 105 (continued)

Description of The experiments would be performed using a Godiva-class burst assembly that would be operation and incrementally driven to hydrodynamic disassembly with suitable diagnostics to measure experimental yield, initial period, FWHM, fuel state (dynamic pressure and temperature). Extra cores data needed from several current or retired burst machines might be available for such experiments. The (continued) site for such a test bed could be LACEF (Kiva III) or the Nevada Test Site (Low Yield Nuclear Explosive Research or LYNER site). experimental LACEF, or the Nevada Test Site (LYNER site) facility

Contact R. Faternoster

Los Alamos National Laboratory

P.O. Box 1663, MS J562

Los Alamos, NM 87545

(505) 667-4728; FAX 665-3657 


\title{
Experiment 106 \\ TOFAZ-II Reactor
}

Contractor Requiring Data Los Alamos National Laboratory, Strategic Defense Initiative Office

Category Highly enriched uranium

Application To increase the safety of the Russian TOPAZ-II space reactor, in support of U.S. Space Reactor Program

$\begin{array}{rrl}\text { Rating } & \begin{array}{r}\text { Status } \\ \text { Priority }\end{array} & \text { Justification completed } \\ & \text { Maximum practical attention }\end{array}$

Description of The Russian TOPAZ-II space reactor is being modified in the U.S. in preparation for a operation and flight test. The large difference in safety philosophy between the two countries necessitates experimental both modification of the reactor and supportive, credible safety analyses. In order to justify

data needed flight testing in the U.S., measurement of the reactor component reactivity-worth measurements are needed for ongoing modifications and safety analyses. By calculation, the TOPAZ-II Space Reactor goes critical in water. The modifications (i.e., redesign of control elements) will alleviate this problem and allow the TOPAZ-II to be launched in this country. Worth measurements would be performed in a TOPAZ-II mock-up assembly at an established critical assembly facility.

\author{
Proposed \\ experimental \\ LACEF \\ facility \\ Contact R. Paternoster \\ Los Alamos National Laboratory \\ P. O. Box 1663, MS K551 \\ Los Alamos, NM 87545 \\ (505) 667-4728; FAX (505) 665-3657
}




\section{Experimental Program 107 \\ Criticality Evaluations of Space Power \& Propulsion Assemblies}

\begin{tabular}{|c|c|c|}
\hline Contractor $\mathbf{R}$ & quiring Data & Sandia National Laboratories \\
\hline & Category & Highly enriched uranium \\
\hline & Application & Support new DOE program \\
\hline Rating & Status & Justification completed \\
\hline & Priority & Required for new or ongoing DOE operation \\
\hline
\end{tabular}

Description of Perform criticality evaluations, control-element reactivity-worth evaluations, and parametric operation and studies (experiments) to characterize proposed and refined designs for nuclear-powered experimental rockets, space power, and propulsion.

data needed

\section{Proposed LACEF/SNL experimental facility}

Contact J. Philbin

Sandia National Laboratories

P.O. Box 5800

Dept. 6523

Albuquerque, NM 87185-5800

(505) 845-9036; FAX (505) 845-9868 


\section{Criticality Experiments Needed to Support Low-Enriched Uranium Operations}




\section{Table of Contents}

\section{Criticality Experiments Needed to Support Low-Enriched Uranium Operations}

Experimental

Program 201 SP-100 Surety Program.

Atomic Vapor Laser Isotope Separation (AVLIS)

Experiment 203 Uranium Fuel Feed Operations

Experimental

Program 204 Monitored Retrievable Storage (MRS) Facility

Experimental

Program 205

Effect of Interspersed Moderation on an

Unmoderated Storage Array

Experiment 206 Sheba Reactivity Parameterization.....

Experiment 207

Sheba Reactivity Void Coefficient

Experiment 208

Benchmark Measurements
LEU - 3

LEU - 4

LEU - 5

LEU - 7

LEU - 8

LEU - 9

LEU - 10

LEU - 11 


\section{Experimental Program 201 \\ SP-100 Surety Program}

\section{Contractor Requiring Data ios Alamos National Laboratory \\ Category Low-enriched uranium \\ Application Support new DOE program}

Rating Status Anticipated need. SP-100 program on hold. This experiment description has not been updated to reflect program status.

Priority Less urgent than priority (2)

Description of The purpose of the overall program is to develop a safe, compact, light-weight, durable, operation and multi-hundred-kilowatt electric (10 to $1,000 \mathrm{kWe}$ ) space reactor (SP-100) and the associated experimental power system technology. The SP-100 reactor core will have 0.33-in.-diam., enriched data needed uranium nitride fuel rods that are cooled by liquid metal. The uranium enrichment will be $50-97$ wt\% $235 U$. The SP-100 would make possible a broad class of space missions in the mid-1990's and into the next century.

Martin Marietta is responsible for the design and development of the SP-100 reactor. LANL is fabricating the fuel. Initial reactor measurements were made in the ZPPR at the Idaho National Engineering Laboratory, Idaho Falls. Due to funding restrictions and program redirections, technology development has been implemented with an evolutionary strategy. Current program plans do not call for ground testing of the prototypic reactor subsystem. We anticipated that both cold- and warm-critical testing of the flight system reactor will be carried out at the Los Alamos Critical Experiment Facility at LANL. The SP-100 program is currently on hold.

Significant milestones are:

- Phase-I Technology Readiness in early 1995.

- Flight Criticals Testing, which will be determined.

\section{Proposed LACEF \\ experimental facility}

Contact J. Bu'ksa

Los; Alamos National Laboratory

P.C. Box 1663 MS K551

Los Alan?os, NM 87545

(505) 665-0534; FAX (505) 665-4938 


\section{Experiment 202 \\ Atomic Vapor Laser Isotope Separation (AVLIS)}

Contractor Requiring Data Advanced Laser Isotope Separation Program Project Manager

Category Low-enriched uranium

Application Support AVLIS program (The AVLIS program may be privatized.

Nonetheless, the need for experimental criticality benchmarks to support the program is recognized here.)

Rating , Status Justification completed

Priority Required for new or ongoing DOE operation

Description of Criticality safety design criteria and margins of safety for the AVLIS project will be based operation and on calculational techniques that are invalidated, and for uranium enrichments for which experimental there are no experimental data. Without adequate benchmark critical experiments, there will

data needed be a large uncertainty associated with the design criteria parameters. This uncertainty means the margins of safety cannot be sufficiently quantified for particular design criteria.

Critical experiments are needed for code validation purposes. The experiments involve an enriched uranium range of 5 to $10 \%$. Three types of experiments are needed to cover the AVLIS processes:

1. Homogeneous systems: uranyl nitrate and uranyl fluoride solutions, and damp uranium oxides, at varying $\mathrm{H} / \mathrm{U}$ atomic ratios, in reflected and unreflected vessels.

2. Heterogeneous systems: uranium metal-water mixtures at various metal-to-water volume fractions and with various metal surface-to-volume ratios.

3. Arrays: arrays of interacting vessels with the above materials and with fixed neutron poisons.

\section{Propased LACEF \\ experimental \\ facility}

Contact R. Vornehm

Oak Ridge Y-12 Plant

P. O. Box 2009

Oak Ridge, TN 37831-8238

(615) 574-3529; FAX (615) 241-2772 


\title{
Experiment 203 \\ Uranium Fuel Feed Operations
}

\author{
Contractor Requiring Data Fernald Environmental Restoration Management Corporation \\ Category Low-enriched uranium \\ Application Increase operational flexibility \\ Rating Status Justification completed \\ Priority Required for new or ongoing DOE operation
}

Description of Margins of safety in production operations are larger than necessary and unduly restrict operation and operational flexibility.

experimental data needed

A few critical experiments would introduce three major advantages:

1. Safety marr ins could be established with more confidence,

2. Storage capacity would be increased significantly in some areas, and

3. Designs of new equipment could be more thorough and complete, because the more flexible computational methods could be used with confidence.

Experimental needs fall into two regions of enrichment and two chemical states. The uranium enrichments range from depleted to $20 \% 235 \mathrm{U}$. The criticality characteristics of uranium enriched to less than $6-7 \%{ }^{235} \mathrm{U}$ is different from more highly enriched uranium in that a moderator must be mixed with the uranium to produce a critical system. For higher ${ }^{235} \mathrm{U}$ enrichments, material can be made critical without the aid of a moderator, although substantial quantities may be required. Two physical states are of interest: water solutions of uranium compounds, and dry metallic (or oxide) systems.

\section{Solution Experiments}

1. For the lower enrichment region, a true minimum in critical size or mass exists. Thus, experiments to determine the critical parameters for, say, solutions at $3 \%$ and $5 \%$ enrichment would be very useful.

2. Given a determination of a critical size at or near the minimum, the change in size (increase) as moderation is increased or decreased is also of interest. 
Experiment 203 (continued)

Description of Solution Experiments (continued)

operation and

experimental

data needed

(continued)

3. In the enrichment range between $6 \%$ and $20 \%$, the critical size of the metal system may be smaller than the optimum moderated case. However, the critical size, in the moderation ranges employed in 1 and 2 above, should be determined for this enrichment range also.

Uranium Metal Experiments

The critical mass and size of highly enriched $(93.5 \% 235 \mathrm{U})$ uranium and $30 \%$ enriched uranium are well known, but no critical experiment has been performed for uranium enriched to $20 \%$. A critical experiment at or near this enrichment would be very useful for plant operations.

Uranium Metal Pieces in Water

Dissolution (or digestion) of metal scrap has been performed on a regular basis at FERMCO. For slightly enriched uranium, arrangements of solid rods or pieces can have a lower critical mass than the same amount of material as a dissolved compound, or as a metal-water mixture. Thus, experiments with the same enrichment used in A.1., but with uranium of finite-sized pieces (e.g., golf ball size) spaced in a regular array is of special interest.

Proposed LACEF or Rocky Flats CML

experimental

facility

Contact T. Brown

FERMCO

P.O. Box 398704

Cincinnati, $\mathrm{OH} \quad 45239$

(513) 738-6682 


\title{
Experimental Program 204 \\ Monitored Retrievable Storage (MRS) Facility
}

\author{
Contractor Requiring Data Oak Ridge National Laboratory \\ Category Low-enriched uranium \\ Application Support new DOE program

\begin{tabular}{rrl}
\hline Rating & Status & Justification completed \\
Priority & Required for new or ongoing DOE operation
\end{tabular}

Description of On March 31, 1987, the DOE submitted to Congress a proposal fivr a monitored retrievable operation and storage (MRS) facility. Storage capacity for 15,000 metric tons of spent, light-water reactor experimental fuel would be provided. Experiment criticality data in two areas will be needed:

data needed

\section{Fuel Rod Consolidation}

The MRS will provide the capability to dicassemble fuel assemblies and consolidate the fuel rods in storage canisters (for a 2:1 volume reduction). Experimental data will benefit the safety and economics of this operation.

2. Spent-Fuel Burnup versus Reactivity

DOE Contractors and NRC licensees are interested in obtaining criticality data for spent LWR fuel to confirn calculations. Operational and storage restrictions can be significantly reduced if credit could be taken for burnup. The calculations must account for (1) ${ }^{235} \mathrm{U}$ depletion and fission product formation, which decrease reactivity, and (2) the formation of plutonium, which increases reactivity.

\section{Proposed LACEF \\ experimental \\ facility}

Contact C. Brown

CAI/DOE-RFO

1050 Tantra Park Circle

Boulder, CO 80303

(303) 966-6185; FAX (303) 966-4763 


\section{Experimental Program 205}

\section{Effect of Interspersed Moderation on an Unmoderated Storage Array}

Contractor Requiring Data Applicable to all Department of Energy Contractors

Category Low-enriched uranium

Application Applies to storage arrays of plutonium, HEU, and LEU, where sprinkler systems can introduce water moderation between units.

Rating Status Justification being prepared

Priority Required for new or ongoing operation

Description of operation and experimental data needed

Proposed experimental facility

Contact R. Anderson
An experiment is needed to provide an experimental benchmark and accurately appraise the effect of introducing low-density water (such as spray from a water sprinkler) into a storage array of unmoderated units of fissile material. Calculations indicate that the water density that produces the highest reactivity depends heavily on the characteristics of the particular system (for LWR fuel rods in water, for example, the highest reactivity appears to occur in the water-density range of $3-5 \%$ ). This experiment could be conducted in conjunction with another array experiment.

Los Alamos National Laboratory

P.O. Box 1663 MS J562

Los Alamos, NM 87545

(505) 667-2821; FAX (505) 665-3657 


\section{Experiment 206 \\ Sheba Reactivity Parameterization}

Contractor Requiring Data Los Alamos National Laboratory

Category Applicable experiment categories

Application Enhance current DOE operation

Rating Status Experiment in progress

Priority Maximum practical attention

Description of This experiment makes the required measurements for the first operations of Sheba. It operation and includes the $1 / \mathrm{M}$ initial approach to critical, initial DC operations, and measure:nents of experimental temperature coefficients, absolute power calibrations, etc.

data needed

Proposed $\mathrm{LACEF}$
experimental
facility

Contact K. Buttertield

Los Alamos National Laboratory

P.O. Box 1663, MS J562

Los Alamos, NM 87545

(505) 667-8944; FAX (505) 665-3657 


\title{
Experiment 207 \\ Sheba Reactivity Void Coefficient
}

\section{Contractor Requiring Data Los Alamos National Laboratory \\ Category Applicable experiment categories \\ Application Enhance current DOE operation \\ Rating Status Experiment in progress \\ Priority Maximum practical attention}

\begin{abstract}
Description of This experiment will attempt to measure the reactivity void coefficient for several regions in operation and Sheba. The first phase is already underway, and consists of calculations using MCNP. experimental data needed

The primary shutdown mechanism in an excursion in a solution system is the introduction of voids due to radiolytic gas formation. The net reactivity effect depends upon the location of the void and the displacement of the free surface. Although it is very difficult to calculate the effects in three dimensions, a better understanding of the reactivity provided by experiment is necessary to model kinetic behavior.
\end{abstract}

\section{Proposed LACEF \\ experimental \\ facility}

Contact K. Butterfield

Los Alamos National Laboratory

P.O. Box 1663, MS J562

Los Alamos, NM 87545

(505) 667-8944; FAX (505) 665-3657 


\title{
Experiment 208 Benchmark Measurements
}

\footnotetext{
Contractor Requiring Data All Department of Energy contractors

Category Applicable experiment categories

Application Enhance current DOE operation, compliance with DOE orders to provide QA tools for criticality software

Rating Status Experiment in progress

Priority Required for new or ongoing DOE operation

Description of The Physics Criteria for the Benchmarks Working Group has generated a list of neutronics operation and observables (Appendix D) that can also be calculated. This proposed series of experiments experimental would try to measure as many of these observables as possible. This effort would help in the data needed certification of computer codes used in criticality safity calculations.
}

\author{
Proposed LACEF/SHEBA \\ experimental \\ facility \\ Contact K. Butterfield \\ Los Alamos National Laboratory \\ P.O. Box 1663, MS J562 \\ Los Alamos, NM 87545 \\ (505) 667-8944; FAX 665-3657
}




\section{Criticality Experiments Needed to Support Plutonium Operations}




\section{Table of Contents}

Criticality Experiments Needed to Support Plutonium Operations

Experiment 301 Plutonium Solution in the Concentration Range from $8 \mathrm{~g} / \mathrm{L}$ to $17 \mathrm{~g} / \mathrm{L}$.. $\mathrm{Pu}-3$

Experiment 302 Transuranic Extraction (TRUEX) Process ................................. Pu - 4

Experiment 303 Effectiveness of Iron in Plutonium Storage and Transport Arrays....... Pu - 5

Experiment 304 Plutonium with Extremely Thick Beryllium Reflection ................. Pu -6

Experimental

Program 305 Arrays of 3-kg Pu-Metal Cylinders Immersed in Water.................... Pu - 7 


\section{Experiment 301 \\ Plutonium Solution in the Concentration Range from $8 \mathrm{~g} / \mathrm{L}$ to $17 \mathrm{~g} / \mathrm{L}$}

Contractor Requiring Data Westinghouse Hanford Company, Los Alamos National Laboratory, Rocky Flats Plant

Category Plutonium

Application Waste handling and storage, low-solution concentration limits

$\begin{array}{rrl}\text { Rating } & \text { Status } & \text { Justification completed } \\ \text { Priority } & \text { Maximum practical attention }\end{array}$

Description of This plutonium concentration range is of interest in the current head-end operation of operation and plutonium processing. These concentration levels are used routinely at LANL, TA-55, and experimental at RFP.

data needed

Experimental criticality data is considered to be insufficient to cover the concentration range from 8 to $17 \mathrm{~g} / \mathrm{L}$ plutonium at $\mathrm{H} / \mathrm{Pu}$ ratios from 1200 to 2700 . The system characteristics for a very large volume (sphere, equilateral cylinder, etc.) means that the location of a reflector outside of this volume becomes vanishingly insignificant as the limiting concentration corresponding to $k_{\infty}=1.0$ is reached. Data for one large sphere (4-ft diam) at $9 \mathrm{~g} / \mathrm{L}(\mathrm{H} / \mathrm{X}=2700)$ are available, but validation of computer codes at $9 \mathrm{~g} / \mathrm{L}$ and above $17 \mathrm{~g} / \mathrm{L}$ appears to give contradictory results with a computational bias appearing to become strongly negative below $20 \mathrm{~g} / \mathrm{L}$.

Slab experiments in the 10 to $20 \mathrm{~g} / \mathrm{L}$ range seem to tie the data points together, but this is not conclusive because of the very different geometries used in the experiment. Cylinder experiments in this range would provide the needed data. Safety of stored waste and waste processing for verification also will require-knowledge of criticality in this $\mathrm{H} / \mathrm{Pu}$ range. Waste programs may also require extension of data for $\mathrm{H} / \mathrm{Pu}$ ratios beyond 2700 to 3600 . Criticality experiments to verify calculations in the 1200 to $2200 \mathrm{H} / \mathrm{Pu}$ range and above will have long-range benefits in applications to head-end plutonium processing, waste storage and processing.

\section{Proposed None available at the present time.}

experimental facility

\section{Contact R. Rothe} EG\&G Rocky Flats

P.O. Box 464

Golden, CO 80402-0464

(303) 966-2989; FAX (303) 966-7326 


\section{Experiment 302 \\ Transuranic Extraction (TRUEX) Process}

\section{Contractor Requiring Data Westinghouse Hanford Company \\ Category Plutonium \\ Application Support criticality safety evaluations for the TRUEX process at WHC and other DOE sites that may use this process.}

\section{Rating Status Anticipated need \\ Priority Required for new or ongoing operation}

Description of A Transuranic Extraction (TRUEX) solvent-extraction process is being developed to operation and support waste vitrification pretreatment. The process removes transuranics from plutonium experimental waste using tri-butyl phosphate as an organic solvent. To assure criticality safety, it is data needed necessary to know how the minimum critical mass of the plutonium-tri-butyl phosphateCMPO system compares to the plutonium/water system. The need for a criticality experiment is anticipated.

Proposed None available at the present time. experimental facility

\section{Contact D. Friar}

Westinghouse Hanford Company

P.O. Box 1970; MS R3-01

Richiand, WA 99352

(509) 372-2891; FAX (509) 372-3522 


\title{
Experiment 303 \\ Effectiveness of Iron in Plutonium Storage and Transport Arrays
}

\author{
Contractor Requiring Data Westinghouse Hanford Company \\ Category Plutonium \\ Application Storage and transportation of TRU waste \\ Rating Status Justification completed \\ Priority Maximum practical attention
}

Description of The effectiveness of the neutron absorption by interspersed iron (or other neutron operation and absorbers) in the container walls in an array increases with increasing neutron leakage from experimental the core fissile material, with all other things (tissile mass, $H / X$, etc.) being equal. It can data needed cause a pronounced change in the reactivity of the array. Since leakage can vary with both shape and material density, advantage can be taken of this effect to allow for much larger arrays, especially for arrays of loosely distributed material such as wastes in 55-gal drums. Improper cross section selection/preparation can also result in an unsafe calculation of a reactivity that is too low. Since there are no experiments to validate the calculations and since the reactivity effect is so strongly dependent on the above characteristics, it is possible that an unsafe analysis could be inade without the analyst realizing how much the accuracy of the result depended on correctly selecting the proper characteristics. Conversely, overly conservative limits on array size could be specified to allow for these uncertainties.

To start these measurements, we will perform a subcritical measurement on a single unit typical of the storage package, and progress to varying concentration, moderation, absorption, and reflection. Array measurements up to a practical limit can be performed as a function of spacing on identical simple elements.

\section{Proposed LACEF \\ experimental \\ facility}

Contact R. Rethe

EG\&G Rocky Flats

P.O. Box 464

Golder, CO 80402-0464

(303) 966-2989; FAX (303) 966-7326 


\title{
Experiment 304 \\ Plutonium with Extremely Thick Beryllium Reflection
}

\author{
Contractor Requiring Data Lawrence Livermore National Laboratory \\ Category Plutonium \\ Application Resolve technical issue \\ Rating Status Experiment in progress, part of the experiment is complete \\ Priority Maximum practical attention
}

Description of UCRL-5349 reports critical beryllium reflector thicknesses for various masses of $\alpha$ -

operation and Plutonium. The results for the most extreme Be reflection of $21-\mathrm{cm}$ and $32-\mathrm{cm}$ thicknesses

experimental have long been questioned (and assumed to be in error experimentally) since computations

data needed tremendously underpredict reactivity (nonconservative). A recent LANL experiment with about $8.3 \mathrm{~cm}$ of beryllium reflection has been performed (Rick Anderson, et al.) with excellent agreement with calculations. Perhaps a source of experimental error could have been made when the data were corrected to ideal spherical configurations. This possibility can only be resolved by locating and reviewing the original experimental notebook or repeating the experiment.

Recommendation: A catalog of experimental notebooks should be compiled for each DOE critical mass facility together with a description of the experiments performed.

Justification: The cost of assembling this information should be small compared to the maintenance and operation of critical facilities. Also, this information would be a tremendous asset to the criticality safety analyst.

\section{Proposed LACEF \\ experimental \\ facility}

Contact D. Heinrich

Lawrence Livermore National Laboratory

P.O. Box 808; MS L-390

Livermore, CA 94551-9900

(510) 424-5679; FAX (510) 423-2854 


\section{Experimental Program 305 \\ Arrays of 3.kg Pu-Metal Cylinders Immersed in Water}

\begin{tabular}{|c|c|c|}
\hline \multicolumn{2}{|c|}{ Contractor Requiring Data } & Lawrence Livermore National Laboratory \\
\hline & Category & Plutonium \\
\hline & Application & Enhance current DOE operation \\
\hline Rating & $\begin{array}{r}\text { Status } \\
\text { Priority }\end{array}$ & $\begin{array}{l}\text { Experimerit complete, but not documented } \\
\text { Maximum practical attention }\end{array}$ \\
\hline
\end{tabular}

Description of

A brief description of these completed experiments has been provided by R. E. Rothe, "A operation and experimental data needed

These experiments used the Pu billets from the LLNL Pu array program. The later experimenters (early 1980's) included critical $3 \times 3 \times 3$ arrays immersed in water. None of the experiments were ever published.

Recommendation: These experiments should be formally documented and published. Two of the investigators, R. E. Rothe (RFP) and J. S. Pearson (LLNL), are still available and interested in this project.

Justification: These experiments provide important, basic, criticality safety information regarding moderated Pu arrays. Such data is quite scarce and is useful for computer code validation in applications such as (1) transportation of wəapon components, (2) weapon disassembly operations, (3) vault storage, and (4) safe spacing criteria.

\section{Proposed LACEF experimental facility}

Contact D. Heinrich

Lawrence Livermore National Laboratory

P.O. Box 808; MS L-390

Livermore, CA 94551-9900

(510) 424-5679; FAX (510) 423-2854 


\section{Criticality Experiments Needed to Support Plutonium/Uranium Fuel Operations}




\section{Table of Contents}

\section{Criticality Experiments Needed to Support Plutonium/Uranium Fuel Operations}

Experiment $4(0)$ Advanced Reactor Design for Metal Fuel (Pu-U-Zr) ....................... Pu/U - 3

Experiment 402 Mixed Oxides of Pu and $\mathrm{U}$ at Low Moderation............................. Pu/U -4

Experiment 403 Minimum Critical Pu Fraction in Pu/Natural-U Mixture .................... Pu/U .5 


\section{Experiment 401 \\ Advanced Reactor Design for Metal Fuel (Pu-U-Zr)}

\section{Contractor Requiring Data Westinghouse Hanford Company \\ Category Plutonium/uranium fuel \\ Application Support new DOE program \\ Rating Status Justification completed \\ Priority Less urgent than priority (2)}

Description of The DOE has announced plans to concentrate their support for advanced reactor designs

operation and that use metal fuel. Past designs have used mixed-oxide fuels.

experimental The plan culls for a new metal fuel for the FFTF reactor and EBR II. Three metal-fuel

data need $/ d$ compositions that need to be evaluated in the FFTF reactor are:

- $90 \mathrm{wt} \% \mathrm{U}(25.2)$ and $10 \mathrm{wt} \% \mathrm{Zr}$

- $82 \mathrm{wt} \% \mathrm{U}(17.5)+8 \mathrm{wt} \% \mathrm{Pu}+10 \mathrm{wt} \% \mathrm{Zr}$

- $71 \mathrm{wt} \% \mathrm{U}(4.5)+19 \mathrm{wt} \% \mathrm{Pu}+10 \mathrm{wt} \% \mathrm{Zr}$.

The EBR II test reactor core which is currently $95 \mathrm{wt} \% \mathrm{U}(52)$ and $5 \mathrm{wt} \%$ nonfissile metal, will be changed to $71 w t \% \mathrm{U}(60)+19 w t \% \mathrm{Pu}+10 \mathrm{wt} \%$ nonfissile metal. Criticality experiments are needed to benchmark calculations in support of the fabrication, storage, transportation, and reprocessing of $\mathrm{Pu}-\mathrm{U}$ metal fuel.

\section{Proposed LACEF \\ experimental \\ facility}

Contact A. Garcia

Argonne National Laboratory

P.O. Box 2528

Idaho Falls, ID 83402

(208) 533-7252; FTS (208) 582-7252 


\title{
Experiment 402 \\ Mixed Oxides of $\mathrm{Pu}$ and $\mathrm{U}$ at Low Moderation
}

\author{
Contractor Requiring Data To be determined \\ Categary Plutonium/uranium fuel \\ Application Enhance current DOE operation
Rating Status Justification completed
Priority Required for new or ongoing DOE operations

Description of For the proposed weapons-grade plutonium burner (LWR version), the following critical operation and experiments will be required:

experimental

data needed

Homogeneous Systems

These experiments will yield data on dry and damp powders to determine critical mass and volume as a function of $\mathrm{Pu}$ or $\mathrm{U}$ concentration. This information is needed to reduce uncertainties in critical volumes and masses, and to serve as benchmarks for validating calculational methods; this information will be required if mixed oxide fuel is used in LWRs. The variables include (1) the Pu content in mixed oxides at 3 to $6 \mathrm{wt} \%$ of $\mathrm{PuO}_{2}$, (2) the ${ }^{240} \mathrm{Pu}$ content of $\mathrm{Pu}$ at $5 \%$ of $240 \mathrm{Pu}$, and (3) the $\mathrm{H} / \mathrm{Pu}$ moderation ratio in the range from $0-3$.

Heterogeneous Systems

Data on lattices of fuel rods in water are needed to determine the minimum critical volumes and the elfect of heavier isotopes of $\mathrm{Pu}$ on criticality. The variables are (1) the fuel-pin diameter, (2) the Pu content in mixed oxides at 3 to $6 \mathrm{wt} \%$ of $\mathrm{PuO}_{2},(3)$ the ${ }^{240} \mathrm{Pu}$ content of $\mathrm{Pu}$ at $5 \mathrm{wt} \%$ of ${ }^{240} \mathrm{Pu}$, and (4) the H/Pu moderation ratio in the range

- from 0-3.

\section{Proposed LACEF \\ experimental facility}

Contact B. Rothleder

U.S. Dept. of Energy, NE-74

19901 Germantown Road

Germantown, MD 20874

(301) 903-326; FAX (301) 903-8693 


\section{Experiment 403 \\ Minimum Critical Pu Fraction in Pu/Natural-U Mixture}

Contractor Requiring Data Westinghouse Hanford Company

Category Plutonium/uranium fuel

Application Enhance current DOE operation

Rating Status Justification completed

Priority Less urgent than 2

Description of The issue of criticality potential in large, waste storage tanks containing TRU could be operation and resolved in most cases by showing that the plutonium held up with uranium in waste sludges experimental is not more than about $0.6 \%$ of the total $U+P u$ contained in a homogeneous water slurry data needed The Pu critical fraction would have to be determined as a function of the $\mathrm{H} / \mathrm{U}$ ratio in the media.

$\begin{array}{r}\text { Proposed } \\ \text { experimental } \\ \text { facility }\end{array}$
Contact A. Hess

Contact A. Hess

P.O. Box 1970

Richland, WA 99352 


\section{Criticality Experiments Needed to Support Transportation/Applications: Waste, Storage, anci Alarm Systems}




\section{Table of Contents}

\section{Criticality Experiments Needed to Support Transportation/Applications: \\ Waste, Storage, and Alarm Systems}

Experiment 501 Assessment for Materials Used to Transport and Store

Discrete Items and Weapons Components .............................. T/A -3

Experimental

Program 502 Waste Processing, Transportation, and Storage

$T / A-5$

Experiment 502a Absorption Properties of Waste Matrices

$\mathrm{T} / \mathrm{A}-6$

Experiment 502b In Situ Drum Stacking

$\mathrm{T} / \mathrm{A}-7$

Experiment $302 \mathrm{c}$ Validation of WIPP Hydrogen Generation Calculations

T/A -8

Experiment 502d The In-Tank Precipitation (ITP) Process for ${ }^{235} \mathrm{U}$

$\mathrm{T} / \mathrm{A}-9$

Experiment 502e The In-Tank Precipitation Process for ${ }^{235} \mathrm{U}+{ }^{239} \mathrm{Pu}$

$\mathrm{T} / \mathrm{A}-10$

Experiment 502f The In-Tank Precipitation Process for ${ }^{239} \mathrm{Pu}$

$\mathrm{T} / \mathrm{A}-12$

Experiment $502 \mathrm{~g}$

Determination of Fissionable Material Concentrations in

Waste Materials

$\mathrm{T} / \mathrm{A}-13$

Experimen: $502 \mathrm{~h}$ Minimum Critical Mass of Fissile-Polyethylene Mixture $\mathrm{T} / \mathrm{A}-14$

Experiment $502 \mathrm{i}$ Criticality Studies That Emphasize Intermediate Energies $\mathrm{T} / \mathrm{A}-15$

Experimental

Program 503 Validation of Criticality Alarms and Accident Dosimetry........

$\mathrm{T} / \mathrm{A}-16$

Experimental

Program 504 Accident Simulation and Validation of Accident Calculations.

$\mathrm{T} / \mathrm{A}-17$

Experimental

Program 505 Evaluation of Measurements for Subcritical Systems.

$\mathrm{T} / \mathrm{A}-18$

Experiment 506

Safe Fissile Mass Thresholds for an Array of Waste Storage Drums

$\mathrm{T} / \mathrm{A}-19$

Experimental

Program 507

Simulator Development

$\mathrm{T} / \mathrm{A}-20$

Experimental

Program 508

Development of a Demonstration Experiment

$\mathrm{T} / \mathrm{A}-21$ 


\section{Experiment 501 \\ Assessment for Materials Used to Transport and Store \\ Discrete Items and Weapons Components}

Contractor Requiring Data All Department of Energy facilities, Pantex, Rocky Flats Plant, Y-12,

Savannah River Plant-Westinghouse Company

Category Applications

Application Enhance current DOE operation

\section{Rating Status Justification completed \\ Priority Maximum practical attention}

Description of Program Applicability: This program is needed for the current and long-term weaponsoperation and component storage mission of the DOE. This program also includes transport and storage experimental of discrete items in well-characterized shipping containers.

data needed Current Calculational Pitfalls and Deficiencies: Criticality safety assessments in this area have an inadequate or nonexistent experimental basis. These assessments have caused overconservatisms in transport and storage requirements (e.g., the transport index) and the calculations are not validated as prescribed in ANSI/ANS-8.1.

Potential Benefit in Risk Management: This program will enable the DOE to take credit for the neutronics properties of the defined shipping container configurations, which will reduce conservatisms in calculations. This should permit larger numbers of containers to be transported and stored in existing facilities. This program will provide relevant and basic criticality safety data, quantify safety margins more accurately, reduce calculational conservatisms, and establish compliance to ANSU/ANS-8.1.

Description of Program: This program will use currently available $\mathrm{U}$ and $\mathrm{Pu}$ components and materials commonly used in shipping containers (i.e., iron, stainless-steel, wood, Celotex, lead, firedike, foamglas, expanded borated polyfoam, polyethylene, plexiglas, depleted uranium, and other materials). These will be used in various reflector and moderator configurations so that a wide range of neutron spectra can be obtained under critical conditions. All selected reflector and moderator conditions will be characterized in this program under actual conditions. Neutron fluxes, spectra, and lifetimes within, between, and exterior to the components will be measured. This program specifically applies to pits, weapons compciients, fuel assemblies, and parts. A specific series of experiments could use the existing enriched uranium hemishells that are delivered to LACEF from RFP in a watermoderated array that contains the interstitial material of choice. 
Experiment 501 (continued)

\section{Proposed LACEF}

experimental

facility

Contact j. McKamy

EG\&G Rocky Flats

P.O. Box 464, Bldg. 886

Golden, CO 80402-0464

(303) 966-4017; FAX (303) 966-7326 


\section{Experimental Program 502 \\ Waste Processing, Transportation, and Storage}

Contractor Requiring Data Hanford, Westinghouse Savannah River Company, Idaho National

Engineering Laboratory, Rocky Flats Plant, Oak Ridge National Laboratory,

Los Alamos National Laboratory

Category Applications

Application Enhance current DOE operation

$\begin{array}{rrr}\text { Rating } & \text { Status } & \text { Justification completed } \\ \text { Priority } & \text { Maximum practical attention }\end{array}$

Description of As part of defense-waste cleanup and environmental restoration, fissile materials in large operation and tanks, drums, trenches, and ultimate disposal options for these materials present special experimental criticality problems. Fissionable materials, such as $\mathrm{Pu}$ and $\mathrm{U}$, are found in combination with data needed other elements. We propose a series of experiments under this program that would evaluate uranium to plutonium ratios (with both high- and low-enriched uranium) at representative moderator-to-fissile (for example, $\mathrm{H}$ and $\mathrm{C}$ ) material ratios and different levels of diluents.

The diluents could be thernial (Cl, B, Li) or resonance (Fe, Ti) absorbers, low absorption diluents $(\mathrm{Zr}, \mathrm{Na}, \mathrm{Mg}, \mathrm{Si}, \mathrm{Ca}$ ), and simulants for fission products. The diluents could also be in reflectors. Selected combinations of the materials will be used to define ranges of applicability. The measurements could be made using approaches-to-critical or reactivityreplacement experiments. Alternate subcriticality determination measurements should be performed concurreatly, especially for approaches-to-critical experiments.

The results from the experiments would provide benchmarks and information to validate computer codes. The validated computer methods should help resolve nuclear criticality issues that currently penalize the processing, transportation, and storage of waste materials. Specific experimental details can be found in Experiments 502a - 502i.

\section{Proposed LACEF experimental facility}

Contact H. Toffer Westinghouse Hanford Company

P.O. Box 1970; MS HO-38

Richland, WA 99352

(509) 376-2894; FAX (509) 376-1293 


\section{Experiment 502a \\ Absorption Properties of Waste Matrices}

Contractor Requiring Data Idaho National Engineering Laboratory

Category Applications

Application Enhance current DOE operation, Resolve technical issue

Rating Status Justification completed

Priority Required for new or ongoing DOE operation

Description of Some of the more interesting waste materials are $\mathrm{SiO}_{2}, \mathrm{MgO}$, graphite, cellulose, $\mathrm{CaO}_{2}$, and operation and $\mathrm{NaCl}$. With the exception of $\mathrm{NaCl}$, these materials are among the more reactive materials that experimental are present in waste. The limiting critical concentration of plutonium or uranium in most of data needed these materials is less than the limiting critical concentration in some of the more traditional and well-known materials, water and polyethylene. However, large differences (greater than $10 \%$ ) in calculated $k_{\text {eff }}$ values are obtained for systems that contain significant quantities of these materials, simply by changing cross-section data sets. Therefore, experinental results are needed to compare with calculational results so that these differences are resolved and realistic biases are established.

Proposed LACEF

experimental

fácilitíy

\section{Contact J. Briggs}

Idaho National Engineering Lab

P.O. Box 1625

Idaho Falis, ID 83415-3890

(208) 526-7628; FAX (208) 526-0528 


\title{
Experiment 502b \\ In Situ Drum Stacking
}

\author{
Contractor Requiring Data EG\&G Rocky Flats \\ Category Applications \\ Application Enhance current DOE operation
Rating Status Justification completed
Priority Required for new or ongoing DOE operation

Description of Rocky Flats has a large variety of waste drums with a large fissile content distribution and a operation and large variety of matrix material. A lot of the waste is in plastic containers. As a practical experimental matter, these waste drums cannot be individually characterized.

data needed

One could stack the drums many layers deep in a large room. This would be accomplished by an in situ subcritical experiment that directly measures the approach toward criticality. The objective is not designed to be a scientific experiment, but it is a direct means of getting a simple, unique, and specific configuration of drums that are stacked all the way to the ceiling. The stacking will be done safely and will be shown-by direct reciprocal multiplication measurement-to be well subcritical.

The drums will be left, so stacked, for many years as a means of storage until a processing method has been selected. This approach could prove to be a practical procedure to enhance drum storage capacity.

The successful application of this technique to the characterization of a large array of illcharacterized elements could provide the basis for the devilopment of a procedure to ensure safe storage on a general basis.

\section{Proposed In situ \\ experimental facility}

Contact R. Rothe

EG\&G Rocky Flats

P.O. Box 464

Golden, CO 80402-0464

(303) 966-2989; FAX (303) 966-7326 


\title{
Experiment 502c \\ Validation of WIPP Hydrogen Generation Calculations
}

\author{
Contractor Requiring Data EG\&G Rocky Flats \\ Category Applications \\ Application Enhance current DOE operation, resolve technical and environmental issues

$\begin{array}{rrr}\text { Rating } & \text { Status } & \text { Justification completed } \\ \text { Priority } & \text { Maximum practical attention }\end{array}$

Description of Program applicability: Packaging containerized waste for WIPP.

operation and experimental

Calculational deficiency: Hydrogen-gas generation from radiolytic decomposition has been data needed over-conservatively estimated, which artificially limits WIPP shipments and storage.

Cost benefit: Results from this study will allow shipments with higher wattages that approach criticality limits. An increase in storage capacity decreases total shipments.

Program description: Thin uranium sheets or uranium shells interstitially moderated with polyethylene or PVC will be operated at high-power delayed critical or in burst mode. The neutron flux and fission products will produce hydrogen gas. The experiment will be performed in a vessel so that $\mathrm{H}_{2}$ can be measured. The results will be used to validate the hydrogen-gas generation models for better estimates of hydrogen-gas generation in waste.

Practicability: The fuel and the moderator are available; the pressure vessel and associated $\mathrm{H}_{2}$ detectors can be fabricated or otherwise obtained.

\section{Proposed LACEF \\ experimental facility}

\section{Contact J. McKamy}

EG\&G Rocky Flats

P.O. Box 464, Bldg. 886

Golden, CO 80402-0464

(303) $966-4017$; FAX (303) 966-7326 


\section{Experiment 502d \\ The In-Tank Precipitation (ITP) Process for 235U}

\section{Contractor Requiring Data Westinghouse Savannah River Company \\ Category Applications \\ Application Support new DJOE program

$\begin{array}{rrr}\text { Rating } & \text { Status } & \text { Justification completed } \\ \text { Priority } & \text { Required for new or ongoing DOE operation }\end{array}$

Description of This experiment is needed to support defense-waste processing; in particular, the in-tank operation and precipitation (ITP) process. Currently, there is only one element, titanium, that we can use experimental for criticality control. Because there is more than the minimum critical mass, we use data needed titanium as the absorber that follows the uranium through the process. There are no experiments that use titanium as an absorber to support this application.

At present, this is the only way to process high-level waste in the tanks. The following bullets highlight the experimental details:

- We will use ${ }^{235} \mathrm{U}$ with titanium as a soluble absorber.

- Our preferred $\mathrm{H} /{ }^{235} \mathrm{U}$ ratios are $125 / 1,240 / 1,325 / 1,385 / 1,465 / 1$, and $530 / 1$.

- We prefer low-neutron leakage geometry.

- Our application is for high-pH systems but experiments with low $\mathrm{pH}$ may be acceptable if free acid molarity is low.

- We prefer at least $65 \%$ enriched uranium.

- The titanium should be natural in isotopic content.

The ITP process is key to long-term storage of wastes from Savannah River waste tanks.

\section{Proposed LACEF \\ experimental \\ facility}

Contact J. Mincey

Westinghouse Savannah River Co.

Building 773-22A

P.O. Box 616

Aiken, SC 29802

(803) 725-2718; FAX (803) 725-8829 


\section{Experiment 502e \\ The In-Tank Precipitation Process for ${ }^{235} \mathrm{U}+{ }^{239} \mathrm{Pu}$}
Contractor Requiring Data Westinghouse Savannah River Company
Category Applications

Application Support new DO: program

Rating Status Justification completed

Priority Required for new or ongoing DOE operation

Description of This experiment is needed to support defense-waste processing; in particular, the ITP operation and process. Currently, there is only one element, titanium, that we can use for criticality control. experimental Because there is more than the minimum critical mass, we use titanium as the absorber that data nceded follows the uranium through the process. There are no experiments that use titanium as an absorber to support this application.

At present, this is the only way to process high-level waste in the tanks. The following bullets highlight the experimental details:

- We will use ${ }^{235} \mathrm{U}+{ }^{239} \mathrm{Pu}$ with titanium as a soluble absorber.

- The maximum useful moderation range $\left[\mathrm{H} /\left({ }^{235} \mathrm{U}+{ }^{239} \mathrm{Pu}\right)\right]$ will be $50 / 1$ to $1000 / 1$, with values around 500 the most important.

- The maximum useful ${ }^{235} \mathrm{U} /{ }^{239} \mathrm{Pu}$ range will be $1 / 1$ to $10 / 1$, with values around $2 / 1$ to $3 / 1$ the most important.

- Our application is for high-pH systems but experiments with low $\mathrm{pH}$ may be acceptable if free acid molarity is low.

- We prefer low-neutron leakage geometry.

- The desired ${ }^{240} \mathrm{Pu}$ and ${ }^{241} \mathrm{Pu}$ content is less than $15 \%$ total $\mathrm{Pu}$, or greater than $85 \%$ ${ }^{239} \mathrm{Pu}$.

- The ${ }^{235} \mathrm{U}$ content should be at least $65 \%$ enriched.

- The titanium should be natural in isotopic content.

The ITP process is key to long-term storage of wastes from Savannah River waste tanks.

\section{Proposed LACEF \\ experimental \\ facility}


Experiment 502e (continued)

\section{Contact J. Mincey}

Westinghouse Savannah River Co.

Building 773-22A

P.O. Box 616

Aiken, SC 29802

(803) 725-2718; FAX (803) 725-8829 


\section{Experiment 502f \\ The In-Tank Precipitation Process for ${ }^{239} \mathrm{Pu}$}

Contractor Requiring Data Westinghouse Savannah River Company

Category Applications

Application Support new DOE program

Rating Status Justification completed

Priority Reauired for new or ongoing DOE operation

Description of This experiment is needed to support defense-waste processing; in particular, the ITP operation and process. Currently, there is only one element, titanium, that we can use for criticality control. experimental Because there is more than the minimum critical mass, we use titanium as the absorber that data needed follows the uranium through the process. There are no experiments that use titanium as an absorber to support this application.

At present, this is the only way to process high-level waste in the tanks. The following bullets highlight the experimental details:

- We will use Pu with titanium as a soluble absorber.

- The preferred $H / 239 \mathrm{Pu}$ ratios will be $225 / 1,325 / 1,385 / 1,465 / 1$, and $530 / 1$.

- We prefer low-neutron leakage geometry.

- The ${ }^{240} \mathrm{Pu}$ and ${ }^{241} \mathrm{Pu}$ content we desire is less than $15 \%$ total $\mathrm{Pu}$, or greater than $85 \%$ ${ }^{239} \mathrm{Pu}$.

- Our application is for high-pH systems but experiments with low $\mathrm{pH}$ may be acceptable if free acid molarity is low.

- The titanium shouid be natural in isotopic content.

The ITI P process is key to long-term storag $\tilde{c}$. wastes from Savannah River waste tanks.

\section{Proposed LACEF \\ experimental \\ facility}

Contact J. Mincey

Westinghouse Savannah River Co.

Building 773-22A

P.O. Box 616

Aiken, SC 29802

(803) 725-2718; FAX (803) 725-8829 


\section{Experiment 502g \\ Determination of Fissionable Material Concentrations in Wast 0 Materials}

Contractor Requiring Data Westinghouse Hanford Company

Category Applications

Application Support new DOE program

$\begin{array}{rrr}\text { Rating } & \text { Status } & \text { Justification completed } \\ & \text { Priority } & \text { Required for new or ongoing DOE operation }\end{array}$

Description of $\mathrm{It}$ is important for criticality and accountability purposes to know concentrations of operation and fissionable elements in waste streams or in waste containers. These concentrations may be experimental too low for subcritical measurements. However, total quantities in containers may be data needed substantial and, under some upset conditions, concentrations could increase to become a criticality concern. Knowledge of the total fissionable material content of tanks or drums is important also for material accountability. Neutron detection methods can be used to evaluate fissile concentrations, and therefore total tank inventories. The neutron detection methods have to be calibrated in a facility where calibration standards can be prepared and handled.

\section{Proposed LACEF experimental \\ facility}

Contact H. Toffer

Westinghouse Hantford Company

P.O. Box 1970; MS HO-38

Richland, WA 99352

(509) 376-2894; FAX (509) 376-1293 


\section{Experiment 502h \\ Minimum Critical Mass of Fissile-Polyethylene Mixture}

Contractor Requiring Data Savannah River Site, Rocky Flats Plant, Westinghouse Hanford Company, Department of Energy/EM-30 (Waste Isolation Pilot Plant)

Category Application

Application Storage and transportation of Pu-polyethylene wastes in 55-gal drums; supercompaction of $\mathrm{Pu}$ wastes that contain polyethylene

Rating Status Justification completed

Priority Maximum practical attention

Description of Some plutonium waste in 55-gal drums contains polyethylene $\left[\left(\mathrm{CH}_{2}\right) \mathrm{n}\right]$. Calculations operation and indicate that the minimum critical mass (MCM) for Pu-( $\left.\mathrm{CH}_{2}\right)$ n mixtures is 360 grams of Pu. experimental This MCM is $30 \%$ lower than the MCM for Pu-water mixtures. Because of the higher data needed reactivity of $\mathrm{Pu}-\left(\mathrm{CH}_{2}\right) \mathrm{n}$ mixtures, the criticality safety limits for storage drums and waste carriers are adjusted accordingly.

The higher reactivity is believed to be due to the higher hydrogen density of polyethylene. However, there are no criticality benchmark measurements to confirm the calculation.

Proposed Experiment: Use Pu or HEU foils layered with polyethylene to obtain a criticality measurenient benchmark.

\section{Proposed LACEF experimental \\ facility}

\section{Contact R. Rothe}

EG\&G Rocky Flats

P.O. Box 464

Golden, CO 80402-0464

(303) 966-2989; FAX (303) 966-7326 


\title{
Experiment 502i \\ Criticality Studies That Emphasize Intermediate Energies
}

\author{
Contractor Requiring Data EG\&G Rocky Flats Critical Mass Laboratory \\ Category Applications \\ Application Enhance current DOE operation \\ Rating Status Justification completed \\ Priority Maximum practical attention
}

Description of Many experiments have been done in the past that could be used for some degree of code operation and validation for large, chunky metal systems and for pure and nearly pure solution systems.

experimental These experiments were the easiest to do; they were the most needed when nuclear weapons

data needed were being manufactured. A plant had pieces of metal and the recovery of the fissile component during subsequent processiiig lead to many kinds of fissile solutions. The recent decision to stop manufacturing nuclear weapons changes the nature of the processes involved in recovery to a large extent. This decisiou does not make the potentially dangerous fissile material go away. Instead, the material will be in a much less common form: relatively large quantities of fissile metal will start showing up in recovery plants in processes not encountered years ago.

This waste will be characterized by a high-hydrogen content due to the paper, plastics, rubber, and other organic materials used, but they will also have fissile metal concentrations in potentially critical concentrations.

We propose to devise a set of critical experiments that purposefully approximate the $\mathrm{H} / \mathrm{X}$ ratio of typical waste streams. We intend to extend this study to include cases where the fissile contaminants are not distributed uniformly.

\section{Proposed LACEF \\ experimental facility}

\section{Contact R. Rothe}

EG\&G Rocky Flats

P.O. Box 464

Golden, CO 80402-0464

(303) 966-2989; FAX (303) 966-7326 


\section{Experimental Program 503 \\ Validation of Criticality Alarms and Accident Dosimetry}

Contractor Requiring Data Department of Energy Complex

Category Applications

Application Criticality safety, radiation protection for workers and the public

$\begin{array}{rrl}\text { Rating } & \begin{array}{r}\text { Status } \\ \text { Priority }\end{array} & \text { Justification complete } \\ & \text { Maximum practical attention }\end{array}$

Description of Criticality accident-alarm systems are used to alert personnel in need of evacuation. Risk operation and reduction requires that the potential for false alarms be minimized. Proper testing and experimental validation requires the ability to provide exposures that simulate accidents for the complete data needed range of potential accident scenarios. Sheba and Godiva can provide this service, particularly when augmented by the HPRR.

Sheba provides a low-energy spectrum characteristic of solution accidents, and Godiva provides the capability for simulating super-prompt critical excursions. In addition, we propose to reactivate the HPRR at LACEF. This well-characterized reactor was specifically developed to evaluate radiation exposures in a mixed (neutron/gamma-ray) environment. It was employed for international intercomparisons of accident dosimetry for over 20 years before its shutdown in 1986.

The data will be used to assure that ANSI and ISO Standards are correct, and that a proper level of protection is provided to workers and the public.

\section{Proposed LACEF \\ experimental \\ facility}

Contact R. Malenfant/K. Butterfield

Los Alamos National Laboratory

P.O. Box 1663; MS J562

Los Alamos, NM 87545

(505) 665-5645; FAX (505) 665-3657 


\section{Experimental Program 504 Accident Simulation and Validation of Accident Calculations}

\begin{aligned} & Contractor Requiring Data \\ & $\begin{array}{r}\text { Category } \\ \text { Application }\end{array} \begin{array}{l}\text { Department of Energy Complex } \\ \text { Bacations } \\ \text { Rating }\end{array} \\ & \begin{array}{r}\text { Statiss } \\ \text { Priority }\end{array} \begin{array}{l}\text { Experimental program } \\ \text { Maximum practical attention }\end{array} \\ &$\hline\end{aligned}

Description of Present safety protection standards and SARs are based on data from accidents, which by operation anid their very nature, are not well characterized due to lack of monitoring equipment or, in experimental many instances, accident dosimetry. This program will apply machines such as Godiva, data necuied Sheba, and Silene (French) to the validation of accident calculations through the simulation, the development, and the validation of accident models.

ANSU/ANS Standard 8.13 specifies the minimum accident of concern in terms of detectability. However, in the absence of well-characterized experiments to simulate accidents, a highly conservative fission yield must be assumed for the SAR. The results of this assumption are then reflected in overly conservative system design or in reduced inventories of material.

Proposed LACEF
experimental
facility

Contact R. MalenfantK. Butterfield

Los Alamos National Laboratory

P.O. Box 1663; MS J562

Los Alamos, NM 87545

(505) 665-5645; FAX (505) 665-3657 


\title{
Experimental Program 505 Evaluation of Measurements for Subcritical Systems
}

\author{
Contractor Requiring Data Department of Energy Complex \\ Category Applications \\ Application Criticality safety, radiation protection for workers and the public \\ Rating Status Justification completed \\ Priority Maximum practical attention
}

Des sription of This program is aimed at deve!oping a meter, or meters, to evaluate the degree of operation and subcriticality in a system or array of fissile material. The need for such a meter has been experimental long recognized, but the difficulties involved are apparent: no such instrument has been

data needed developed in the fifty years of work with fissile systems. Techniques that might be employed include (1) source jerk, (2) cross-correlation techniques, (3) Rossi-alpha, (4) pulsed neutron, (5) reciprocal multiplication, and (6) other. Successful development and validation of a technique will contribute substantially to worker and public safety and reduce the degree of conservatism.

\section{Proposed LACEF \\ experimental \\ facility}

Contact J. Richter

Los Alamos National Laboratory

P.O. Box 1663; MS F699

Los Alamos, NM 87545

(505) 667-1390; FAX (5G5) 665-7725
R. Malenfant

Los Alamos National Laboratory

P.O. Box 1663; MS J562

Los Alamos, NM 87545

(505) 665-5645; FAX (505) 665-3657 


\title{
Experiment 506
}

\section{Safe Fissile Mass Thresholds for an Array of Waste Storage Drums}

\author{
Contractor Requiring Data Sandia National Laboratories \\ Category Applications \\ Application Resolve technical issues

$\begin{array}{rrl}\text { Rating } & \text { Status } & \text { Justification completed } \\ \text { Priority } & \text { Required for new or ongoing DOE operation }\end{array}$

Description of The stacking of fissile-waste storage drums represents a waste handling, storage, and operation and transportation issue.

experimental data needed

We propose to measure neutronic coupling between array components of 55-gal drums.

The coupling will be measured for low-fissile-mass drum loading, which will be representative of loadings in waste drums. We hope to establish drum loadings below which infinite arrays are criticality safe.

The purpose of these experinents will be to define loadings below which infinite arrays of touching drums are permissible with no separation between drums required. Conversely, above this threshold limit, we could specify the safe center-to-center spacing for the drum arrays and the upper size limit for the array $(3 \times 3 \times 3,4 \times 4 \times 4$, etc. $)$ with a specified fissilemass loading.

\section{Proposed In situ experimental facility}

Contact J. Philbin

Sandia National Laboratories

P.O. Box 5800; Dept. 6523

Albuquerque, NM 87185-5800

(505) 845-9036; FAX: (505) 845-9868 


\section{Experimental Program 507 \\ Simulator Development}

\section{Contractor Requiring Data Department of Energy Complex}

Category Applications

Application Support new DOE program, enhance current DOE operation, resolve rechnical issue, and compliance with DOE orders

Rating Status Justification completed

Priority Required for new or ongoing DOE operation

Description of Laboratory training, DOE training, and any other courses that deal with nuclear safety and operation and cannot be taught at LACEF need a criticality simulator. The LACEF experience with experimental computer-driven and hardware-assisted simulators is a unique resource for criticality data needed training.

Proposed LACEF
$\begin{gathered}\text { experimental } \\ \text { facility }\end{gathered}$

Contact R. Walston

Department of Energy

Albuquerque Operations Office

SPD

Albuquerque, NM

(505) 846-1323; FAX (505) 845-6437 


\title{
Experimental Program 508 \\ Development of a Demonstration Experiment
}

\author{
Contractor Requiring Data Los Alamos National Laboratory \\ Category Applications \\ Application Enhance current DOE operations \\ Rating Status Experiment in progress \\ Priority Maximum practical attention
}

Description of For several years, nuclear criticality safety training classes at LANL have utilized a stack of operation and HEU foils interspersed between lucite plates to demonstrate experimental procedure and the experimental characteristics of multiplying systems. Present day safety and security requirements severely data needed complicate this procedure, increasing the number of instructors who must be involved, and place a strain on the security systems. It is proposed to design and construct an experimental apparatus employing LEU in place of the HEU. This would allow the experiment to be conducted outside of the high-security area.

\begin{aligned} $\begin{array}{r}\text { Proposed } \\ \text { experimental } \\ \text { facility }\end{array} &$ LACEF \\ \cline { 2 - 2 } Contact & R. Walston \\ & Department of Energy \\ & Albuquerque Operations Office \\ & SPD \\ & Albuquerque, NM \\ & (505) $846-1323 ;$ FAX (505) $845-6437\end{aligned}$




\section{Criticality Experiments Needed to Resolve Baseline Theoretical Criticality Problems}




\section{Table of Contents}

Criticality Experiments Needed to Resolve Baseline Theoretical Problems

Experiment 601 Critical Mass Experiments for Actinides ................................ BT - 3

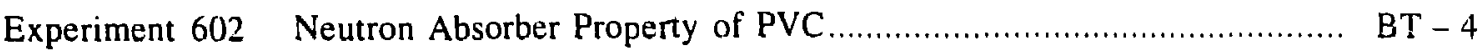

Experiment 603 Effect of Poorly Absorbing, Neutron-Scattering Elements on Critical Size ...................................................... BT -5

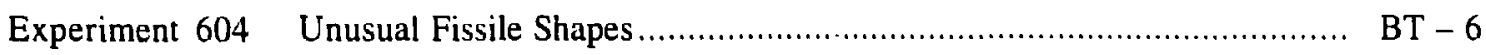

Experimental

Program 605 Measurement of Delayed-Neutron Parameters and Time-Dependent. Delayed-Neutron Spectra for ${ }^{235} \mathrm{U},{ }^{238} \mathrm{U},{ }^{237} \mathrm{~Np},{ }^{239} \mathrm{Pu}$, and $241 \mathrm{Am}$

BT -7

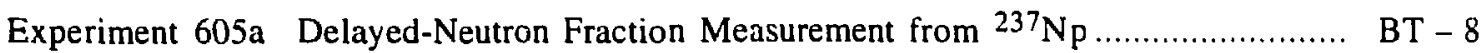

Experiment 605b Measurement of Time-Dependent, Delayed-Neutron Spectra............ BT -9

Experiment 606 Establishing the Validity of Neutron-Scattering Kernels.................... BT -10

Experiment 607 Extending the Standard ANSI/ANS 8.7 to Moderated Arrays.............. BT - 11

Experiment 608 Fission Rate Spectral Index Measurements in Three Assemblies......... BT - 12

Experiment 609 Validation of Calculational Methodology in the Intermediate Energy Range............................................................ BT -13 


\section{Experiment 601 \\ Critical Mass Experiments for Actinides}

Contractor Requiring Data Los Alamos National Laboratory, Oak Ridge National Laboratory, Idaho Chemical Processing Plant, Savannah River Site

Category Baseline theoretical

Application Processing, transport and storage of special actinide elements

Rating Status Justification completed

Priority Maximum practical attention

Description of Critical mass estimates have been calculated for some of the actinide elements using operation and reactivity coefficient measurements in fast-metal assemblies. This technique results in large experimental uncertainties in the minimum critical masses. The nuclides ${ }^{236} \mathrm{U},{ }^{237} \mathrm{~Np},{ }^{241} \mathrm{Pu},{ }^{242} \mathrm{Pu}$, data needed ${ }^{241} \mathrm{Am}$ exist in the DOE complex in quantities exceeding critical masses. However, there have been no direct measurements of criticality for any of these special actinides. Therefore, new measurements are necessary for validating mass limits to be used in processing, transport and storage of this material. We can perform some of these measurements to determine the critical mass for these actinides and additional, refined worth measurements for the actinides with higher atomic numbers.

The results of this program would address known inadequacies in the standard ANSI/ANS 8.15, "Nuclear Criticality Control of Special Actinide Elements."

\section{Proposed LACEF experimental facility}

\section{Contact R. Sanchez}

Los Alamos National Laboratory

P.O. Box 1663; MS J562

Los Alamos, NM 87545

(505) 665-5343; FAX (505) 665-3657 


\section{Experiment 602 \\ Neutron Absorber Property of PVC}

Contractor Requiring Data Applicable to most Department of Energy contractors

Category Baseline theoretical

Application Limited interest for DOE contractors

Rating Status Experiment completed

Priority Less urgent than priority (2)

Description of PVC plastic Raschig rings are used as a fixed neution poison in fissile material solutions, operation and similar to the use of Pyrex glass Raschig rings. Experimental criticality data exists for experimental chlorinated-PVC (which is similar to PVC), but a critical benchmark is still needed for PVC data needed tubes or rings in uranium solution to measure and confirm the neutron-absorption property of PVC. The neutron absorber in PVC is chlorine. The advantages of PVC over glass are (1) corrosion resistance in the presence of fluoride ion, and (2) no breakage as with glass.

\section{Proposed LACEF \\ experimental \\ facility}

\section{Contact F. Alcorn}

Babcock \& Wilcox Company

Research \& Development Division

P.O. Box 11165

Lynchburg, VA 24506-1165

(804) 522-5157 


\section{Experiment 603}

\section{Effeci of Poorly Absorbing, Neutron-Scattering Elements on Critical Size}

Contractor Requiring Data Westinghouse Hanford Company

Category Baseline theoretical

Application Enhance current DOE operation

$\begin{array}{rrl}\text { Rating } & \text { Status } & \text { Experiment in progress } \\ \text { Priority } & \text { Less urgent than priority (2) }\end{array}$

Description of While it can be shown through calculaiions that the addition of low-atomic-number operation and elements, such as oxygen and aluminum, can decrease the critical mass of reduced-density experimental systems (compared to simply reducing the density of a solution) and decrease the minimum data needed critical solution density and the minimum critical areal density, no experimental data exist to directly determine the magnitude of the effect. This is a concern for other situations in which the critical parameters of fissile bearing wastes are determined.

We propose a criticality experiment to resolve this question.

\section{Proposed LACEF experimental facility}

Contact D. Rutherford

Los Alamos National Laboratory

P.O. Box 1663; MS J562

Los Alamos, NM 87545

(505) 665-5038; FAX (505) 665-3657 


\section{Experiment 604 \\ Unusual Fissile Shapes}

Contractor Requiring Data Applicable to most Department of Energy contractors

Category Baseline theoretical

Application Enhance current DOE operation

\begin{tabular}{|c|c|c|}
\hline in & $\begin{array}{r}\text { Status } \\
\text { Priority }\end{array}$ & Justification completed \\
\hline
\end{tabular}

Description of Geometry description packages have been provided 'n various Monte Carlo computer codes operation and to treat unusual shapes that are not the "standard" geometries (spheres, cylinders, and experimental cuboids). These special geometry routines are used frequently in criticality safecy analysis. data needed However, with few exceptions, these special geometry routines (e.g.. General Geometry in the KENO code and "hole routines" in the MONK code) are always validated against the standard shapes because essentially no experimental data exist for nonstandard geometries. It is proposed that a series of critical experiments be supported that will provide nonstandard geometries (cones, truncated spheres, hemispheres, annular tanks with nonuniform annuli, triangular tanks, etc.) to validate the nonstandard geometry calculations.

\section{Proposed LACEF experimental facility}

Contact R. Malenfant Los Alamos National Laboratory P.O. Box 1663, Lus Alamos, NM 87545 (505) 667-4839; FAX (505) 667-3657
R. Rothe

EG\&G Rocky Flats

P.O. Box 464

Golden, CO 80402-0464

(303) 966-2989; FAX (303) 966-7326 


\section{Experimental Program 605 \\ Measurement of Delayed-Neutron Parameters and Time-Dependent,

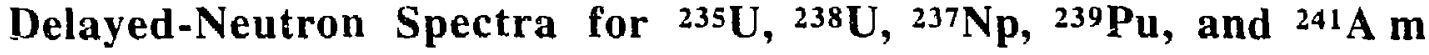

Contractor Requiring Data Applicable to most Department of Energy contractors

Category Baseline theoretical

Application Use in modeling criticality accidents, reactor kinetics, and subcriticality measurements

Rating Status Justification completed

Priority Required for new or ongoing DOE operations

Description of System-applicable, delayed-neutron parameters should be measured for Godiva, Big Ten, operation and Flattop, Sheba, and for several thermal and fast systems on Honeycomb. The parameters experimental include the delayed-neutron yield for each system, the delayed-neutron fraction for each data needed delay group, and the delayed-neutron spectra as a function of time after fission.

Proposed $\mathrm{LACEF}$
experimental
facility

\section{Contact C. Goulding}

Los Alamos National Laboratory

P.O. Box 1663; MS J562

Los Alamos, NM 87545

(505) 667-0769; FAX (505) 665-3657 


\section{Experiment 605a \\ Delayed-Neutron Fraction Measurement from ${ }^{237} \mathbf{N}_{\mathbf{p}}$}

Contractor Requiring Data Los Alamos National Laboratory

Category Baseline theoretical

Application Enhance current DOE operation

Rating Status Justification completed

Priority Required for new or ongoing DOE operation

Description of We propose to measure delayed-neutron flux spectra from ${ }^{237} \mathrm{~Np}$. A ${ }^{235} \mathrm{U}$ target will be operation and used as the reference. A time domain of $0.5 \mathrm{sec}$ to $5 \mathrm{sec}$ after fission will be used. We need experimental very small self-multiplication; a 1 -gm sample will suffice. NE213 and Curler-Shalev data needed detectors will be used to measure the neutron spectrum over the energy range $5 \mathrm{keV}$ to $5 \mathrm{MeV}$.

The fissions will be produced using Godiva-IV, and the target samples will be transferred using the existing pneumatic system that connects the existing counting system in Kiva III.

\section{Proposed LACEF experimental facility}

Contact C. Goulding

Los Alamos National Laboratory

P.O. Box 1663; MS J562

Los Alamos, NM 87545

(505) 667-0769; FAX (505) 665-3657 


\section{Experiment 605b \\ Measurement of Time-Dependent, Delayed-Neutron Spectra}

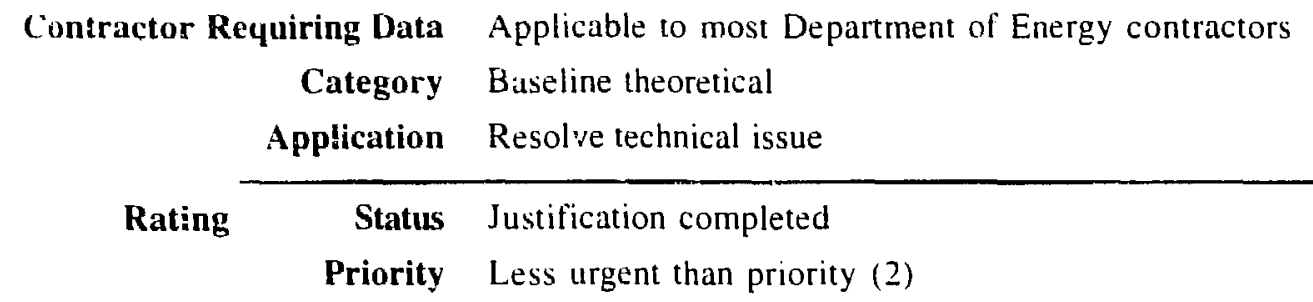

Description of Some discrepancies need to be reconciled to the various measurements and syntheses of operation and equilibrium delayed-neutron spectra; it may be necessary to consider the time variation of experimental delayed-neutron spectra in fast-reactor calculations. These data would be of interest in the data needed nuclear power industry, in criticality safety determinations for the production and handling of nuclear materials, and in the investigation of neutron-rich nuclei in the study of nuclear structure.

\section{Proposed LACEF experimental facility}

Contact C. Goulding

Los Alamos National Laboratory

P.O. Box 1663: MS J562

Los Alamos, NM 87545

(505) 667-0769; FAX (505) 665-3657 


\title{
Experiment 606 \\ Establishing the Validity of Neutron-Scattering Kernels
}

Contractor Requiring Data Applicable to most Department of Energy contractors

Category Baseline theoretical

Application Fissile systems controlled by separation with moderating materials

\begin{tabular}{|c|c|c|}
\hline \multirow[t]{2}{*}{ Rating } & Status & Justification completed \\
\hline & Priority & Maximum practical attention \\
\hline
\end{tabular}

Description of Slowing-down measurements made by the National Institute of Science and Technology

operation and indicate discrepancies of up to $7 \%$ in therma! tission activities.

experimental

data needed

Assessment of discrepancies between experiments and calculations of neutron-scattering kernels for moderating materials, both fissite and nonfissile, has indicated a need for basic physics measurements with various compounds such as mixtures of the elements $\mathrm{H}, \mathrm{O}$, and $\mathrm{C}$ in water, polyethylene. Plexig!ar, and other compounds.

\author{
Proposed NIST, LACEF \\ experimental \\ facility \\ Contact C. Hopper \\ Oak Ridge National Laboratory \\ P.O. Box 2008 \\ Oak Ridge, TN 37831-6370 \\ (615) 576-8617; FAX (615) 576-3513
}




\title{
Experiment 607
}

\section{Extending the Standard ANSI/ANS 8.7 to Moderated Arrays}

Contractor Requiring Data Applicable to most Department of Energy contractors, Rocky Flats Plant, Los Alamos National Laboratory. Savannah River Site, Y-12, Oak Ridge

National Laboratory, Lawrence Livermore National Laboratory

Category Baseline theoretical

Application Enhance current DOE operation

Rating Status Justification completed

Priority Maximum practical attention

Description of This ANSVANS standard 8.7, "Guide for Nuclear Criticality Safety in the Storage of Fissile operation and Materials," currently applies to low-moderated and unmoderated fissile material. A experimental criticality experimental program will extend this standard to moderated arrays as well. This data needed standard has a high ievel of demonstrated usefulness in safety analyses for fissile material storage and transportation. The experiments would vary array unit moderation, array size, array spacing, and room return cn a parametric basis.

\author{
Proposed LACEF \\ experimental \\ facility \\ Contact C. Hopper \\ Oak Ridge National Laboratory \\ Building 6011; MS 6370 \\ Oak Ridge, TN 37831-6370 \\ (615) 576-8617; FAX (615) 576-3513
}




\section{Experiment 608}

Fission Rate Spectral Index Measurements in Three Assemblies

Contractor Requiring Data Potential use by Department of Energy Cross-Section Working Evaluation Group

Category Baseline theoretical

Application Resolve technical issue

$\begin{array}{rrl}\text { Rating } & \text { Status } & \text { Justification completed } \\ \text { Priority } & \text { Maximum practical attention }\end{array}$

Description of In 1978, fission rates for the isotopes ${ }^{235} \mathrm{U},{ }^{238} \mathrm{U},{ }^{237} \mathrm{~Np}$, and ${ }^{239} \mathrm{Pu}$ were measured in the operation and neutron spectra at the center of Flattop, with a $93 \% 235 \mathrm{U}$ core, and Big Ten, a $10 \% 235 \mathrm{U}$ experimental assembly machine. However, these data are suspect, since the detector developed a leak data needed during the measurements.

The purpose of this experiment is to repeat the 1978 measurements and provide more - reliable data for use to validate differential fission cross sections in different spectral systems. In addition, other measurements could be made using actinide samples, particularly the threshold fission actinides ${ }^{238} \mathrm{Pu},{ }^{242} \mathrm{Pu}$, etc.

\section{Proposed LACEF experimental \\ facility}

Contact D. Barton/D. R itherford

Los Alamos National Laboratory

P.O. Rox 1663; MS $\mathbf{5 5 6 2}$

Los Alamos, NM 87545

(505) 665-5038; FAX (505) 665-3657 


\section{Experiment 609}

\section{Validation of Calculational Methodology in the Intermediate Energy Range}

Contractor Requiring Data Los Alamos National Laboratory, Oak Ridge National Laboratory, Rocky

Flats Plant, Savannah River Site, Lawrence Livermore National Laboratory, Enriched facilities, etc.

Category Baseline theoretical

Application Initial request

Rating Status Justification completed

Fissile material in facilities under remediation and decommissioning are subject to low-moderation and generate intermediate energy spectra.

Priority Maximum practical attention

Description of Criticality citculations for systems involving relatively thin fissile regions (1-to $3 \cdot \mathrm{mm}$ thick operation and separated by $1103 \mathrm{~cm}$ of hydrogenous material) would depend on the accuracy of cross experimental sections pertinen to those systems. A search of the literature fails to find any critical data needed experiments for which a large fraction of the fissions occur between neutron energies of $1 \mathrm{eV}$ and $100 \mathrm{~K}: \mathrm{V}$. Many experiments have been done for thermal systems (fissile solutions) for which nearly all fissions occur at energies below $1 \mathrm{eV}$.

At the other extreme, many experiments have been done for "fast" systems (fissile solids) for which nearly all fissiors occur at energies above $100 \mathrm{KeV}$ and up to $2 \mathrm{MeV}$.

This situation leaves a very large range of systems which have never been tested experimentally. For any thermal systems, neutrons must decelerate from fast to thermal. The neutrons exist and interact at many energies between fast and thermal. Furthermore, this region is often characterized by the "resonance region," which exhibits wide fluctuations in cross section.

One does not know if good agreement between theory and experiment for a thermal system is the result of:

1. error canceling in the codes that handle neutron deceleration through these energies; or

2. a real bias in the code that happens to be in opposition to the errors in the code's handling of neutron deceleration. 
Description of operation and experimental data needed (continued)

\section{Proposed LACEF experimental facility}

Contact R. Anderson

Los Alamos National Laboratory

P.O. Box 1663; MS J562

Los Alamos, New Mexico 87545

(505) 667-2821; FAX (505) 665-3657 


\section{Criticality Experiments Needed to Support Criticality Physics Operations}




\section{Table of Contents}

Criticality Experiments Needed to Support Criticality Physics Operations

Experimental

Program 701 Investigation and Development of Subcritical Measurements

$\mathrm{CP}-3$

Experiment 702 Spent Fuel Safety Experiments (SFSX)

$\mathrm{CP}-5$

Experimental

Program 703 Differential Parameter Measurements.

$r P-7$

Experimental

Program 704 Homogeneity versus Heterogeneity.

CP -8

Experiment 705 How to Measure Hydrogen.

CP -9

Experiment 706

"Dry Water".

CP -10

Experiment 707 Anomalous Critical Experimental Results........

$C P-11$ 


\section{Experimental Program 701 \\ Investigation and Development of Subcritical Measurements}

Contractor Requiring Data Los Alamos National Laboratory, Oak Ridge National Laboratory, Rocky

Flats Plant, Lawrence Livermore National Laboratory, Sandia National

Laboratories

Category Criticality physics

Application Handling and storage of significant quantities of fissile material, (e.g., Complex 21)

$\begin{array}{rrl}\text { Rating } & \text { Status } & \text { Justification completed } \\ \text { Priority } & \text { Required for new or ongoing DOE operation }\end{array}$

Description of Measurement of the delayed critical point is relatively easy and commonly done. The operation and measurement of $\mathrm{k}_{\mathrm{eff}}<1.0$ is more difficult with the situation getting worse as the experimental measurement is attempted further away from critical.

data needed

The availability of a simple reliable measurement of subcritical reactivity "ould be valuable for many applications:

- Periodic checks on the subcriticality of storage areas - checks on the loss of hydrogen or the leaching of poison from storage vault concrete.

- Measurement of the reactivity of reactor core subassemblies befor: they are inserted into the reactor core.

- Measurement of the reactivity of SNM or SNM waste before these materials are inserted into highly reflecting and moderating well counters and assay chambers.

Developing procedures and investigating the accuracy and ranges of validity for a number of techniques used in subcritical reactivity measurements would provide valuable results for much of the DOE community that handles or stores significant quantities of SNM.

Techniques that would be employed include (a) source jerk, (b) cross-correlation techniques, e.g., ${ }^{252} \mathrm{Cf}$ noise analysis, (c) Rossi-alpha, (d) pulsed neutron, and (e) reciprocal multiplication. 
Experiment 701 (continued)

Proposed LACEF

experimental

facility

Contact R. Anderson

Los Alamos National Laboratory

P. O. Box 1663; MS J562

Los Alamos, NM 87545

(505) 667-3346; FAX (505) 665-3657 


\section{Experiment 702 \\ Spent Fuel Safety Experiments (SFSX)}

Contractor Requiring Data Sandia National Laboratories

Category Applicable experiment categories

Application Applications are throughout the DOE complex for the storage, transportation, disposal of spent nuclear fuel from DOE reactors as well as from commercial reactors in support of the Civilian Radioactive Waste Management Program. Data from these experiments could also be used by commercin! reactors and the NRC to evaluate on-site storage of spent fuel.

Rating Status Justifization completed

Priority Maximum practical attention

Description of The following information is required to validate burn-up credit:

operation and experimental data needed
I. Fuel Rod Consolidation.

The MRS may provide the capability to disassemble fuel assemblies and consolidate the fuel rods in storige canisters. Experimental data will benefit the safety and economics of this oparation.

2. Spent Fuel Burnup Versus Reactivity.

DOE contractors and NRC licensees are interested in obtaining criticality data for spent LWR fuel to confirm calculations. Operational and storage restrictions can be significantly reduced if crecit could be taken for burnup. The calculations must account for: (1) ${ }^{235} \mathrm{U}$ depletion and fission product formation, which decrease reactivity; and (2) the formation of plutonium, which increases reactivity.

3. Reactivity Worth of Spent Fuel.

The reactivity worth of spent fuel samples that are from a fully characterized spent fuel assembly would have to be experimentally verified. This verification would include chemical assay data.

4. Approach to Critical

An approach to critical would have to be performed for (1) an array of fresh fuel rods (the lattice should be composed of differing enrichment rods, water rods and Gd-bearing rods to simulate BWR); (2) centrai rods replaced with spent fuel that represent average assembly conditions; and (3) central rods replaced with spent fuel rods that represent the burnup that is typical of the tips of fuel rods and is a consequence of the axial burnup distribution in PWRs. 
Proposed SNL

experimental

facility

Contact M. Brady

Sandia National Laboratories

Albuquerque, NM

(505) 845-9099; FAX (505) 844-0244

Criticality Physics

CP -6 


\section{Experimentai Program 703 \\ Differential Parameter Measurements}

Contractor Requiring Data Rocky Flats Critical Mass Laboratory, Department of Energy Complex

Category Criticality physics

Application Enhance current DOE operation

Rating Status Justification completed

Priority Required for new or ongoing DOE operation

Description of At the present time, all code validation is done by comparing only the one "integral"

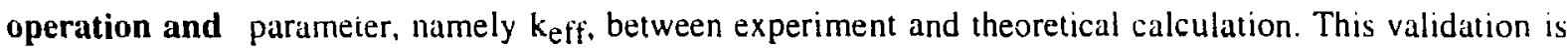
experimental done only at delayed criticality, or $\mathrm{k}_{\mathrm{eff}}=1.00$. However, computer codes give much more data needed information than just this single, integral parameter. They give neutron fluxes, or currents in various regions, and a wealth of other dati. These might be called "differential data" because their absolute value would depend on the instantaneous power level of the critical configuration. Still, the relative magnitude of some differential parameter at one location reit tive to another location would be independent of power level. This magnitude would be auother independent test of the code's ability to estinate the real conditions.

We propose to set up an experimental program to measure these differential parameters in addition to the integral parameter, $k_{\text {eff }}$. Such a study would be designed to assure that an observed perfect agreement between theory and experiment (zero bias) in a particular validation was not just due to the accidental cancellation of opposing enors within the code. Experiments within this program would be very simpla geometrical systems; and the material compositions would be almost irrelevant. However, the boundaries between one material and another should be clearly defined at least in two widely separated locations.

This will promote more effective utilization of all data available such as in Experiments 208 and 608 .

\section{Proposed LACEF}

experimental

facility

Contact R. Rothe

EG\&G Rocky Flats

P.O. Box 464

Golden, CO 80402-0464

(303) 966-2989; FAX (303) 966-7326 


\section{Experimental Program 704 \\ Homogeneity versus Heterogeneity}

\section{Contractor Requiring Data Department of Etuergy Complex}

Category Applicable experimental categories

Application Enhance curreni DOE operation

Ratin: Status Justification completed

Priority Required for new or ongoing DOE operation

Description of Several experiments should be performed to illustrate the difficulties in making simplifying operation and assumptions, which are of general interest for developing second-order corrections to experimental analytical techniques.

data needed For example how small must a cell of one material surrounded by another material be before one can consider that a truly heterogeneous mixture is neutronically homogeneous'?

One example o: this problem wruld be Raschig-ring-filled tanks containing fissile solution. Another example would be a uniform suspension of foreign material in an otherwise homogeneous fissile solution.

The practical issue is this: are we wasting too much time calculating and modeling heterogeneous systems when not much accuracy would be lost in assuming that the entire system is homogeneous? Or, conversely, do we too easily make the assumption of homogeneity when we should be modeling a heterogeneous system?

Although these questions are usually answered by calculations, it would be desirable to validate several of these calculations by a few selected experiments.

\section{Proposed LACEF}

\section{experimental}

facility

\section{Contact R. Rothe}

EG\&G Rocky Flats

P.O. Box 464

Golden, CO 80402-0464

(303) 966-2989; FAX (303) 966-7326 


\section{Experiment 705 \\ How to Measure Hydrogen}

Contractor Requiring Data Rocky Flats Critical Mass Laboratory

Category Applicable experinental categories

Application Enhance current DOE operation; all hydrogenous materials

$\begin{array}{rrl}\text { Rating } & \begin{array}{r}\text { Status } \\ \text { Priority }\end{array} & \text { Justification complete } \\ & \text { Less urgent than priority (2) }\end{array}$

Description of This proposal would be a nonfissile experiment. It is designed to devise a new analytical nperation and capability to improve the way laboratories measure the properties of fissile solutions.

experimental

data needed

In practice, an analytical laboratory can measure the fissile metal content of a solution to a

little better than $\pm 1 \%$. The same laboratory cannot measure the hydrogen content of a complex solution-such as a nitrate solution of a metal salt-to much better than $\pm 5 \%$. The

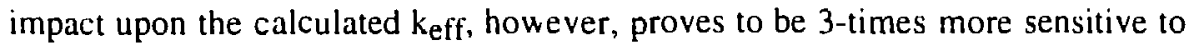
uncertainties in $\mathrm{H}$ concentration than to the measurement uncertainty in $\mathrm{U}$ or $\mathrm{Pu}$ concentration. Thus, a the uncertainty in $\mathrm{H}$ concentration contributes about 15-times more to errors in $\mathrm{k}_{\mathrm{eff}}$ than does the uncertainty in the fissile content.

We propose to develop a laboratory method to measure the hydrogen content of a true-butcomplex solution to better than $\pm 0.3 \%$.

\section{Proposed LACEF}

experimental

facility

Contact R. Rothe

EC\&U Rockyi Flats

H.O. $\sin x+64$

Goldier. CO 80402-0464

(303) 966-2989; ГAX (303) 966-7326 


\section{Experiment 706 \\ "Dry Water"}

\section{Contractor Requiring Data Department of Energy Complex}

Category Applicable experimental categories

Application Enhance current DOE operation

$\begin{array}{rrl}\text { Rating } & \text { Status } & \text { Justification conpleted } \\ \text { Priority } & \text { Required for new or ongoing DOE operation }\end{array}$

Description of We propose to design an experiment to measure the critical parameters of a fissile

operation and "solution" where hydrogen content is accurately measured. This would be accomplished experimental by blending a "dry" fissile solution composed of powciered, or finely ground, plastic data needed granules and the powdered oxide of a fissile metal. This mixture should have the same $H / X$ ratio as an aqueous solution might have, but it would be better known because the laboratory analysis of both the metal oxide and the plastic would be accurate in both cases. The granular size of the powders would have to be small enough so that the fabricated "solution" would neutronically resemble a homogeneous situation in spite of the obvious fact that any mixture of plastic and oxide would be truly heterogeneous.

Proposed LACEF

experimental

facility

Contact R. Rothe

EG\&G Rocky Flats

P.O. Box 464

Golden, CO 80402-0464

(303) 966-2989; FAX (303) 966-7326 


\section{Experiment 707 \\ Anomalous Critical Experimental Results}

Contractor Requiring Data Department of Energy Complex

Category HEU, Pu, Criticality Physics

Application Resolve technical issue

Rating Status Justification completed

Priority Required for new or ongoing DOE operation

Description of When critical experinental results are compared with the results of Monte Carlu

operation and calculations, the calculated values of $k_{e}$ ff are typically within a few percent of 1.0. There are, experimental however, several critical experiments for which the calculated values of $k_{\text {eff }}$ are near 0.90 .

data needed These calculated $k_{\text {eff }}$ factors are quite far from the expected value of 1.0 , and are nonconservative. These experiments included an array of high-enriched uranyl nitrate slabs and cylinders, a Pu ball reflected by Be, and others. Several of these experiments shoulc oc repeated in order to confirm if the experimental results are incorrect or if the codes are wrong.

Proposed LACEF

experimental

facility

Contact R. Anderson

Los Alamos National Laboratory

P.O. Box 1663; MS J562

Los Alamos, NM 87545

(505) 667-2821; FAX (505) 665-3657 


\section{Árchived Experiments}

$$
\text { AX - } 1
$$




\section{Table of Contents}

\section{Archived Experiments}

Experiment 801 Fuel-Processing Restoration Project

$\mathrm{AX}-3$

Experiment 802 Fluorinel and Storage (FAST) Facility...

AX -4

Experiment 803 Mixtures of Soluble Boron and Cadmium

$\mathrm{AX}-5$

Experiment 804

Glycol-Water/Boron Mixture

$\therefore \mathrm{X}-6$

Experiment 805

Carbon-Reflected U(93) Plant (MMES)

$\mathrm{AX}-7$

Experiment 806

U(93) Metal Reflected by Refractory Materials

AX -8

Experiment 807

Multi Megawatt Reactor Program (canceled)

$A X-9$

Experiment 808

Compact Nuclear Power Source (CNPS)

$A X-10$

Experiment 809 Refurbishment or Replacement for the N-Reactor.

$A X-11$

Experiment 810

Special Isotope Separation (SIS) (canceled)

$A X-12$

Experiment 81

Neutron Absorber Property of Pyrex Cylinder Walls.

AX -13 


\section{Experiment 801 \\ Fuel-Processing Restoration Project}

\section{Contractor Requiring Data Westinghouse Idaho Nuclear Conıpany \\ Category Highly enriched uranium \\ Application Support new DOE program \\ Rating Status Experiment in progress \\ Priority Required for new or ongoing DOE operation}

Description of The Fuel-Processing Restoration Project is in the final design st:age. The criticality

operation and experiments needed to support design and operation have been identified and are in experimental progress at the Los Alamos Critical Experiments Facility.

data needed

Proposed LACEF

experimental

facility

Contact J. Tanner

Westinghouse Idaho Nuclear Company

P.O. Box 4000

Idaho Falls, ID 83403

(208) 526-1361; FTS (208) 583-1361 


\section{Experiment 802 \\ Fluorinel and Storage (FAST) Facility}

\section{Contractor Requiring Data Westinghouse Idaho Nuclear Company \\ Category Highly enriched uranium \\ Application Support new DOE program \\ Rating Status Experiment complete \\ Priority Required for new or ongoing DOE operation}

Description of The Fluorinel and Storage (FAST) Facility is now in operation. A series of criticality operation and experiments to stipport this facility were completed in 1986. One additional experiment experimental remains to be completed. This is an experiment to measure the effect of a cadmium/boron data needed poison mixture on the critical size of a cylinder of $U(93)$ uranyl nitrate (see Experiment 103).

Proposed LACEF

experimental

facility

Contact J. Tanner

Westinghouse Idaho Nuclear Company

P.O. Box 4000

Idaho Falls, ID 83403

(208) 526-1361; FTS (208) 583-1361 


\section{Experiment 803 \\ Mixtures of Soluble Boron and Cadmium}

Contractor Requiring Dasa Westinghouse Idaho Nuclear Company

Category Highly enriched uranium

Application Enhance current DOE operation

$\begin{array}{rrr}\text { Rating } & \text { Status } & \text { Justification completed } \\ \text { Priority } & \text { Maximum practical attention }\end{array}$

Description of The use of two soluble neutron poisons (boron plus cadmium) in a fissile solution results in operation and two benefits. First, one poison is a backup, chemically, to the other. Second, advantage can experimental be taken of the broader range of neutron-absorption cross sections in the resonance region.

data needed Because their high-neutron-absorption cross sections occur at different neutron energies (even though they overlap), boron and cadmium logether may be more effective in some operations than either one alone. The actual margin of safety with two poisons, however, is not known-the synergistic effect has not been measured. A benchmark critical experiment is needed to verify this concept. The first application would be the Fluorinel and Storage (FAST) Facility (see Experiment 102). The Westinghouse Idaho Nuclear Company is anxious that this experiment be performed to provide support for their fluorinel-dissolution process operations.

Proposed LACEF experimental facility

Contact J. Tanner

Westing arouse Idaho Nuclear Company

P.O. Box 4000

Idaho Falls, ID 83403

(208) 526-1361; FTS (208) 583-1361 


\section{Experiment 804 Glycol-Water/Boron Mixture}

contractor Requiring Data Y-12 Plant (Martin Marietta Energy Systems)

Category Highly enriched uranium

Application Enhance current DOE operation

Rating Status Justification completed

Priority Required for new or ongoing DOE operation

Description of Personnel at the Y-12 Plant have identified the need for this experiment for highly enriched operation and $235 \mathrm{U}$ systems. The glycol/water mixture is used as a coolant in machining operations. The experimental boron concentration in glycol/water solutions can be made several times higher than in data needed water alone before boron precipitation occurs. A criticality measurement of a simple water/boron system could result in more economical operations.

Proposed LACEF

experimental

facility

Contact W. Mee, Superintendent

Radiation Safety Department

Martin Marietta Energy Systems, Inc.

P.O. Box Y; M/S 3

Oak Ridge, TN 37831

(615) 574-3534; FTS (615) 624-3534 


\section{Experiment 805 \\ Carbon-Reflected U(93) Plant (MMES)}

Contractor Requiring Data Y-12 Plant (Martin Marietta Energy Systems)

Category Highly enriched uranium

Application Enhance current DOE operation

Rating Status Justification completed

Priority Required for new or ongoing DOE operation

Description of More refined criticality data on carbon-reflected $93 \%$-enriched uranium metal could result

operation and in production improvements at the $\mathrm{Y}-12$ Plant.

experimental

data needed

Proposed LACEF

experimental

facility

Contact R. Vornehm

Martin Marietta

F.O. Box 2007

Y-12, MS A238

Oak Ridge, TN 37831

(615) 576-2289; FAX: (615) 24I-2772 


\section{Experiment 806 \\ U(93) Metal Reflected by Refractory Materials}

\section{Contractor Requiring Data Y-12 Plänt (Martin Marietta Energy Systems) \\ Category Highly enriched uranium \\ Application Snhance current DOE operation \\ Rating Status Justification completed \\ Priority Required for new or ongoing DOE operation}

Description of No experimental benchnsarks are available for common and specialized refractory

operation and materials. It is expected that benefits to the Y-12 Plant and other operations will justify the experimental experiment.

data needed

Proposed LACEF

experimental

facility

Contact R. Vornehm

Martin Marietta

P.O. Box 2007

Y-12, MS A238

Oak Ridge, TN 37831

(615) 576-2289; FAX: (615) 241-2772 


\section{Experiment 807}

Multi Megawatt Reactor Program (canceled)

Contractor Requiring Data Idaho National Engineering Laboratory

Category Highly enriched uranium

Application Support new DOE program

Rating

Status Justification completed

Priority Required for new or ongoing DOE operation

Description of Planning is in the preliminary stages for this reactor program. The RFPs will be evaluated in

operation and the fall of 1987 . The need for criticality experiments to support this project stinuld be

experimental assessed about January 1988.

data needed

Proposed LACEF

experimental

facility

Contact J. Lake, Manager, Nuclear Engineering

EG\&G Idaho, Inc.

Idaho National Engineering Laboratory

P.O. Box 1625

Idaho Falls, ID 83415

(208) 526-7670; FTS (208) 583-9054 


\section{Experiment 808 \\ Compact Nuclear Power Source (CNPS)}

\section{Contractor Requiring Data Not yet identified}

Category Low enriched U

Application Support new DOE program

\section{Rating Status Experiment complete \\ Priority Required for new or ongoing DOE operation}

Description of The CNPS will comprise about 492 fuel pins in a graphite matrix, arranged in a

operation and 4.775 -cm-square lattice. The fuel is $19.9 \%$-enriched $235 \mathrm{U}$ in a uranium-carbon-oxygen

experimental mixture. The fuel pins are $1.245 \mathrm{~cm}$ in diameter, and the fuel is $10.65 \mathrm{~g} / \mathrm{cm}^{3}$. Consideration

data aeeded is being given to military use (United States) and civilian use (Canada) for the CNPS.

Two phases of criticality experiments to support this program have been identified as follows:

Phase 1: Experiments to support reactor technology.

These experiments are in progress at the LACAF.

Phase 2: Experiments to support criticality safety applications.

Experiments will te needed to support nuclear criticality safety in the areas of tuel fabrication, storage, transport, and reprocessing.

\section{Proposed LACEF}

\section{experimental}

facility

Contact E. Hansen

Advanced Nuclear Technology

P.O. Box 1663

Los Alamos National Laboratory

Los Alamos, NM 87545 


\section{Experiment 809 \\ Refurbishment or Replacement for N-Reactor}

\section{Contractor Requiring Data Westinghouse Hanford Company \\ Category Low-enriched uranium \\ Application Support new DOE program}

$\begin{array}{rrl}\text { Rating } & \text { Status } & \text { Justification completed } \\ \text { Priority } & \text { Required for new or ongoing DOE operation }\end{array}$

Description of If the $\mathrm{N}$-Reactor is replaced and a different fuel type is used in the new reactor, new operation and criticality experiments will be needed to support this reactor. Requiremertis will not be experimental clarified, however, until 1988-1992. Several options currently exist for this project: use of a data needed WPPS nuclear fuel reactor, currently under construction, or construct a new production reactor.

If the $\mathrm{N}$-Reactor were placed in a tritium production mode, different fuel elements will be used in the reactor. The fuel sould use some higher enrichment and be made out of a special alloy. Critical mass measurements or in situ measurements would be needed to better define operational critical mass parameters. The need for such measurements would be identified in FY 1988 - 1989.

\section{experimental \\ facility}

Proposed LACEF

Contact H. Toffer

Westinghouse Hanford Company

P.O. Box 1970

Richland, WA 99352

(509) 376-2894; FTS (509) 444-2894 


\section{Experiment 810 \\ Special Isotope Separation (SIS) (canceled)}

Contractor Requiring Data Westinghouse Idahe Nuclear Company

Category Plutonium

Application Support new DOE program

Rating Status Justification completed

Priority Required for new or ongoing DOE operation

Description of The Special Isotope Separation (SIS) project will separate ${ }^{239} \mathrm{Pu}$ from plutonium mixtures

operation and high in ${ }^{240} \mathrm{Pu}$. Experiments needed to support SIS have not been completely defined.

experimental Expected needs are given below:

data needed $\mathrm{PuCl}_{3}$ Solutions: The SIS facility employs an aqueous process involving $\mathrm{PuCl}_{3}$ solution for the recovery of plutonium from the waste streams of various pyrochemical processes.

Criticality data on $\mathrm{PuCl}_{3}$ solution systeñi is currently not available; hence, critical experiments on $\mathrm{PuCl}_{3}$ sciution are needed before ( 1 ) the credit presented by chlorine as a neutron poison can be properly accounted for in the design, and (2) the calculational methods used in the design can be properly validated. Such criticality data are also beneficial to other plutonium facilities using hydrochloric acid as a means of plutonium recovery.

Plutonium Hydride: The SIS facility employs a hydriding/dehydriding process for the recovery of plutonium from the AVLIS system. No criticality data on plutonium-hydride is currently ayailable, and designing the process or verifying the design parameters based on criticality data of other forms of plutonium may or may not be conservative. Therefore, a need for critical experiments with plutonium-hydride is identified for the design, as well as for the validation of the calculational method.

Salt-Reflected/Moderated System: The pyrochemical processes employed by the SIS facility involves plutonium metal in a salt-reflected/moderated system.

Proposed LACEF

experimental

facility

Contact W. Jensen, Nuclear Safety Branch

U.S. Department of Energy/Operational Safety Division

785 DOE Place

Idaho Falls, ID 83402

(208) 526-1387; FTS (208) 583-1387 
Contractor Requiring Data Applicable to most Department of Energy contractors

Category Criticality Physics

Application Support new DOE program

\begin{tabular}{|c|c|c|}
\hline $\mathbf{R}$ & $\begin{array}{r}\text { Status } \\
\text { Priority }\end{array}$ & $\begin{array}{l}\text { Justification completed } \\
\text { Less urgent than priority (2) }\end{array}$ \\
\hline
\end{tabular}

Description of The boron in Pyrex glass cylinder walls reduces the neutron interaction between cylinders operation and This suggests that Pyrex glass cylinders in a storage array could be closer together than experimental present practice. Before storage operations can take advantage of this reduced spacing. data needed however, a criticality experiment is needed to provide verification data.

Note: The poisoning effect of Pyrex cylinder walls could be studied during the neutron interaction experiments (see Experiment 601).

\section{experimental \\ facility}

Proposed LACEF

Contact D. Rutherford

Los Alamos National Laboratory

P.O. Box 1663

N-2, MS J562

Los Alamos, NM 87545

(505) 665-5038; FAX (505) 665-3657 


\section{Appendix A \\ Glossary of Nuclear Criticality Terms}


albedo, neutron: The probability, under specified conditions, that a neutron entering into a region through a surface will return through that surface.

absorbed dose: The energy imparted to matter by directly or indirectly ionizing ritiation per unit mass of irradiated material at the point of interest; unit of absorbed dose has been the rad ani now, in the International System of Units (SI) is the gray (Gy), $100 \mathrm{rad}=1 \mathrm{~Gy} .{ }^{2,3}$ See rad, gray.

absorption, neutron: A neutron-induced reaction, including fission, in whi. h the neutron disappears as a free particle. 1 The absorption cross section is designated $\sigma_{\mathrm{a}}$. See capt re, neutron; cross section, neutron.

alarm system, criticality accident: A system capable of sounding an audible alarm after detecting neutron or gamma radiation from a criticality accident. See criticality accident.

alpha particle: A helium-4 nucleus emitted during a nuclear transformation. ${ }^{1}$

beta particle: An electron of either positive or negative charge that has been emitted in a nuclear transformation. 1

buckling: For our purposes, algebraic expressions that relate critical dimensions of varicus simple shapes (sphere, cylinder, or cuboid) of cores of the same composition and similar reflectors. For example, the known radius of a critical sphere may úc used to obtain the radius and length of a corresponding critical cylinder. For a specific definition of buckling, see Ref. 4, pp 7 and 8. See core, reflector.

burst, prompt: Usually refers to the pulse of energy from fissions produced by a prompt burst reactor. See prompt burst reactor, spike (in a prompt power excursion).

capture, neutron: Neutron absorption not leading to fission or other neutron production. The capture cross section is designated $\sigma_{c}$. See absorption, neutron; cross section, neutron.

cent: $A$ unit of reactivity equal to one-hundredth of the increment between delayed criticality and prompt criticality (a dollar). I See dollar, reactivity

chain reaction, fission: A sequence of nuclear fission reactions in which fissions are induced by neutrons emerging from preceding fiss:ions. Depending on whether the number of fissions directly induced by neutrons from one fission is on the average less than, equal to, or greater than unity, the chain reaction is, respectively convergent (subcritical), self-sustáinilig (critical), or divergent (supercritical). !

core: That part of a fissile system containing most or all of the fissile material, as distinguished from an external reflector. See fissile system, reflector.

critical infinite cylinder: For specified fissile medium and surrounding reflector, the infinitely long cylinder with a diameter that would be critical.

critical infinite slab: For specified fissile medium and reflector on each sirface, the slab of infinite lateral dimensions with a thickness that would be critical. 


\section{Glossary of Nuclear Criticality Terms}

criticality accident: The release of energy as a result of accidentally producing a self-sustaining or divergent fission chain reaction.!

criticality safety Standards: These Standards describe criticality control practices for which there is industrywide consensus. Consensus is established through procedures of the American National Standards Institute. Chapter 4 of Ref. 4 lists and discusses existing and proposed criticality safety Standards, and explains capitalization of the term.

cross section $(\sigma)$, neutron: The proportionality factor that relates the rate of a specified reaction (such as capture or fission) to the product of the number of neutrons per second impinging normally onto a unit area of a thin target and the number of target nuclei per unit area. It may be considered a small area assigned to each target nucleus, usually expressed in barns, i.e., $10^{-24} \mathrm{~cm}^{2}$. See absorption, neutron; capture, nelitron; fission, nuclear.

decay, radioactive: A spontaneous nuclear transformation in which particles or gamma radiation is emitted, in which $\mathrm{x}$-radiation is emitted following orbital electron capture, or in which the nucleus undergoes spontaneous fission.' See fission, nuclear; gamma radiation.

delayed criticality: State of a fissile system such that $k_{\text {eff }}=1$, the steady-state condition. See multiplication factor.

delayed neutrons: Neutrons from nuclei produced by beta decay following fission. They follow fission by intervals of seconds to minutes. See prompt neutrons.

dollar: A unit of reactivity equal to the increment between delayed criticality and prompt criticality for a fixed chain-reacting system. See reactivity.

dose equivalent: The absorbed dose multiplied by the quality factor and other less significant modifying factors, so that doses from different radiations (alpha, beta, gamma, slow neutron, fast neutron) can be summed to provide an effective total dose at the point of interest. ${ }^{2}$ The conventional unit of dose equivalent has been the rem, and now in the International System of Units (SI) is the sievert (Sv), $100 \mathrm{rem}=1 \mathrm{~Sv} .^{5} \mathrm{See}$ rem, sievert.

dose rate: Absorbed dose delivered per unit time. ${ }^{2}$ See absorbed dose.

excursion, nuclear: An episode during which the fission rate of a supercritical system increases, peaks, and then decreases to a low value.

excursion, prompt-power: A nuclear excursion as the result of a prompt-critical configuration of fissile material. In general, a sharp power spike followed by a plateau that may be intermupted by smaller spikes. See excursion, nuclear; spike (in a prompt power excursion).

exr:irsion period ( $\mathrm{T})$ : The reciprocal coefficient of $\mathrm{t}$, where fission poiver in a nuclear excursion increases as $\mathrm{e}^{\mathrm{t} T}$ before a quenching mechanism becomes effective. See excursion, uuclear; quenching mechanism.

exponential column: A subcritical block or cylinder of fissile-bearing material with an independent neutron source at one end. Under appropriate conditions, the response of a neutron detector decreases exponentially with distance from the source. From the logarithmic rate of this decrease and lateral dimensions of the column, critical dimensions of an unreflected assembly of the material may be deduced. 
exposure: A measure of the ionization produced in air by $x$-rays or gamma radiation; the sum of electric charges on all ions of one sign in a small volume of air when all electrons liberated by photons are completely stopped, per unit mass of the air. Note that exposure refers to the environment, not absorbing material. The unit of expo:iure is the roentgen. ${ }^{2}$ See gamma radiation, roentgen. Alternatively, exposure is the incidence of radiation on living or inanimate material. 1

favorable geometry: Geometric constraint of fissile material in which subcriticality is maintained under anticipated conditions. Examples are limited diarneter of pipes intended to contain fissile solution, or limited volunes of solution containers.

fissile nuclide: A nuclide capable of fission by thermal neutrons, provided the effective neutron production cross section, $\overline{v \sigma_{f}}$ exceeds the effective absorption cross section, $\overline{\sigma_{\mathfrak{a}}}$. The common fissile nuclides are $235 \mathrm{U}$,

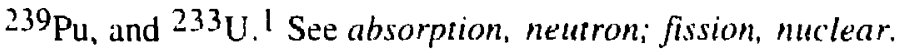

fissile system: A system containing ${ }^{235} \mathrm{U},{ }^{239} \mathrm{Pu}$, or ${ }^{233} \mathrm{U}$ (or certain other transuranic) nuclides and capable of significant neutron multiplication. See fissile nuclide; multiplication, subcritical.

fission, nuclear: Disintegration of a nucleus (usually $\mathrm{Th}, \mathrm{U}, \mathrm{Pu}$, or heavier) into two (rarely more) masses of similar order of magnitude, accompanied by a large release of energy and the emissior of neutrons. Although some fissions take place spontaneously, neutron-induced fissions are of major interest in criticality safety. The fission cross section is designated $\sigma_{f}$, and $v$ is the number of neutrons emitted per fission. See cross section, neutron.

fission products: Nuclides produced by fission or by the subsequent radinactive decay of nuclides formed in this manner. ${ }^{1}$ See fission, nuclear: nuclide.

fission yield, excursion: The total number of fissions in a nuclear excursion. See excursion, nuclear.

fissionable nuclide: $A$ nuclide capable of fission by neutrons of some energy. Fissionable nuclides include ${ }^{238} \mathrm{U},{ }^{240} \mathrm{Pu}$, and others with neutron-energy fission thresholds, in addition to those that are fissile. See fissile nuclide.

gamma radiation: Short-wavelength electromagnetic radiation emitted in the process of nuclear transition or particle annihilation. ${ }^{1}$

gray (Gy): A unit of absorbed dose; $1 \mathrm{~Gy}=1 \mathrm{~J} / \mathrm{kg}=100$ rads. Adopted in 1976 by the International Conference on Weights and Measures to replace the rad. ${ }^{5}$ See rad.

hazard: A potential danger. "Potentially hazardous" is redundant. Note that a hazardous facility is not necessarily a high-risk facility. See risk. .

H/X: Conventionally, the atomic ratio of hydrogen to ${ }^{235} \mathrm{U},{ }^{239} \mathrm{Pu}$, or ${ }^{233} \mathrm{U}$ in a solution or hydrogenous mixture. Where there is more than one fissile species, the ratios must be specified separately.

inhour: A unit of reactivity that, when added to a delayed-critical system, would produce a period of one hour; now seldom used. I' See reactivity.

Ionizing radiation: Any radiation consisting of directly or indirectly ionizing particles, photons, or a mixture or boti. X-rays and the radiations emitted in radioactive decay are examples. ${ }^{1}$ See decav, radioactive. 


\section{Glossary of Nuclear Criticality Terms}

Irradiation: Exposure to ionizing radiation.' See exposure (alternative definition).

Isotopic code: Combined final digits of atomic number and atomic weight, such that ${ }^{235} \mathrm{U}$, and ${ }^{239} \mathrm{Pu}$ are represented "25," "49," and "23"; $240 \mathrm{Pu}$, however, is called "410"; these appear in some documents but now are seldom used.

linear energy transfer (LET): The average energy lost by an ionizing radiation per unit distance of its travel in a medium. A high LET is generally associated with protons, alpha particles, and neutrons, whereas a low LET is associated with $x$-rays, electrons, and gamma rays. 2 See ionizing radiation.

monitor, radiation: A detector to measure the level of ionizing radiation. A purpose may be to give information about dose or dose rate.' See ionizing radiation.

multiplication, subcritical: In a subcritical fissile system containing a neutron source, the equilibrium ratio of the total number of neutrons resulting from fission and the source to the total number of neutrons from the source alone. 1

multiplication factor $\left(k_{\mathrm{eff}}\right)$ : For a chain-reacting system, the mean number of fission neutrons produced by a neutron during its life within the system. It follows that $k_{\text {eff }}=1$, if the system is critical; $k_{\text {eff }}<1$, if the system is subcritical; $k_{\text {eff }}>1$, if the system is supercritical.

neutron: An elementary particle having no electric charge, a rest mass of $1.67495 \times 10^{-24} \mathrm{~g}$, and a mean life of about $10 \mathrm{~min} .1$

neutron poison: A nonfissionable neutron absorber, generally used for criticality control. See absorption neutron: capture, neutron.

neutrons, epithermal: Neutrons of kinetic energy greater than that of thermal agitation, often restricted to energies comparable with those of chemical bonds. $?$

neutrons, fast: Neutrons of kinetic energy greater than some specified value, often chosen to be $0.1 \mathrm{MeV}$ (million electron volts). ${ }^{\text {l }}$

neutrons, thermal: Neutrons in thermal equilibrium with the medium in which they exist. ${ }^{\prime}$ At room temperature, the mean energy of thermal neutrons is about $0.025 \mathrm{eV}$ (electron volt).

nonfavorable geometry: See favorable geometry.

nuclide: A species of atom characterized by its mass number, atomic number, and a possible, elevated, and prolonged nuclear energy state. ${ }^{1}$

oralloy (Oy): Introduced in early Los Alamos documents to mean enriched uranium (Qak $\underline{\text { Ridge }}$ alloy); now uncommon except to signify highly enriched uranium. See tuballoy.

personnel monitor (radiation): A device for measuring a person's exposure to radiation. Information on the dose equivalent of ionizing ra jiation to biological tissue is derived from exposures recorded by film badges, ionization chambers, and thermoluminescent devices; from whole-body counting and analysis of biological specimens; and from area monitoring and special surveys. ${ }^{2}$ 


\section{Glossary of Nuclear Criticality Terms}

photon: A quantum of electromagnetic radiation. ${ }^{\prime}$

prompt burst reactor: A device for producing nondestructive super-prompt-criticai nuclear excursions. See burst, prompt: excursion, nuclear.

prompt criticality: State of a fissile system such that the prompt-neutron contribution to $k_{\text {eff }}$ equals unity. See multiplication factor.

prompt neutrons: Neutrons emitted immediately during the fission process. Sste delayed nelurons.

quality factor (QF): The linear energy-transfer-dependent factor by which absorbed doses are multiplied to obtain, for radiation-protection purposes, a quantity that expresses on a common scale the biological effectiveness of the absorbed dose derived from various radiation sources. ${ }^{2}$ Approximately the ratio of dose equivalent and absorbed dose. See absorbed dose, dose equivalent, linear energy transfer.

quenching mechanism: physical process other than mechanical damage that limits an excursion spike. Examples are thermal expansion, or microbubble formation in a solution. See spike (in a prompt power excursion)

rad: A unit of absorbed dose; $1 \mathrm{rad}=10^{-2} \mathrm{~J} / \mathrm{kg}$ of the medium. In 1976, the International Conference on Weights and Measures adopted the gray $(1 \mathrm{~Gy}=1 \mathrm{~J} / \mathrm{kg})$ as the preferred unit of absorbed dose, ${ }^{5}$ but this unit has not appeared in the criticality-accident literature, which was essentially complete before that date. See absorbed dose, gray, and discussion under personnel monitor.

radiation: In context of criticality safety, alpha particles, beta particles, neutrons, gamma rays, and combinations thereof. See alpha particle, beta particle, neutron, x-ray.

reactivity: A parameter of a fissile system that is proportional to $1-1 / \mathrm{k}_{\mathrm{eff}}$. Thus, it is zero if the system is critical, positive if the system is supercritical, negative if the system is subcritical. See dollar, cent, and inhour, various units of reactivity; mulriplication fu.

reflector: Material outside the core of a fissile system capable of scattering back to the core some neutrons that would otherwise escape. See core, fissile system.

reflector savings: The absolute difference between a dimension of the reflected core of a critical system and the corresponding dimension of a similar core that would be critical if no reflector were present. ${ }^{1}$ See core, fissile system, reflector.

relative biological effectiveness (RBE): A factor used to compare the biological effectiveness of absorbed radiation doses (i.e., rads or grays) because of different types of ionizing radiation; more specifically, it is the experimentally determined ratio of an absorbed dose of a radiation in question to the absorbed dose of a reference radiation required to produce an identical biological effect in a particular experimental organism or tissue. ${ }^{3}$ This term should be used only in radiobiology, not instead of the term "quality factor" in radiation protection. See quality factor.

rem: $A$. unit of dose equivalent (Roentgen Equivalent, Man), replaced by the sievert, which was adopted in 1980 by the International Conference on Weights and Measures. 5 This unit, however, has not appeared in the criticality-accident literature. See dose equivalent, sievert. 


\section{Glossary of Nuclear Criticality Terms}

rep: An obsolete term for absorbed dose in human tissue, replaced by rad, Originally derived from Roentgen Equivalent, Physical.!

risk: The cost of a class of accidents over a given period, usually expressed as dollars or fatalities, per year or during plant lifetime. Unless established by experience, risk is estimated as the product of the probability of occurrence and the consequences of the accident type. Not to be confused with hazard. See hazard.

roentgen (R): A unit of exposure; $1 \mathrm{R}=2.58 \times 10^{-4} \mathrm{C} / \mathrm{kg}$ in air, where $\mathrm{C}$ is coulombs. ${ }^{3}$ Strictly, the roentgen applies to $x$-rays or gamma radiation, although in one report of a criticality accident beta "dosages" are expressed in units of R. See exposure.

scram: An alternative term for reactor trip. ${ }^{1}$ Reference 6 gives accounts of the origin of this term.

shutdown mechanism: Quenching mechanism and mechanical damage, if any, that limits a prompt-power excursion spike. See excursion, prompt power; quenching mechanism; spike.

sievert (Sv): A unit of dose equivalent; $1 \mathrm{~Sv}=1 \mathrm{~J} / \mathrm{kg}=100 \mathrm{rem}$. Adopted in 1980 by the International Conference on Weights and Measures to replace the rem..$^{5}$ See dose equivaterii, rcm.

spike (in a prompt-power excursion): The initial power pulse of a prompt-power excursion, limited by the shutdown mechanism. See excursion, prompt power; shutdown mechanism.

tuballoy (Tu): A wartime term for natural uranium, originating in England; now obsolete. See oralloy.

uranium enrichment (enrichment): The weight percentage of $235 \mathrm{U}$ in uranium, provided that percentage exceeds its natural value; if the reference is to enhanced ${ }^{233} \mathrm{U}$ content, "233 $\mathrm{U}$ enrichment" should be specified.

x-ray: Electromagnetic radiation of wavelength in the range $10^{-10} \mathrm{~cm}$ to $10^{-6} \mathrm{~cm} .^{7}$ 


\section{Criticality Symbois}

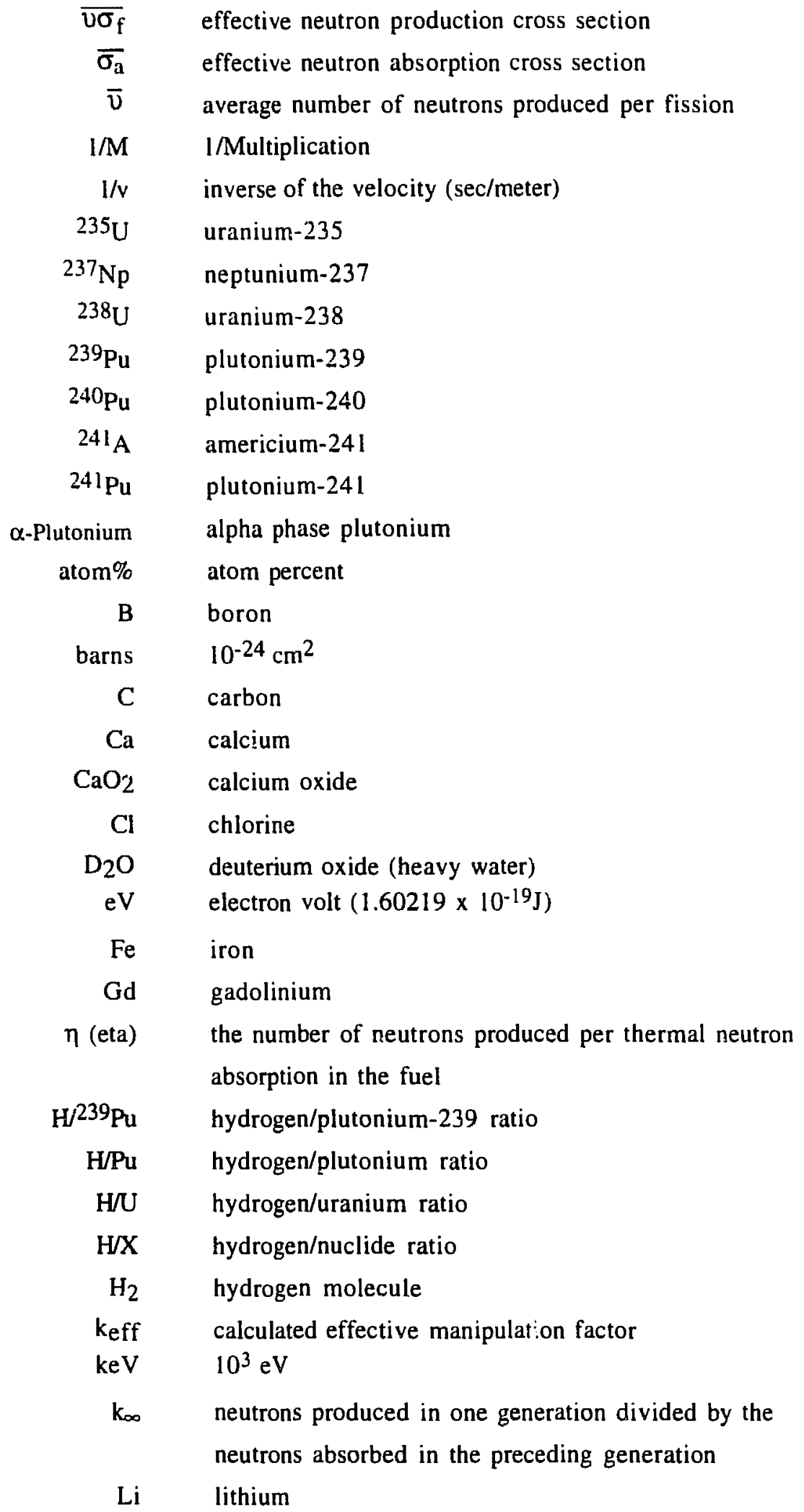


Criticality Symbols (continued)

$\begin{aligned} \mathrm{Mg} & \text { magnesium } \\ \mathrm{MgO} & \text { magnesium oxide } \\ \mathrm{v} & \text { number of neutrons emitted per fission } \\ \mathrm{Na} & \text { sodium } \\ \mathrm{NaCl} & \text { sodium chloride } \\ \mathrm{O} & \text { oxygen } \\ \mathrm{Oy} & \text { oralloy (highly enriched uranium) } \\ \mathrm{pH} & \text {-log[H+], a measure of solution acidity } \\ \mathrm{Pu} & \text { plutonium } \\ \mathrm{Pu}-(\mathrm{CH})_{\mathrm{n}} & \text { plutonium-polyethylene } \\ \mathrm{Pu} / \mathrm{U} & \text { plutonium/uranium ratio } \\ \mathrm{PuCl} & \text { plutonium chloride } \\ \sigma & \text { neutron cross section } \\ \sigma_{\mathrm{a}} & \text { absorption cross section } \\ \sigma_{\mathrm{b}} & \text { capture cross section } \\ \sigma_{\mathrm{f}} & \text { fission cross section } \\ \mathrm{Si} & \text { silicon } \\ \mathrm{SiO} & \text { silicon oxide } \\ \mathrm{Ti} & \text { titanium } \\ \mathrm{U}(93) & 93 \% \text { enriched uranium } \\ \mathrm{Zr} & \text { zirconium } \\ {\left[(\mathrm{CH})_{\mathrm{n}}\right] } & \text { polyethylene } \\ & \end{aligned}$




\section{REFERENCES}

1. Glossary of Terms in Nuclear Science and Technology, prepared by ANS-9, the American Nuclear Society Standards Subcommittee on Nuclear Terminology and Units, Harry Aiter chairman (American Nuclear Society Publications, La Grange Park, IL, 1986 revision).

2. George L. Voelz, M.D., "Terms Used in Radiation, Radiobiology, and Radioepidemiology," Los Alamos National Laboratory, Group HSE-2 .

3. Radiological Health Handbook, "Glossary," pp 413-441 (U.S. Department of Health, Education, and Welfare, Public Health Service, Consumer Protection and Environmental Health Service, Rockville, MD 20852, Revised Edition, January 1970).

4. Ronald A. Knief, Nuclear Criticality Safety Theory and Practice (American Nuclear Society, La Grange Park, IL, 1985).

5. H. G. Jerrard and D. B. McNeill, Dictionary of Scientific Units, Fifth Edition (Champman and Hall, London, 1972).

6. Raymond L. Murray, "The Etymology of 'Scram'," Nuclear News 31, 105-107 (1988); "Letters," Nuclear News, 31, 17-18 (1988).

7. F. W. Sears and M. W. Zemansky, University Physics, 2nd Ed. (Addison-Wesley, Reading, MA, 1955). 


\section{Appendix B \\ Recommendation 93.2 to the Secretary of Energy}

Appendix B

$$
\text { B - I }
$$




\section{RECOMMENDA: ON 93-2 TO THE SECRETARY OF ENERGY \\ pursuant to 42 U.S.C. \& $2286 a(5)$ \\ Atomic Energy Act of 1954, as amended.}

Dated: March 23, 1993

The end of the international competition in manufacture of nuclear weapons, and the transition to large scale dismantling of nuclear weapons, have generated strong pressures to reduce the defense nuclear budget and to close down many defense nuclear facilities and operations. At the same sime, the development of firm plans for a Complex 21 to serve future nuclear defense needs has slowed. These trends lead to a possibility that capabilities and functions necessary for current and future needs could be terminated along with those no longer required. One of these, important for the avoidance of certain types of atcidents, is support of nuclear criticality control.

Because of the importance of avoiding criticality accidents, the Board carefully follows the state of criticality control at DOE's defense nuclear facilities. This interest has been evident as Board members and staff have reviewed practices at the Pantex Plant. The Board believes it is important to maintain a good base of information for criticality control, covering the physical situations that will be encountered in handling and storing fissionable material in the future, and to ensure retaining a community of individuals competent in practicing the control.

In the course of retrenchment of its activities in recent years, the Department of Energy and its predecessor agencies have terminated use of all but one of its general purpose facilities for conducting neutron chain-reacting critical experiments with fissionable material. The research at these facilities had served programmatic purposes of diverse DOE programs, as well as laying a general experimental basis for practices that ensure averting criticality accidents. The Board is informed that there is now a strong possibility that the last DOE facility capable of general purpose critical experiments will be shut down in the near future, due to lack of funding. This possibility arises because no single program of the Department has an overriding need for this remaining facility at the Los Alamos National Laboratory, and therefore no single program office is motivated to provide its financial support in this period of budget stringency. A certain complacency fed by some years of freedom from criticality accidents seems also to underlie this possibility.

The Board observes that the art and science of nuclear criticality control have three principal ingredients. The first is familiarity with factors that contribute to achieving nuclear criticality, and the physical behavior of systems at and near criticality. This familiarity is developed in individuals only through working with critical systems. It cannot be imparted solely through learning theory and using computer codes. The second is theoretical understanding of neutron multiplication processes in critical and subcritical systems, leading to predictability of the critical state of a system by methods that use theory benchmarked against good and well characterized critical experiments. 
The third is thorough familiarity of nuclear criticality engineers with the first two factors, obtained through a sound program of training that indoctrinates them in the experimental and theoretical aspects.

The Board has reviewed the status of benchmarking the theoretical methods of criticality control against existing critical experiments and has found that there are notable failures of theoretical analysis to account for the results of a number of experiments. It is not known whether this discrepancy results from inadequate nuclear data used in the analysis or from inadequate care in conducting the experiments and recording their physical features. Both factors could contribute. In addition, it seems that on the average there may be a smal! non-conservative bias in overall predictions of the theory. In spite of these shortcomings, conservatism in methods used to develop the limits to be applied during handling and storage of fissionable material seems to have led to adequate safety in recent years. The Board believes that in the interest of continued safety it is important to clear up the existing discrepancies, which are obstacles to confident understanding of criticality control. To do so will require conduct of further neutron chain-reacting critical experiments targeted at the major sources of discrepancy between the theory and the experiments, as well as careful analysis of the experiments.

Finally, the Board believes that there is no guarantee that the physical circumsiances of handling and storage of fissionable material in the future will always be found in the realm of benchmarked theory. This point is especially important under circumstances that will exist for a number of years to come, with increasing amounts of fissionable material to be stored in a variety of chemical and physical forms. This does not appear to be an appropriate time to eliminate an ability to ensure that such activities will be free of criticality hazard. For safety purposes it will be necessary to retain the capability to perform experiments under conditions not foreseen at this time. This capability once lost would be most difficult to reproduce, and it could be approximated only at great cost and after substantial time, deterring such development even if it were needed badly.

For all the above reasons, the Board believes that continuation of an experimental program of general purpose critical experiments is necessary for continued safety in handling and storing fissionable material. It is needed to improve the basis for the methodology. It is needed as part of the process of properly educating criticality control engineers. It is needed to ensure the capability of answering criticality questions with new and previously unresearched features.

Therefore the Board recommends that:

1. The Department of Energy should retain its program of general purpose critical experiments. 
2. This program should normally be directed along lines satisfying the objectives of improving the information base underlying prediction of criticaiity, and serving in education of the community of criticality engineers.

3. The results and resources of the criticality program should be used in ongoing departmental programs where nuclear criticality would be an important concern.

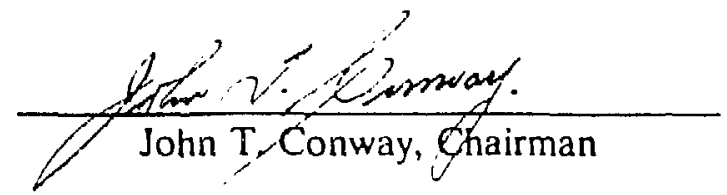




\section{Appendix C}

\section{Request for Criticality Experimental Programs or Criticality Experiments}




\section{CRITICALITY EXPERIMENTS WORKGROUP}

NUCLEAR CRITICALITY TECHNOLOGY AND SAFETY PROJECT (Sponsored by DOE OFFICE OF NUCLEAR SAFETY, POLICY, AND STANDARDS)
REQUEST FOR

CRITICALITY EXPERIMENTAL PROGRAMS OR CRITICALITY EXPERIMENTS

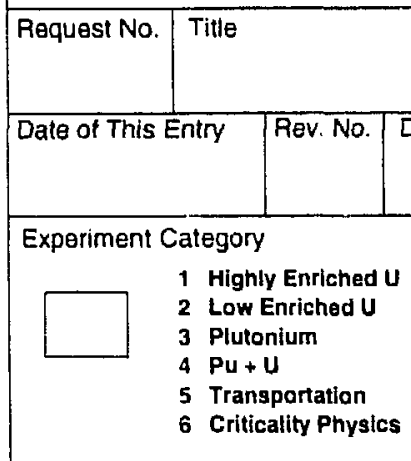

Experiment

Application

1 Support New DOE Program

2 Enhance Current DOE Operation

3 Resolve Technical lssue

4 Compliance with DOE Orders

5 Environmental issues
Status of Request

1 Initial Request

2 Jusitification Completed

3 Jutitflcation Being Prepared

4 Experiment Identified

5 Anticlpated Need

6 Experiment in Progress

7 Experiment Complete

Comments

Requested by

Other Contacts
Priority

1 Maximum Practical Aftention

2 Required lor New or Ongning DOE Operation

3 Less Urgent than PRIORITY (2) 
Appendix D

Physics Criteria for Benchmark Critical Experiments 


\section{Appendix D \\ Physics Criteria for Benchmark Critical Experiments}

April 1990

Workgroup Report, Nuclear Criticality Technology and Safety Project

Workgroup Chairperson: Nancy Landers; Cochairs; Mike Westfall, Brian Koponen

Subject: Physics Criteria for Benchmark Critical Experiments

Item (1) Define the criteria for acceptance of critical and subcritical experiments as benchmarks.

I. For acceptance as a benchmark, the method used to determine $k_{\text {eff }}$ should be specified.

II. Consistency among experimentally measured parameters is desirable. For example, the fundamental mode multiplication should be determined by more than one method in order t. asure consistency.

III. A rigorous and detailed description of the experimental mockup, its mechanical supports, and its surroundings is necessary. For example, measurements fixing the position of the experiment within the room should be provided. Accompanying photographs and drawings are essential.

IV. A complete specification of the geometry dimensions and material compositions including the methods of determination and the known sources of error and their potential propagation is necessary. Aiso, for completeness, list unknown but suspected sources of error.

V. A series of experiments is desirable in order to demonstrate the reproducibility of the results. Positive and negative period measurements provide useful supplementary information for well-defined near-critical systems.

VI. A description of the experiment and results, containing at least the elements of the 1983 ANS Standard 8.1, should appear in a refereed publication.

Item (2) Define neutron physics parameters that may be used to classify benchmark experiments by measurement technique.

\section{Physics Parameters}

I. Measurements of critical experiments
A. Observation of the multiplication factor of a critical configuration $\left(\mathrm{k}_{\mathrm{eft}}=1.000\right)$
B. Effective moderator to fissile atom ratio 
II. Other than critical measurements

A. Subcritical keff measurements by one or more methods

B. Pulsed neutron measurements for neutron lifetime and system multiplication and, through delayed neutron fraction and neutron lifetime, source jerk, rod drop, noise analysis, etc.

C. Central worth and replacement measurements

D. Reaction ratios (activation ratios)

E. Reactivity worths

F. Flux traverses-foil or wire traverses

G. Leakage spectra measurements

H. Laplace Transforms, the relaxation length, etc.

I. Neıtron source measurements

1. $\bar{v}$, the average number of neutrons per fission

2. $f$, the thermal utilization factor (ratio of thermal neutrons absorbed in the fuel/total thermal neutrons absorbed in the system)

3. $\eta$, the number of neutrons produced per thermal neutron absorption in the fuel

4. Spectral measurements (slowing down spectral measurements and thermal scattering kernels)

5. Slowing down time measurements

J. Neutron noise method in time/frequency domain

Item (3) Consider the aspects of present-day computations that are not adequately benchmarked by existing measurements. Define extensions of experimental techniques that may eliminate these deficiencies.

I. Physics parameters that can be calculated (with desired experimental accuracy).

A. Of primary importance and can be calculated directly

1. $\mathrm{k}_{\text {eff }}$ (within 25\%)

2. reaction ratios $(5 \%)$ (ratios of activities)

3. thermal utilization, $\eta(1 \%)$

4. neutron spectra $(5 \%)$.

B. Of secondary importance and can be calculated directly.

I. lifetime (5\%) (requires kinetics codes)

2. generation time (5\%) (requires kinetics codes)

3. number of neutrons per fission (1\%)

4. reactivity worths (10\%). 
C. Parameters of interest requiring extensions of present calculational and/or experimental capabilities.

1. flux traverses (extend calculational capabilities to reduce uncertainities)

2. leakage spectrum (extend calculational and experimental capability)

3. slowing down measurements (extend calculational capabilities)

4. subcritical measurements (develop calculational capabilities and extend experimental capabilities)

5. thermal scattering kernels (extend calculational and experimental capabilities)

6. delayed fission neutron spectra (extend calculational capabilities and enhance experimental capabilities)

7. time eigenvalues and the effect of time eigen-functions

8. complex fluxes from neutron wave experiments.

Criticality codes can presently calculate parameters with varying ievvels of uncertainties that are related to spectral measurements and certain replacement worth measurements. These include: eigenvalue, time to death, time to birth, $\bar{v}$, fission production matrix, tluxes. fission densities, the fission energy spectrum, the leakage energy spectrum and reaction rate ratios.

Present day kinetics codes can determine some of the parameters measured in dynamics experiments. However, the present methodology is limited to either point kinetics or diffusion theory.

Item (4) Identify steps that can be made towards standardization in the reporting of benchmark measurements.

The reporting of any experiment intended to be considered a benchmark should include, at a minimum, the relevant portions of the factors listed below. Several of the items are perhaps beyond the capability of even today's relatively sophisticated calculational techniques. However, rather than again fall into the trap of noting only those factors that can be used in contemporary codes, it is possibly preferable to err in "over recording" and "over reporting."

I. A description of the following factors:

A. Fissile materials

1. Comiposition

a. Isotopic analysis

b. Concentration and density (usually applicable to solutions, but can apply to mixtures such as carbon-uranium) as a function of experimental conditions such as temperature

c. Impurities: identification, abundance

d. Departure from stochiometric (e.g., excess acid in solution)

2. Dimensions (diagrams can help)

B. Associated materials (diluents, grid plates, support structures, control elements, etc.)

1. Composition

2. Dimensions and location (diagram)

C. Overall environment (particularly for nominally unreflected measurements; diagram)

1. Description and location of other materials, fissile and not, in the cell; i.e., tanks, structures, "stored" components, other experiment setups, etc. 


\section{Physics Criteria for Benchmark Critical Experiments}

2. Location (diagram), including but not limited to location of experiment with respect to cell walls, floor, ceiling

3. Document problems such as leaky valves, limited fuel inventory, etc.

D. Programmatic constraints (desirable peripheral information)

1. Total cost of experiment

2. Staff/facility requirements

3. Total program time and time required per measurement

II. "Critical": actual determination or extrapolation (include method of extrapolation, curve, and data)

A. Sensitivity of "control device" (i.e., table position, liquid height, control rod(s) near critical)

B. Experiment conditions, such as temperature, relative humidity, barometric pressure, if relevant and not included as a part of Item I above

III. Experimenter estimate of errors, uncertainties

A. Critical Dimensions

B. Compositions-everything, particularly fissile materials and intimately associated other materials, such as container/support materials

C. Reactivity determinations

D. Reproducibility (independent analyses of material isotopics concentrations, etc., are desirable)

E. Preserve samples for analysis as long as practical

F. Estimate perturbation due to the detectors

G. Measured physics parameters should be compared for internal consistency and for consistency with previously published values

IV. Documentation of auxiliary measurements (including Item III, above)

A. Flux distribution and spectrum measurements

1. Detector (composition, size, energy, locations, supports)

2. Perturbation to system (method of determining)

3. Treatment of raw data (consider archiving of raw data)

B. Rod drop

1. Geometry of system

2. Composition, dimensions of rod; location if not specified in Item I.B above

3. Data and treatment of data, not simply the "answer" (consider archiving raw data)

C. Source jerk

1. Geometry of system

2. Source dimensions, composition, strength

3. Data and treatment of data, not simply the "answer" (consider archiving raw data) 
D. Pulse-noise, fixed-source measurements

1. Description of setup (detectors, source locations)

2. Description of detectors, source, including dimensions

3. Data and treatment of data (consider archiving raw data)

Item (5) Identify modifications to application-specific experiments that will permit them to serve as benchmarks.

Criticality experiments have always been an important aspect of nuclear criticality safety. At the inception of the nuclear industry, an experiment could be little more than a replica of the storage vessel arrangement to be employed; often, actual plant items would be used in its construction. This direct approach is still maintained in some laboratories. Almost by definition, the results of such experiments are of limited interest outside the facility concerned. More recently, the importance of criticality experiments to code validation has been recognized. Often the experimental arrangements continue to be application specific. However, they might also be of interest co the wider criticality safety, code validation, and nuclear data evaluation communities. The inrorporation of reaction rate measurements will increase their usefulness in this regard.

An integral quantity is $k_{\text {eff }}$. It is possible for a code to calculate $k_{\text {eff }}$ correctly for the wrong reasons. The code may, for example, contain canceling errors that may not compensate for one another under different circumstances. Reaction rate measurement allows the validator to examine code performance in terms of event balances in different parts of the neutron spectrum. In an experiment involving low enriched uranium, for example, it might be possible to measure the Fast Fission Ratio (FFR), the ratio of fissions in ${ }^{238} \mathrm{U}$ to those in ${ }^{235} \mathrm{U}$, and the Relative Conversion Ratio $(R C R)$ the ratio of capture in ${ }^{238} \mathrm{U}$ to fission in ${ }^{235} \mathrm{U}$. The measured quantities may be compared with reaction-rate ratios given by the code, providing a more stringent test of code performance. The result of such an experiment will provide information that can be included in nuclear cross-section evaluation. As far as the criticality assessor is concerned, confidence in this method of calculation is enhanced.

Item (6) What steps can be taken to insure that data are archived and available to help researchers who may need data that weren't included in the original reporting?

This subject has been considered by the DOE Nuclear Criticality Technology Safety Consultants. To date, little has been accomplished toward this end other than to identıfy facilities probably having logbooks available for archival, media for storage, mechanisms for storage, and authority for retrieval, distribution and funding of such an endeavor. It was judged that such an endeavor should be delayed for a short time, to permit the currently emerging archival technologies to settle into an accepted and standardized media.

Though there may be substantial information within the "private sector," it was concluded that such information is likely proprietary and not available to a central authority for etrieval, archival and distribution. As such, hope for such an endeavor was hung on retrieving I. (ERDA, AEC) Contractor critical experiments information via the central authority of DOE. Such an effort seems plausible with proper planning and cooperation of specific critical-experiment, facilities-records custodians and funding. Adequate planning has not occurred to approach the DOE with a formal proposal. However, preliminary efforts have identified the following: 
Origin of information

ORNL, LANL, RFP, PNL, UKAEA, BNFL, ANL, KAPL, B\&W, SRS, Pratt \& Whitney, BNL, Shippingport, AI, MIT, Westinghouse Astronuclear.

Preparation for archival

It was concluded that before information is archived, it should be abstracted and indexed by the originating facility; otherwise, information retrieval will be unwieldy and time consuming. However, we recognize that in many instances archival may not be practical.

Media of archival

The current customary media for easiest archival, distribution and retrieval is microfiche. A growing technology for high-resolution storage and rapid retrieval of such documents is the optical disk memory.

Point of archival

The official archival point for all DOE records is the Office of Scientific and Technical Information (OSTI) in Oak Ridge, formerly the DOE-TIC. Though the final originai archival record would be required to be stored at OSTI, an informal record could be inade available for central use through a system like the Nuclear Criticality Informationi System (NCIS). Initial distribution of an archived record could be made through USTI providing the media of storage is consistent with OSTI's capabilities (currently paper or microfiche or supplied copies of another media). It was determined that further investigations should be pursued with people at the LLNL NCIS Project to assure optimum utilization of the NCIS and its users.

Persons wishing to take an active role in this effort should contact Clint Kolar through the NCIS. A project has been initiated to locate the information, decide what data to archive, and evaluate current technology for storage and retrieval of the information. 
Appendix E

Initial Draft of Criteria for Establishing Area of Applicability 


\section{Initial Draft of Criteria for Establishing Area of Applicability}

This effort is the result of several days of focused discussion by six to eight criticality analysts and specialists acting on a volunteer basis. It represents their collective considerations on this topic and is offered as guidance for testing and further development. It should not be construed to have any procedural authority. Its intended usefulness is restricted to the context and purpose described above.

\section{Experimental Approach for Code Validation}

The criticality safety community has a strong need for critical experiments for multiple purposes. The most pressing need is to perform a series of experiments that would serve as validation for the many computer codes (KENO, MONK, MCNP, etc.) that are widely used in criticality analyses. Validation of codes is an issue that has been debated for some time, but only limited progress has been made. One of the major roadblocks is that the term "area of applicability," as used in ANSI/ANS-8.1, has not been adequately defined. The result is that the community has to use existing experiments and has to try to determine if these experiments can be extended, under "area of applicability," to serve as validation for a particular analysis code. Generally, these experiments were not meant to be used for validation. This has been an exercise with limited results since key definitions do not exist at this tirne. This appendix contains an initial draft of criteria for establishing "area of applicability."

E. P. Elliott

Oak Ridge Y-12 Plant

Nuclear Criticality Safety Department

Cak Ridge, Tennessee 
There are three conditions which must be satisfied to assure that the calculations done to analyze or support a real situation fall within the "Area of Applicability" for the validation of the code being used. These are: (1) materials, (2) geometry, and (3) neutron energy spectrum.

\section{Materials}

A. Material Types
1. Fissionable
2. Absorber
3. Moderator
4. Scatterer

B. Criteria (Applicable to all four)
1. Element
2. Isotopic Composition
3. Physical form (metal, solution, compound)
4. Ratio to fissionable material
5. Temperature

\section{Geometry}

A. Homogenous and Heterogenous
1. Shape
2. Reflection
3. Layering-ordering
4. Relative material thickness

B. Array Criteria

1. Mixed or same type units

2. Number of units

3. Shape of unit

4. Lattice pattern and spacing

5. Interstitial material

6. Reflection

7. Coupling

8. Layering-ordering

\section{Neutron Energy Spectrum}

A. Neutron density versus energy
1. Leakage
2. Flux 


\section{Materials}

A. Fissionable (all materials of atomic $\# 90$ or greater)

Criteria

- Element

- Isotopic

- Composition

(Fissionable materials which are present in quantities of less than $0.5 \%$ of tutal fissile material may be neglected)

\begin{tabular}{cc}
\hline $\begin{array}{c}{ }^{235} \mathbf{U},{ }^{239} \mathbf{P u}, \\
\%{ }^{235} \mathbf{U},{ }^{241} \mathbf{P u}\end{array}$ & $\begin{array}{c}\text { Absolute } \\
\mathbf{\%}\end{array}$ \\
\hline $0-2$ & \pm 1 \\
$2-5$ & \pm 1.5 \\
$5-10$ & \pm 2.5 \\
$10-20$ & \pm 5 \\
$20-80$ & \pm 15 \\
$80-100$ & \pm 10 \\
\hline
\end{tabular}

(If the experimental data point and the actual case fall in different zones, the most conservative tolerance applies.)

$\%{ }^{240} \mathrm{Pu}$ (in $\mathrm{Pu}$ )

Tolerance

$0-32 \%$

- Physical form

- Density as fissionable material

- Density as scatterer

- Temperature
Tolerance

No Tolerance

than 
- Isotopic composition

$\mathrm{H}$

Others

- Physical form

- Ratio to fissionable material (in fuel region)

- Density (when present in a reflector)

- Temperature $\pm 20 \%$ for interpolation

$\pm 5 \%$ for extrapolation

No restriction

No tolerance (the same chemical composition and the same phase)

Must be present at the same atom ratio with respect to the

fissionable material $\pm 20 \%$ for interpolation, $\pm 5 \%$ for extrapolation

If the element is present in the experiment or the actual case in quantities of greater than $1 \mathrm{w} / \mathrm{o}$, then the experiment and actual case must agree to $\pm 3 \mathrm{w} / \mathrm{o}$ for an extrapolation or $\pm 10 \mathrm{w} / \mathrm{o}$ for an interpolation.

Same as fissionable materials
Absorber

- Element ( 2 classes)

$$
1 / v\left({ }^{3} \mathrm{He}, \mathrm{B}^{10}, \mathrm{Li}^{6}\right)
$$

- Others

- Isotopic composition

$$
1 / \mathrm{v}\left(\mathrm{He}^{3}, \mathrm{~B}^{10}, \mathrm{Li}^{6}\right)
$$

- Others

- Physical form

- Ratio to fissionable material

- Density in reflector

\section{Tolerance}

Interchangeable given the same macroscopic absorption at 2200 $\mathrm{m} / \mathrm{s}$.

No tolerance (isotopes with macroscopic absorption cross sections of less than $10^{-4} \mathrm{~cm}^{-1}$ at any energy and an atom ratio with respect to the fissile material of less than $10^{-4}$ need not be considered.

No additional restriction

Duplicate the isotopic ratio $\pm 5 \%$

No restriction

Must be present at the same atom ratio with respect to the fissionable material $\pm 20 \%$ for interpolation, $\pm 5 \%$ for extrapolation

If an absorber contributes greater than $1 \%$ of the total absorption in the reflector, then atom ratios of the absorber to scatterer and absorber to fissionable, if present, must agree $\pm 5 \%$ for extrapolation, $\pm 20 \%$ for interpolation, and the total absorptions due to the element in the experiment must agree with the actual case to within $15 \%$.

Same as fissionable materials

Absorbers are nonfissionable, nonmoderative isotopes with microscopic absorption cross sections of greater than 2 barns at any energy. 
Scatterer

- Material serving as a reflector

- Material within the fuel region

- Isotopic

- Physical form

- Temperature

\section{Tolerance}

Isotope must be present in the experiment and actual case to within \pm 10 w/o and the physical density of the actual reflector must agree with the exp. reflector to within $\pm 25 \%$.

The atom ratio of the scatterer to fissionable material must agree \pm $5 \%$ for extrapolation, $\pm 20 \%$ for interpolation.

No requirement

Same as fissionable materials

Scatterers include all isotopes which are neither moderators nor absurbers nor fissionable. For isotopes present within a region (either fuel or reflector) at less than 3 w/o in both the actual case and validation, the isotopes need not be considered.

\section{Geometry}

Homogenous units: Feature

Shape

Reflection

Layering/ordering

Relative material thickness
Tolerance

For non-reentrant bodies, $50 \%$ variation on mean cord length calculated as $4^{*}$ volume/surface

For internal reentrant bodies, $25 \%$ variation on mean cord length calculated as $4^{*}$ volume/(internal surface)

For external reentrant bodies, no tolerance in shape or size

Solid angle to within $\pm 10 \%$ Mean spacing between reflector and fuel $\pm 10 \%$

For systems with multiple material layers, the layer sequence in the experiment and the actual case must be identical Physical thicknesses of all materials must agree to within $\pm 50 \%$

[homogenous-a single material system or one which combines multiple thin (less than I optical thickness) material regions in a uniform pattern (a void is considered a material)]

Heterogenous systems: Feature

Shape of single inits

Mixed or same type units

Number of units

\section{Tolerance}

\section{Same as homogenous}

For systems which have mixes of material or unit shapes which would be expected to have strong spectral differences within the system, a technical defense must be presented justifying the comparability of the experiment and the actual case The number of units is a coupling concern and is addressed there 
Heterogenous systems:

\section{Tolerance}

Feature

Interstitial materials

Reflection

Layering/Ordering

See layering/ordering and relative material thickness

The differential $K_{\text {eff }}$ worth of the reflector when comparing the experiment and the actual ase must agree within $15 \%$ of the differential $\mathrm{K}_{\mathrm{eff}}$, for systems where the total reflector worth is less than $0.01 \mathrm{~K}_{\mathrm{eff}}$, the reflector comparison need not be considered

Coupling Same as for homogenous

The sum of all couplings normalized per source neutron must agree to within $\pm 20 \%$

\section{Neutron Energy Spectra}

Feature

Neutron density versus energy
Tolerance

The normalized neutron production rate averaged overall fuel regions must agree within $0.1 \%$ in all 3 energy ranges

The absorption and leakage for the complete system must agree within $1.0 \%$ in all 3 energy ranges

The 3 energy ranges are:

$0-\mathrm{IeV}$

$1 \mathrm{eV}$

$100 \mathrm{keV}-20 \mathrm{MeV}$ 


\title{
Appendix F
}

\author{
Charter \\ Experiment Needs Identification Workgroup \\ Nuclear Criticality Technology and Safety Project
}




\section{Charter \\ Experiment Needs Identification Workgroup \\ Nuclear Criticality Technology and Safety Project}

\section{Purpose}

The purpose of the Experiment Needs Identification Workgroup is to

- Identify new criticality experiments needed to support U. S. nuclear facilities.

- Serve as the national focal point for experiment requests.

- Publish a list of the experiments identified.

\section{Scope}

The workgroup will identify criticality experiments needed to support the following:

- New U. S. Department of Energy (DOE) programs.

- Modifications to existing DOE facilities.

- Resolution of criticality physics problems.

- Advancement of criticality safety technology.

\section{Membership}

Membership will be from organizations with a vested interest in nuclear criticality safety, including, but not limited to:

- DOE Contractors DOE Program Offices, and Criticality Safety Committees. The Nuclear Regulatory Commission and Licensees, Critical Mass Laboratories.

\section{Responsibilities}

- The Chair coordinates workgroup activities.

- The Vice Chairman serves in the absence of the chairman

- The Secretary prepares and distributes meeting minutes.

Members

- Identify experiment needs.

- Contribute to the Workgroup report.

- Prepare experiment justification statements.

- Attend Workgroup meetings.

- Suggest experiment strategies for ENIWG. 


\section{Report}

A report listing identified experiments will be published through the Nuclear Criticality Information System and updated annually. This report may include input from the Experimental Needs Coordinating Group (ENCOG) regardi..g experiment priority.

\section{Meetings}

The Workgroup will meet annualiy.

\section{Funding}

Participation is voluntary. No funding is provided.

Charter for the EXPERIMENT NEEDS IDENTIFICATION WORKGROUP reviewed and reaffirmed at workgroup meeting on April 28, 1987.

D. A. Rutherford, Chair 